\title{
UTILIZING ATCS DATA TO INFORM A DYNAMIC REASSIGNMENT SYSTEM FOR MUNI METRO LIGHT RAIL VEHICLES DEPARTING EMBARCADERO STATION
}

\author{
A Professional Project \\ presented to \\ The Faculty of California Polytechnic State University, \\ San Luis Obispo \\ In Partial Fulfillment \\ of the Requirements for the Degree \\ Master of City and Regional Planning /Master of Science in Engineering \\ (Transportation Planning Specialization)
}

By

April M. Hickey

August 2013 
(C) 2013

April M. Hickey

ALL RIGHTS RESERVED 
TITLE:

AUTHOR:

DATE SUBMITTED:

COMMITTEE CHAIR

COMMITTEE MEMBER

COMMITTEE MEMBER
Utilizing ATCS data to inform a dynamic reassignment system for MUNI METRO light rail vehicles departing Embarcadero Station

April M. Hickey

May 2013

Cornelius Nuworsoo, Ph. D., AICP

Associate Professor

Department of City \& Regional Planning

Christopher Pangilinan, P.E.

Associate Engineer

San Francisco Municipal Transportation Agency

Anurag Pande, Ph. D.

Assistant Professor

Department of Civil \& Environmental Engineering 


\title{
ABSTRACT
}

Utilizing ATCS Data to Inform a Dynamic Reassignment System for Muni Metro Light Rail Vehicles Departing Embarcadero Station

\author{
April M. Hickey
}

This is a report of a professional project intended to act as an informational tool for the evaluation of a dynamic dispatch system at Embarcadero Station for the San Francisco Municipal Transportation Agency (SFMTA). Systems that operate dispatch algorithms do so in response to ontime performance and reliability. The optimization problem is documented in many transportation contexts including airline networks, bus dispatch, and freight routing. According to the research, optimizing available options and re-routing based on available options can create a more efficient system that would minimize operating costs and improving service reliability for customers.

The methodology presented here uses current headway information to dynamically change dispatch assignment between $\mathrm{J}, \mathrm{L}$, and $\mathrm{M}$ lines. The reassignment program was applied to randomly selected weekdays in March of 2012. After analysis it was determined that the application has the potential to decrease mean operating headways by up to $3 \%$ (or approximately 15 seconds).

Keywords: Reliability, On-time Performance, Transit Operations, SFMTA, Dynamic Dispatch, Reassignment, ATCS, Re-Routing, B\&B Algorithm 


\section{ACKNOWLEDGMENTS}

I owe a great deal of gratitude to my committee members Cornelius Nuworsoo, Chris Pangilinan, and Anurag Pande for their patience and guidance. I would also like to thank the following for supporting materials, advice, and direction:

- Byron Morgan, SFMTA

- Davide Puglisi, SFMTA

- Terry Byrne, Vanasse Hangen Brustlin, Inc.

- Mike Hickey, Metro North Railroad

Also, my family: Mike, Maureen, Michael, Timothy, and Brandon.

I want to thank my MTA families both in New York and San Francisco.

There are two rules for success:

1. Never reveal everything you know 


\section{TABLE OF CONTENTS}

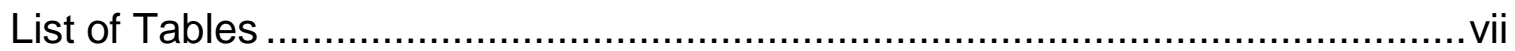

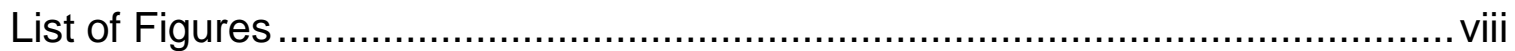

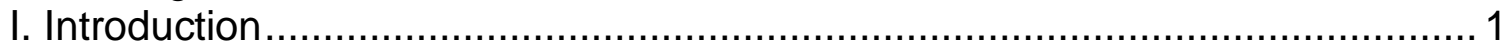

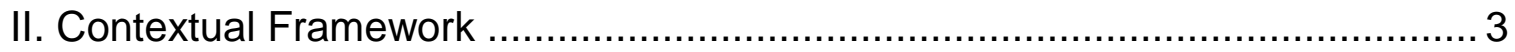

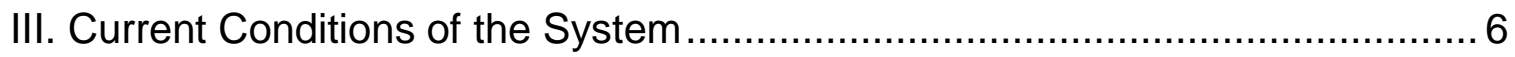

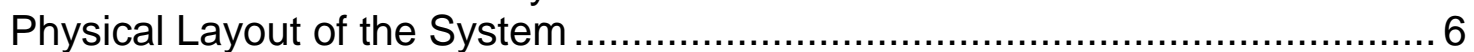

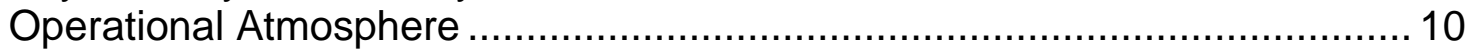

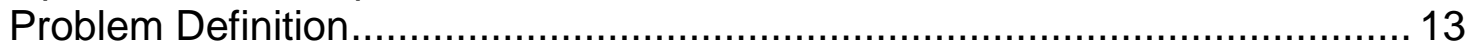

Limitations and Assumptions ................................................................ 14

IV. State of the Practice / Related Research: Reassignment and Re-routing ..... 16

Performance Measures.......................................................................... 17

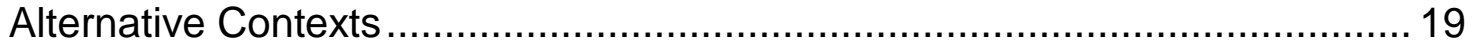

Roadway Freight Re-Routing in Europe: DHL® .................................... 20

Commercial Airline Re-Routing: Continental Airlines ................................ 23

Bus Dispatching System (BDS): TriMet in Portland, OR ............................ 25

Case Study: Boston's Green Line ........................................................... 27

Case Study: ROMA (Railway-Optimization by Means of Alternative Graphs)

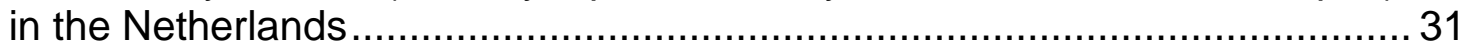

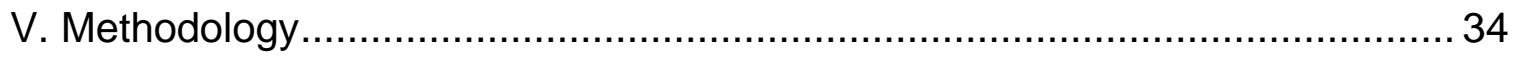

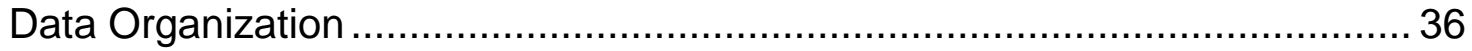

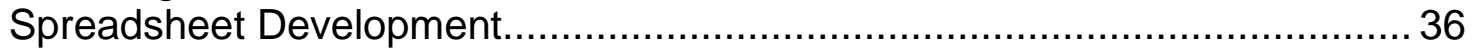

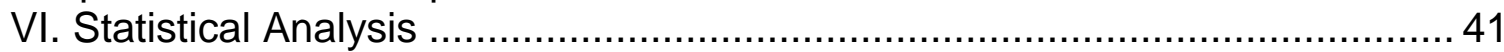

Run \#1: Current Schedule............................................................... 41

Runs \#2 \& \#3: March 1 ${ }^{\text {st }}$, 2012 All-Day \& AM Peak ....................................... 43

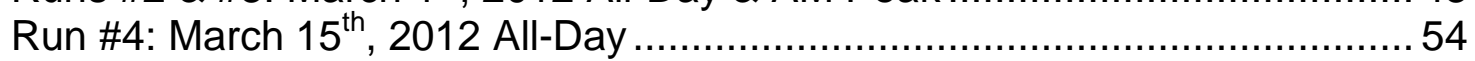

Potential Costs and Benefits ..................................................................... 59

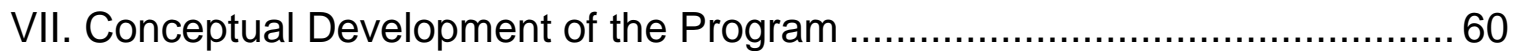

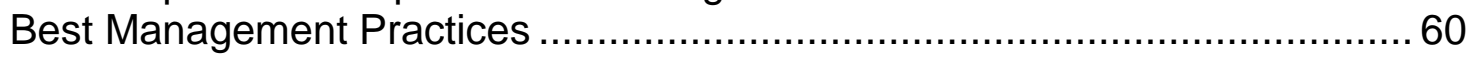

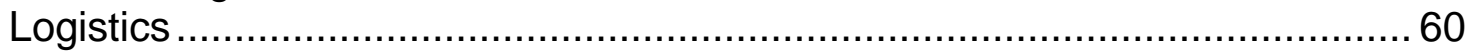

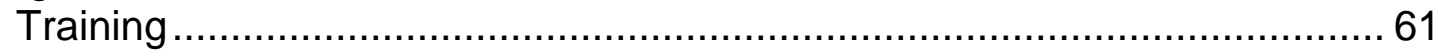

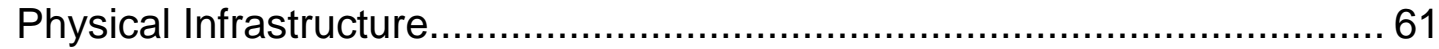

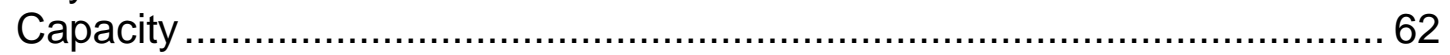

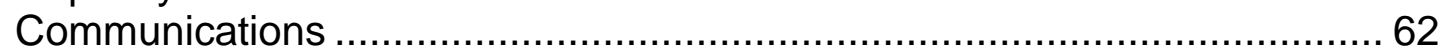

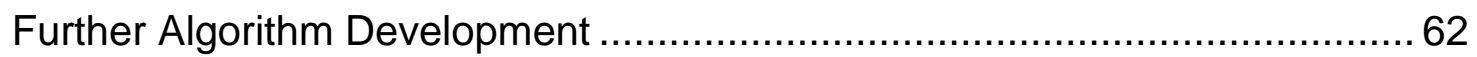

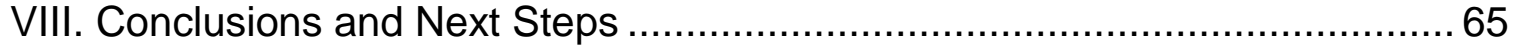

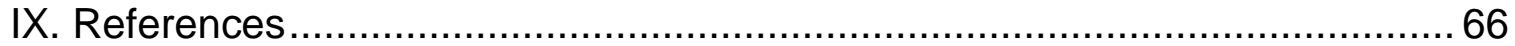

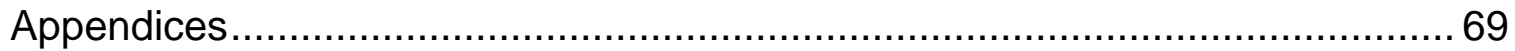

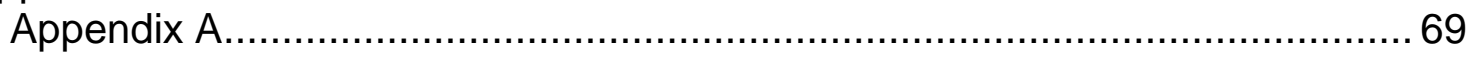

Appendix B

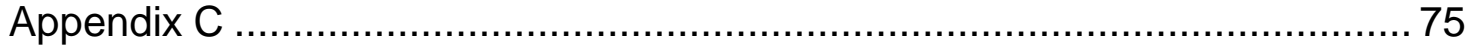




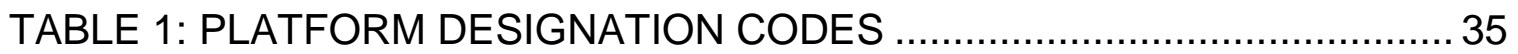

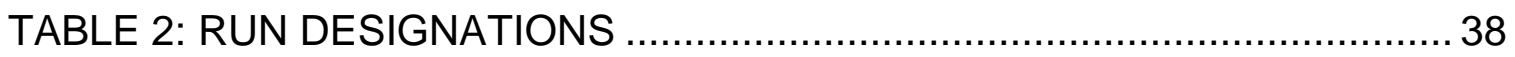

TABLE 3: ALL DAY SCHEDULED VERSUS ACTUAL HEADWAYS …..............41

TABLE 4: AM PEAK SCHEDULED VERSUS ACTUAL HEADWAYS ................ 42

TABLE 5: ALL DAY SCHEDULED VERSUS REASSIGNED HEADWAYS ........ 43

TABLE 6: 03.01.2012 ALL DAY SCHEDULED VERSUS REASSIGNED

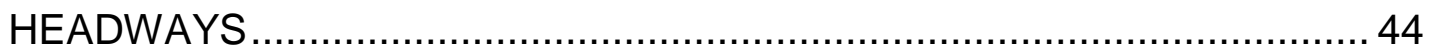

TABLE 7: 03.01.2012 AM PEAK SCHEDULED VERSUS REASSIGNED

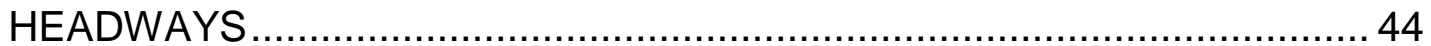

TABLE 8: CHANGE IN LINE TRAINS PER RUN FROM REASSIGNMENT ...... 45

TABLE 9: SPSS T-TEST OF SIGNIFICANCE OF HEADWAY MEANS: 03.01 .2012

TABLE 10: 03.15.2012 ALL DAY SCHEDULED VERSUS REASSIGNED HEADWAYS

TABLE 11: 03.15.2012 AM PEAK SCHEDULED VERSUS REASSIGNED HEADWAYS

TABLE 12: SPSS T-TEST OF SIGNIFICANCE OF HEADWAY MEANS: 03.15 .2012 
FIGURE 1: MUNI MAP

FIGURE 2: DOUBLE BARREL TUNNEL STRUCTURE SIMILAR TO THAT IN DOWNTOWN SAN FRANCISCO.

FIGURE 3: OPERATIONS DIAGRAM OF LIVE SNAPSHOTS OF SUBWAY DETAILING WHERE SHORT-TURN SWITCHOVERS CAN TAKE PLACE . 8

FIGURE 4: VISUALIZATION OF HEADWAYS. 18

FIGURE 5: SYSTEMS ARCHITECTURE OF LS/ATN 21

FIGURE 6: INFORMATION FLOW BETWEEN ON BOARD SENSORS AND CENTRAL CONTROL TO DELIVER UPDATED SCHEDULE IN REAL TIME.

FIGURE 7: MASSACHUSETTS BAY TRANSPORTATION AUTHORITY GREEN LINE MAP

FIGURE 8: MBTA OPERATIONS CONTROL CENTER …...............................30

FIGURE 9: ROMA SYSTEM ARCHITECTURE.......................................... 32

FIGURE 10: REASSIGNMENT SPREADSHEET 1 OF 2: RUN \#2 …................39

FIGURE11: REASSIGNMENT SPREADSHEET 2 OF 2: RUN \#2 ….................. 40

FIGURE 12: RUN \#2 ACTUAL AVERAGE HEADWAY OF J'S AT TIME OF DEPARTURE. 03.01.202................................................................ 46

FIGURE 13: RUN \#2 REASSIGNED AVERAGE HEADWAY OF J'S AT TIME OF DEPARTURE. 03.01.2012.

FIGURE 14: RUN \#2 ACTUAL AVERAGE HEADWAY OF L'S AT TIME OF DEPARTURE. 03.01.2012.

FIGURE 15: RUN \#2 REASSIGNED AVERAGE HEADWAY OF L'S AT TIME OF DEPARTURE. 03.01.2012.

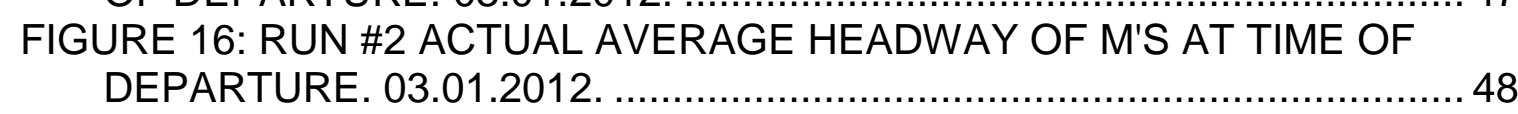

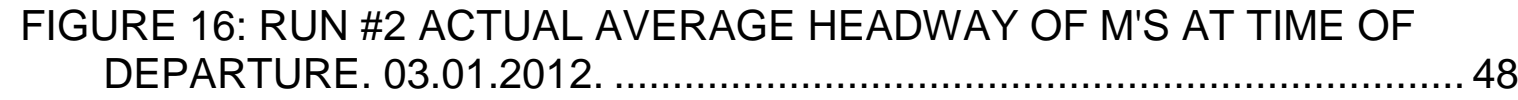

FIGURE 17: RUN \#2 REASSIGNED AVERAGE HEADWAY OF M'S AT TIME OF DEPARTURE. 03.01.2012...................................................... 48

FIGURE 18: RUN \#2 ACTUAL LARGEST HEADWAY AVERAGE OF J, L, \& M. 03.01.2012.

FIGURE 19: RUN \#2 REASSIGNED LARGEST HEADWAY AVERAGE OF J, $L, \&$ M. 03.01.2012.

FIGURE 20: AVERAGE ACTUAL HEADWAYS VERSUS AVERAGE REASSIGNED HEADWAYS: J, L, \&M BY TIME OF DAY. 03.01.2012 ......51

FIGURE 21: AVERAGE ACTUAL HEADWAYS VERSUS AVERAGE REASSIGNED HEADWAYS: J, L, M BY AVERAGE TIME OF REASSIGNED HEADWAY. 03.01.2012. 52

FIGURE 22: RUN \#4 ACTUAL LARGEST HEADWAY AVERAGE OF J, L, \& M. 03.15.2012.

FIGURE 23: RUN \#4 REASSIGNED LARGEST HEADWAY AVERAGE OF J, L, \& M. 03.15.2012.

FIGURE 24: AVERAGE ACTUAL HEADWAYS VERSUS AVERAGE REASSIGNED HEADWAYS: J, L, M BY AVERAGE TIME OF REASSIGNED HEADWAY. 03.15.2012 
FIGURE 25: AVERAGE ACTUAL HEADWAYS VERSUS AVERAGE REASSIGNED HEADWAYS: J, L, M BY AVERAGE TIME OF REASSIGNED HEADWAY. 03.01.2012....... 


\section{INTRODUCTION}

The San Francisco Municipal Transportation Agency (SFMTA) has in recent years begun an in-depth review of the physical and operational efficiency of San Francisco's public transit system. Current projects focus on reliability, decreasing dwell and travel times, and improving and enhancing the overall experience for customers (SFMTA, 2012). The agency collects a wealth of information through ridership surveys as well as more advanced technologies such as Automatic Vehicle Location (AVL) and Automatic Passenger Counter (APC) equipment. All Muni vehicles are equipped with $\mathrm{AVL}$ and about one-third of the bus fleet is equipped with APC. The data provided by this equipment in particular has been shown to have the ability to inform policy decisions and operational changes that better reflect the need patterns of Muni's customers (SFMTA, 2012).

Muni, the operating entity of the light rail vehicle fleet in the city, operates 71.5 miles of track (not including cable car routes), a large percentage of which are railways inlaid in vehicular rights of way (SFMTA, 2012). The history of transit infrastructure in San Francisco is over a century old and the physical nature of the system has dictated the limitations and operational parameters within which the system functions.

This professional project is intended to explore the use of vehicle location (Advanced Train Control System or ATCS) data as an informational tool to examine the potential of reassigning three light rail vehicle (LRV) lines at their 
turnaround at Embarcadero Station in downtown San Francisco. The current delays throughout the system cause an irregular pattern of light rail vehicles to enter the Embarcadero turnaround, particularly during peak hours. When one vehicle deviates from the schedule, this disrupts the distribution of headways and propagates through the system. The current practice of Muni lines J-Church, LTaraval, and M-Ocean View is for LRV's to enter the pocket at Embarcadero and be turned and continue outbound $(\mathrm{OB})$. Current operation practices limit the dispatch methods to achieve more evenly distributed headways. By reassigning the vehicles based on schedule realignment or based on special event need, the system could potentially support demand.

A statistical analysis of historical ATCS data is presented to support a dynamic line reassignment between these three lines $(\mathrm{J}, \mathrm{L}$, and $\mathrm{M})$. By applying a reassignment algorithm to the departure data, a before/after analysis is performed to examine the change in headway variability. The potential implications of a system change as well as limitations and key assumptions are presented as support material.

The evaluation of the operational change will inform future planning decisions and innovative problem solving. The use of data in real time is a more active approach to analysis of current conditions and has the potential to adjust system operations more dynamically to meet needs. 


\section{Contextual Framework}

There are political, physical, and technological bounds that construct the framework in which Muni functions. The current nature of operations represents past investments and help to inform efforts to improve the system. Muni is constantly collecting transit pattern information and evaluating new ways of meeting need in the most efficient way possible.

The physical nature of San Francisco's setting presents a unique set of complications in the scheduling of transit vehicles. A significant percentage of the system runs in rights of way with general traffic at street level. The 100-year old system is constricted both physically and financially, leaving professionals with limited solutions and a frustrated public in dealing with on time performance and reliability. Advancements in intelligent technologies have aided in working with the operating system to better meet demand while changes to the physical infrastructure are limited by time and financial resources. A change in the nature of the operations standards and policies is suggested for an analysis of optimization.

ATCS (Advanced Train Control Systems) data is collected by Muni and is recorded in the ATCS Management Center network on the Central Control servers. This data informs the data presented by Nextbus $\AA^{\circledR}$, the independent firm that presents the public with information about arriving fleet vehicles. Dynamic signs at bus shelters and smartphone application development are part of the effort by the Agency to operate more transparently (SFMTA, 2012). The availability of many data in a simple format is desirable for easy communication 
with customers. This data is already being harvested and ought to be utilized by the agency in an effort to respond to the needs of customers. Responsive service based on data collected is a strategy for operations and service planning.

Plans are in place to identify and allocate resources effectively by SFMTA to transit improvement projects. The San Francisco Capital Plan for 2012-2021 ranks the design and update of the ATCS Management Center as part of the Central Control and Communications System a top Renewal Initiative (City and County of San Francisco Capital Plan, 2011). The Capital Plan (2011) states:

...replace its obsolete radio system with a state-of-the-art wireless system featuring mobile and handheld radios, mobile data terminals and will interface from new mobile radios to vehicle on-board power, control, and communication systems...fleet overhaul and facilities modernization program... (p.87)

The modernization of the technology has been clearly identified as a priority for the city's transportation specialists.

The SFMTA identifies and addresses on time performance measures and service standard changes through the Transit Effectiveness Project (TEP). This plan offers a list of prescriptive methods of improving service and increasing reliability of transit city-wide with a focus on key corridors. The TEP includes both engineering improvements and operational changes. The toolkit currently being developed in conjunction with the project prescribes transit only lanes, bus bulbs, and stop consolidation, among other tools, to minimize delays and increase 
efficiency. Additional studies are underway to aid in accomplishing the goals in the SFMTA's long term development plan.

Union contract agreements for vehicle operators limit the routes on which they are trained. In order to operate a vehicle on a particular route the individual must sign up for a list to be trained on a specific route. They are then limited to working routes on which they are trained. Contracts also mandate breaks during the hours of work (Current CBA's, 2010 to 2012). These breaks must be accommodated in the scheduling and any operations practices (Davide Puglisi, personal correspondence, December 12, 2012). 


\section{Current Conditions of the System}

There is a support system within which Muni operates. This support system's framework consists of the physical infrastructure, operational structure, and financial support provided by the Agency. This contextualizes a list of limitations and opportunities for improvements. A study of the existing conditions is required to statistically show any inconsistencies or shortfalls of the overall operation. The following section details the physical layout and operational atmosphere, resulting in defining the problem and its current limitations.

\section{PHYSiCAL LAYOUT OF THE SYSTEM}

The light rail infrastructure is centered at the Embarcadero in downtown and branches into surrounding neighborhoods on the seven mile by seven mile peninsula. The J, KT, L, M, \& $N$ are the designated routes, shown in Figure 1. The double barrel tunnel structure is shown in Figure 2. The operational capacity of the subway is a function of the engineering of the double barrel - type tunnels. Each barrel is built with one set of tracks equipped to handle Muni's fleet of light rail vehicles. The tunnels align with Market Street from the Embarcadero to Duboce Avenue (above operational Bay Area Rapid Transit BART rail tunnels).

The Transit Operations Division within SFMTA has identified the physical limitations of the downtown subway and the capacity with which it functions. Each of the barrels serves a main right of way (one in the inbound (IB) direction and one in the outbound $(\mathrm{OB})$ direction). The $\mathrm{IB}$ trains run in the northeast direction towards the Embarcadero in the south tunnel. Conversely, the OB trains run in the southwest direction from the Embarcadero in the northern tunnel. 
These rails run parallel to one another from The Embarcadero to the Duboce Portal, approximately 2.5 miles. There are two locations (one between Duboce Portal and Van Ness Station and one between Montgomery Station and Embarcadero Station) where there are crossovers, allowing the vehicles to pull into the other barrel and switch tunnels and/or direction. Figure 3 shows a publicly available version of the real-time location mapping of trains. The Embarcadero serves as the turnaround point for inbound $\mathrm{J}, \mathrm{L}$, and $\mathrm{M}$ lines while the $\mathrm{N}$ line continues through the terminal onto the CalTrain Station while KT continues to Sunnydale. The ability to deliver needed trains in the OB direction is a function of all other trains in the subway system and each train's unique characteristics (i.e. number of vehicles in the consist, headways, operating speed, number of passengers, etc.).

Figure 1: Muni Map

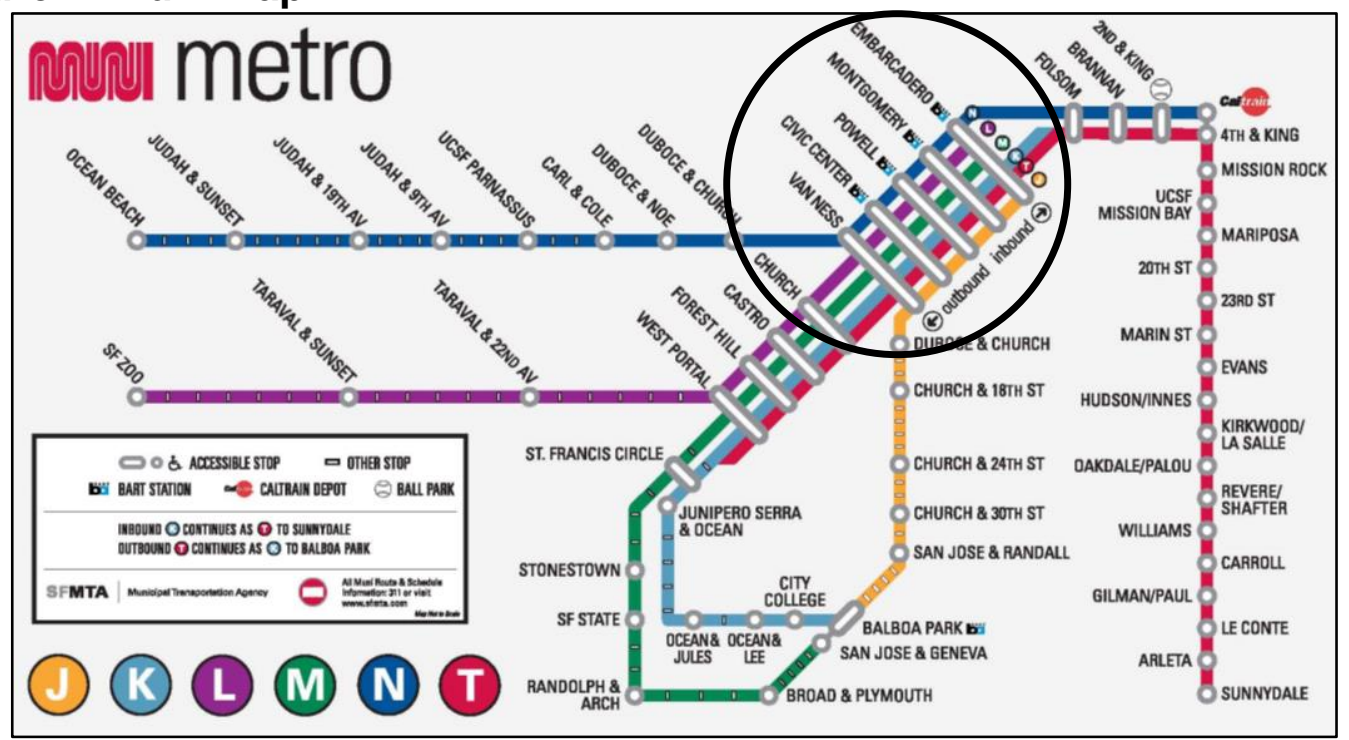

Source: SFMTA, 2013 
Figure 2: Double Barrel Tunnel Structure similar to that in downtown San Francisco

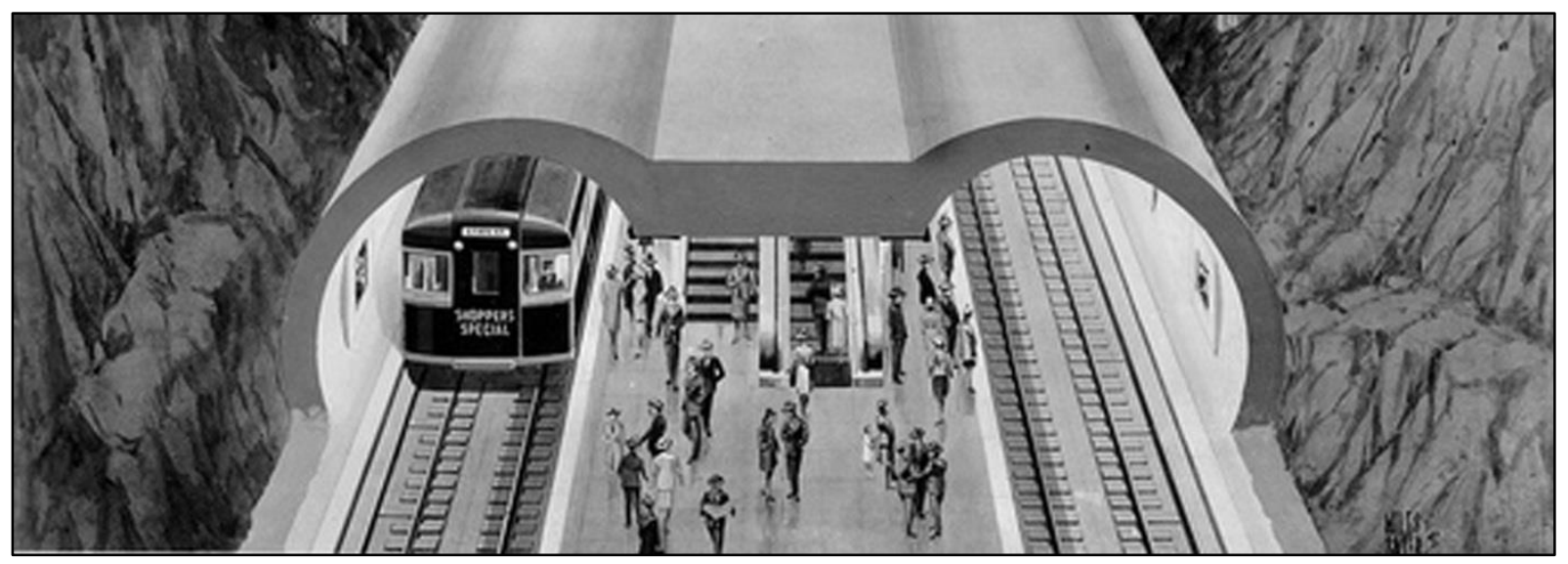

Source: Chicago Transit Authority, 1941

Figure 3: Operations diagram of live snapshots of Subway detailing where short-turn switchovers can take place

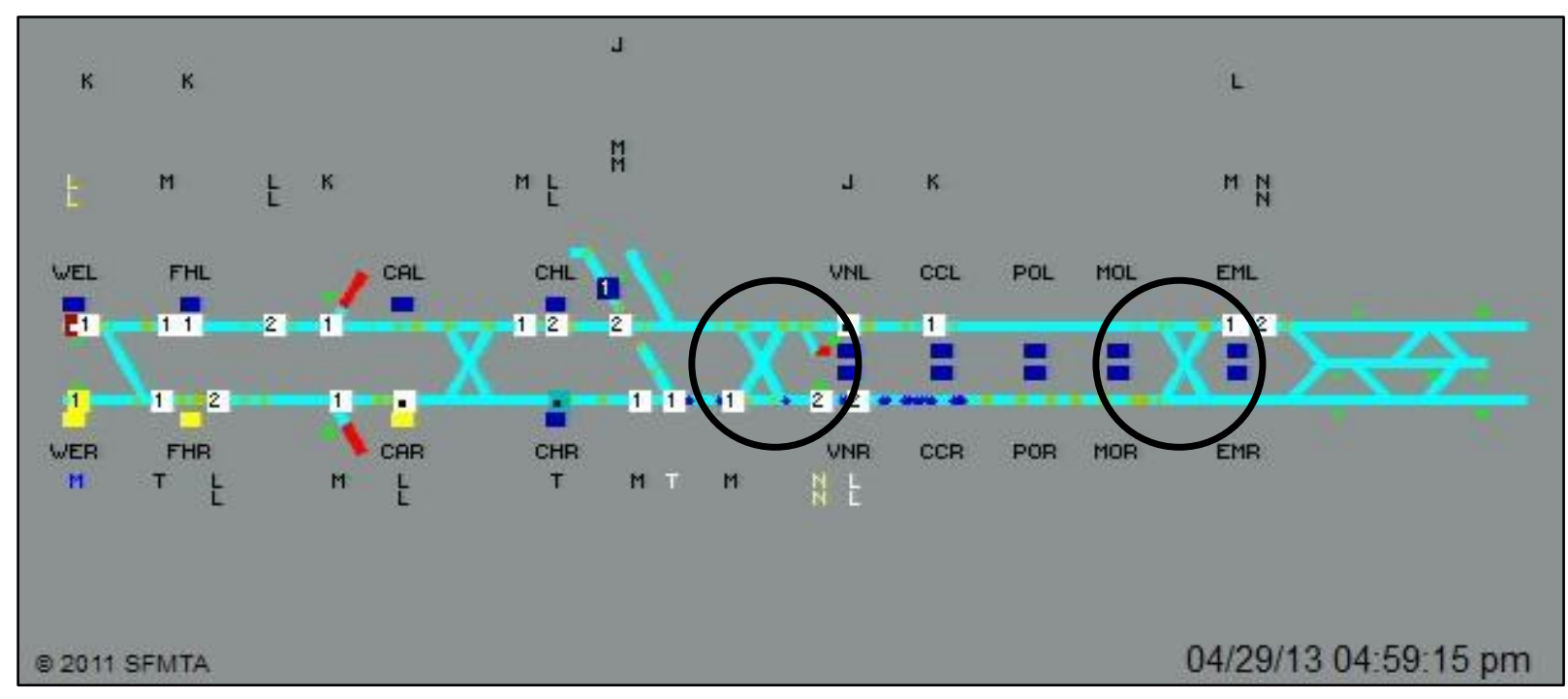

Source: SFMTA, 2013 
The Embarcadero turnaround facility is limited by its train-turning capabilities. It effectively acts as a stub-end point for the $\mathrm{J}, \mathrm{L}$, and $\mathrm{M}$ routes. The facility is built with three turnaround platforms with three platforms for designated coupling and decoupling maneuvers. The process of turning vehicles must take place in these three pockets (unless in an emergency case the consist can pull into the through-tunnels utilized by the $\mathrm{N}$ and $\mathrm{KT}$ lines). According to the Conceptual Engineering Report Summary (SFPUC, 1990), when the turnaround was redesigned in the late 1980's, the following were prioritized:

- Increase subway train capacity

- Provide opportunities to reduce coupling of trains at portals (therefore reducing delays and operating expenses)

- Improving reliability through signal system modification

- Provide off-mainline track turnaround facilities

- Minimize impacts to surrounding land uses and development plans

Changes to the physical infrastructure pose costly alternatives for the Agency. Until the full scope of on-time reliability and other performance measures are quantified and defensible, the improvement methods are limited. The turnaround facility acts as a barrier to turning the number of scheduled vehicles in the amount of time they are scheduled (Davide Puglisi, personal correspondence, December 12, 2012).

A portion of the rail infrastructure is laid at street level, directly in conflict with automobile traffic. Transit vehicles are subject to the same delay factors that 
automobile traffic is. San Francisco prides itself on its historic streetcar fleet and cable car lines. Rail and overhead wires are a longtime city investment and will remain as such in the foreseeable future.

\section{Operational AtMOSPHERE}

Weekday light rail service runs from approximately 5 a.m. to 1 a.m. Dispatched from various locations (See Appendix A for complete maps of each line), the vehicles are under manual operation at the street level and are part of an automated system in the subway. Each vehicle is operated with the minimum supervision of one Muni Train Operator. The operational system requires the training of an individual for each route separately (Davide Puglisi, personal correspondence, December 12, 2012).

Transit vehicle movements are a function of the success (or failure) of the environment it operates in, such as variable and unpredictable movements like pedestrian crossing activity and parking maneuvers (including double parked vehicles). The multiple uses of the right of way allows for a wider range of possible causes of delay. These delays result in "bunching" or "platooning", a phenomenon where multiple (two or more) transit vehicles operate with an unacceptably small headway of one another, therefore creating a larger than normal headway between themselves and the next arriving vehicle (increasing wait time for passengers). Platooning increases travel time variability, on time variability, costs more money, and wastes time (Gershenson \& Pineda, 2009). 
The non-automated nature of the street-level operations leads to some of these human errors, which makes the system susceptible to inaccuracy and instability (Strathman, Kimpel, \& Callas, 2003). Transit operators are most susceptible to delay through operating at variable operating speeds. Buses have the ability to deviate slightly from the route while rail operators are severely limited in "moving around" or avoiding obstructions. This is most common when there is an object inappropriately in the right of way of the rail car. In certain cities such as San Francisco and Portland, this causes a unique problem where certain segments are in direct conflict in a single lane right of way between the transit rail line and roadway traffic.

$\mathrm{L}$ and $\mathrm{M}$ lines are designated two-car routes while the $\mathrm{J}$ is designated as a one-car route. All $\mathrm{J}$ runs are single vehicles due to the lower volumes of users and stop infrastructure (such as the length of boarding islands). The $L$ and $M$ lines are designated for two cars on all runs but do on occasion only contain one car. There are ten designated coupling areas within the subway tunnels. The ability to couple and de-couple vehicles is vital to the change in routing concept (D'Ariano, 2008). The act is time consuming and labor-intensive. Coupling and de-coupling severely increases the amount of time for a vehicle to switch routes (D’Ariano \& Pranzo, 2009).

The system currently operates on a schedule-based system. However, it is progressively moving towards implementation of a headway-based operation. This increases reliability and on time performance (Cevallos, Wang, Chen, \& Gan 2011). The turnaround process is recognized as a limitation of the physical 
capacity of the tunnels that directly influences the operational support system (SFPUC, 1990).

Muni currently employs the following practices at Embarcadero in an attempt to remedy the system when it begins to fall outside an acceptable headway distribution:

- Fallback: Trains will be instructed to hold in the pocket and allow a train behind them to advance ahead and enter the OB platform first.

- Route Change: Trains will change drivers and apply new signage and couple as needed to switch from one route to another. This often takes place on the platform and creates confusion for customers.

- Reconfiguration: The addition of a secondary "coupling" or removal "uncoupling" of two trains to accommodate peak hour demands.

These practices act as reactive strategies to account for disturbances in the system. The concept proposed in this study is a more proactive approach to resolving these disturbances in real time. The challenge lies in preparing the system to react in the quickest time possible. This requires excellent resources and highly effective system architecture.

According to the Transit Capacity and Quality of Service Manual (2003), automatic train supervision is sparse in North America. The lack of up to date technology and funding act as a barrier to predictive control. Capacity is a function of the right-of -way constraints (On-street a function of light cycle length and lane exclusivity while subway a function of its single track). 


\section{Problem Definition}

The tunnel's current configuration presents a challenge for the operational removal of disabled or stalled vehicles. The two subsurface tunnels have one crossover point between Embarcadero Station and Montgomery Station (between $E M R / E M L$ and $M O R / M O L)$. If there is an issue with a vehicle, the vehicle would need to be deadheaded through the tunnel, disrupting service to all other five service lines (SFPUC Engineering Bureau, 1987).

Major causes of travel time unreliability include incidents, work zones, weather, fluctuations in demand, traffic control devices, and inadequate base capacity (Mirijello, 2010). Street-level delay is caused by the conditions within an area or along a route. Roadway congestion is a major source of high delay (Chang, 2010). When the number of vehicles increases along a route, the density reaches close to capacity provided by the rights of way. If the transit vehicles are operating in this right of way (as bus or LRV with rails in the right of way) then the transit vehicles are subject to the delay on the roadway. This includes broken down cars and trucks, turn movements by both vehicles and transit, and signal delay (when there is not a preemptive transit priority connection).

Operators are individually programmed to operate vehicles at a certain speed on a spectrum of "acceptable" speeds. It is difficult for transit vehicles to operate at the designated speed at all times and therefore a majority of them

operate consistently at speeds faster or slower than what the schedule is designed for. Operators also attempt to meet the needs of customers by making exceptions to the rules of operation. An example of this would be opening the 
doors for passengers while they idle at the nearside stop waiting for a traffic signal to change. Passenger behaviors often dictate the efficiency at which transit operates (Chang, 2010; D'Ariano \& Pranzo, 2009; D’Ariano, 2008). Unruly and disruptive passengers tend to cause more frequent and/or unscheduled stops along a route.

The problem being addressed is the lack of proactive strategy in relationship to on time performance (OTP) and reliability. The hypothesis of this study is that there is an opportunity to analyze data and potential to develop a new and innovative strategy to meet the needs of users of public transit. Flexibility allows Operations to be proactive and reactive on a case-by-case basis. The ability to quickly and efficiently react to conditions in real time (while potentially predicting multiple possible future system conditions) can help improve operations for users.

\section{LIMITATIONS AND ASSUMPTIONS}

The fixed route system is defined by the rail on which light rail vehicles must operate. In San Francisco, the rail system operates on decades old infrastructure that is expensive to improve upon. As discussed, the facility constraints that Muni operates within are limited in both number and condition. The rail lines that operate through the heart of the city provide only two track routes and a single turnaround point at Embarcadero Station. The Embarcadero Station turnaround has the capacity to hold up to four light rail vehicles, two in storage and two for turnaround. This severely limits the ability to turn vehicles at 
this facility. These physical conditions are difficult to alter. Politically, spatially, and financially they are hard to plan and gain support for.

The network operates on the same level as roadway traffic and it is therefore subject to those conditions in addition to the typical rail service transit conditions. The right of way is primarily shared with roadway traffic. Additional efforts need to be made to accommodate these constraints.

The transit operators are under contract with the agency through multiple Collective Bargaining Agreements (CBA's) organized by the unions (See Appendix B for a complete list of up to date CBA's). Union laws provide strict guidance with respect to the working conditions and can therefore present a hurdle when attempting to test new and possibly innovative processes. In the case of the SFMTA, union contracts provide breaks to Muni train operators. The CBA's fail to designate specific times or locations for these breaks, for example. These breaks are commonly made at the turnaround point at Embarcadero Station in conjunction with the recovery time built into the scheduling. This practice adds to the potential for off schedule departures from Embarcadero.

The AVL data collected by the Agency is assumed to be more thoroughly cleaned for application of the program presented here. Upgrades in data filtering and cleaning are necessary for technical upgrades to the operational procedures to be necessary. 


\section{State of the Practice / Related Research: Reassignment and Re- ROUTING}

On time performance and reliability are well documented performance measures for transit system operations. Optimization of scheduling is recognized as a classic operations research problem (TCRP, 2004). For transportation agencies "efficiency" boils down to cost and time.

The optimization problem is a function of the chosen input variables as well as the constraints it is applied within. The reassignment and re-routing optimization problem is one that is documented and applied throughout different contexts worldwide. The response to the problem includes algorithm development and operational adjustments/standards with an aim to improve upon performance measures such as schedule adherence, headway deviation,

delay propagation, and "immediate delay costs" (Corman, D'Ariano, Pranzo, \& Hansen, 2011; D’Ariano \& Pranzo, 2009).

This section examines the common performance measures in the current research as well as case studies of dynamic rail reassignment in Boston, Portland, and Europe. Keeping in mind that the practice is a function of the environmental constraints and opportunities, different approaches to reassignment and re-routing problems in different transportation contexts are evaluated (airline industry and roadway freight operations specifically). This serves to bring in new ideas on approaches and applicability amongst alternative contexts. 


\section{Performance Measures}

The changes in procedural operations are to be monitored by reasonable measures of effectiveness (MOE's). Documented MOE's include change in variability in headway, changes in travel time / travel time reliability (Berkow, ElGeneidy, Bertini, Crout, 2009), change in speed profiles (D'Ariano, 2008; Berkow, El-Geneidy, Bertini, Crout, 2009; Ding \& Chien, 2001), and costs (monetary and social) to both the consumer and the Agency (D'Ariano et al., 2008; Gershenson \& Pineda, 2009).

On-time performance continues to be a performance measure for urban public transportation systems. Fleet vehicles are subject to right of way limitations such as congestion, signal timing, passenger loading dwell time, and parking maneuvers (Berkow, El-Geneidy, Bertini, Crout, 2009). A schedule is based on demand and fleet capabilities and deviation from that schedule leads to an increased cost of operation and less reliable service (Gershenson \& Pineda, 2009). Agencies aim to reduce headway and travel time variability and minimize costs both to customers and the operations department. These are characteristics of a more effective and efficient system (Berkow, Chee, Bertini, Monsere, 2007).

Transportation agencies want variability of headway to be low. Headways are measured in unit time between successive trains. Headway is typically measured from the front most section of the train to the front most section of the successive train. Figure 4 visualizes the concept of headway measurement. When one vehicle is delayed for any reason (or is ahead of schedule due to 
increased speed that is a result of the manual operation system (Ding \& Chien 2001), this directly results in the change of two headways, one preceding the vehicle and one following the vehicle. For example, if a vehicle departs a station one minute late, the headway between it and the vehicle in front of it is now increased by one minute and (assuming train 2 is running on schedule) the next vehicle is separated by a headway that is lessened by one minute. Because of this, delays propagate through the network. This defines that network as unstable (D’Ariano \& Pranzo, 2009; Gershenson \& Pineda, 2009).

Figure 4: Visualization of Headways

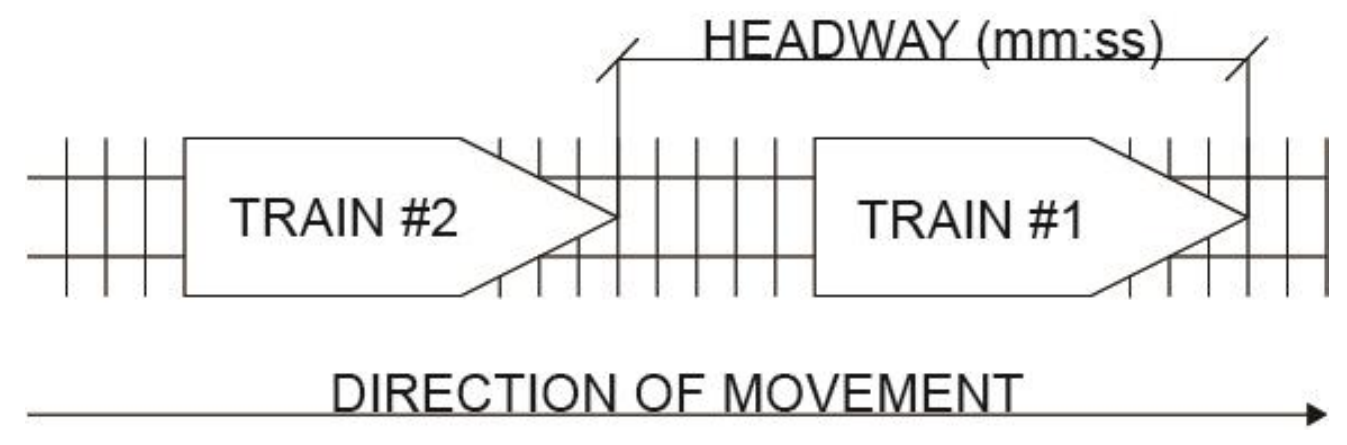

Transit riders expect buses and trains to arrive when the schedule says they will. Reliability rates high on satisfaction levels among customers (Gershenson \& Pineda, 2009; Strathman, et al. 1999).

Research by Furth and Nash (1985) showed higher on time reliability as a result of pooling transit vehicles at their common terminal. The probability with the application of a distribution function increased the probability by 0.07 . A hierarchy of steps was created to estimate the reliability changes of a pooled 
system. The first step is analysis of the base schedule and adding subsequent hierarchies. The following are applied in hierarchy:

- Nearest Neighbor Swap

- Paired Nearest Neighbor Swap

- Three Nearest Neighbor Swaps

- 2-3-1/3-1-2/3-2-1 Swaps: Based on arrival times the $1^{\text {st }}, 2^{\text {nd }}$, and $3^{\text {rd }}$ bus arrive, it is reassigned to depart $1 \mathrm{st}, 2^{\text {nd }}$, or $3^{\text {rd }}$.

- Other two-train swaps

These swaps were applied to the Massachusetts Bay Transportation Authority's Orange Line in 1985 and it was concluded that with a fleet of 42 buses the existing reliability was $31.2 \%$ while the pooling effect peaked at a reliability of 36.8\% (Furth \& Nash, 1985). By decreasing the number of buses, higher reliability was observed (in the simulation). This simulation does not take into account the capacity and demand of the system. The extrapolation of probabilities decreases as variability increases in headways. Furth and Nash note that the biggest and most important barrier is the communications network for real time application. The "pooled" system applies a "run as directed" assignment for operators.

\section{Alternative Contexts}

The theoretical construct of optimizing resources is applicable to other aspects of transportation. The ability to monitor movement of vehicles in real time and construct a reactive framework has the potential to save both time and 
money. Ding \& Chien (2001) describe the practice of real-time control mode that is applied to determine the best departure time based on optimal arrival time station by station. Independent variables include acceleration/deceleration and speed profile. Headway disturbance causes higher wait times at subsequent stations (Ding \& Chien, 2001). Varying approaches to similar problems are used in the freight trucking and airline industries.

These alternative contexts adopt different versions and capabilities of the "case base reasoning" technique described by Sadek, Smith, \& Demetsky (2001). Real-time reassignment of vehicles is made for the purpose of relieving congestion in certain areas. This decision-based procedure is systematically applied by a computer generated "decision narrowing system" before the final decision is made by the dispatcher (Sadek, Smith, \& Demetsky, 2001).

RoAdWAY FrEIGHT RE-ROUTING IN EUROPE: DHL®

Greenwood, Dannegger, \& Dorer (2009) document the use of transportation management systems that are utilized for optimization of freight deliveries worldwide. Optimized routing of freight requires the careful evaluation of costs and benefits (in both the physical and financial contexts). Technologies in the European freight transportation network have developed to better meet the needs of their customers. Typically routed within a stochastic network, technologies by private carriers have the ability to reroute after the cargo has left the distribution center. Living Systems Adaptive Transportation Networks (LS/ATN) software, developed by Whitestein Technologies demonstrates how the "ability of automatic, real-time optimization and execution capabilities lead to 
reductions in transportation operating costs while improving service quality to the customer" (Greenwood, Dannegger, and Dorer, 2009 p.1). Figure 5 shows the system architecture of the LS/ATN software. The issue the technology is intended to solve is dubbed "Multiple Pick-up and Delivery Problem with Soft Time Windows in Real Time" (R/T mPDPSTW) wherein the software reacts to the real-time conditions of the routes and assigns optimized routes within the applied constraints. After the orders are entered, the software matches origin to destination and prepares for execution unless manual dispatching/re-routing is needed. Reactive strategies include deploying a new vehicle or accepting late penalties (Greenwood, Dannegger, and Dorer, 2009).

Figure 5: Systems Architecture of LS/ATN

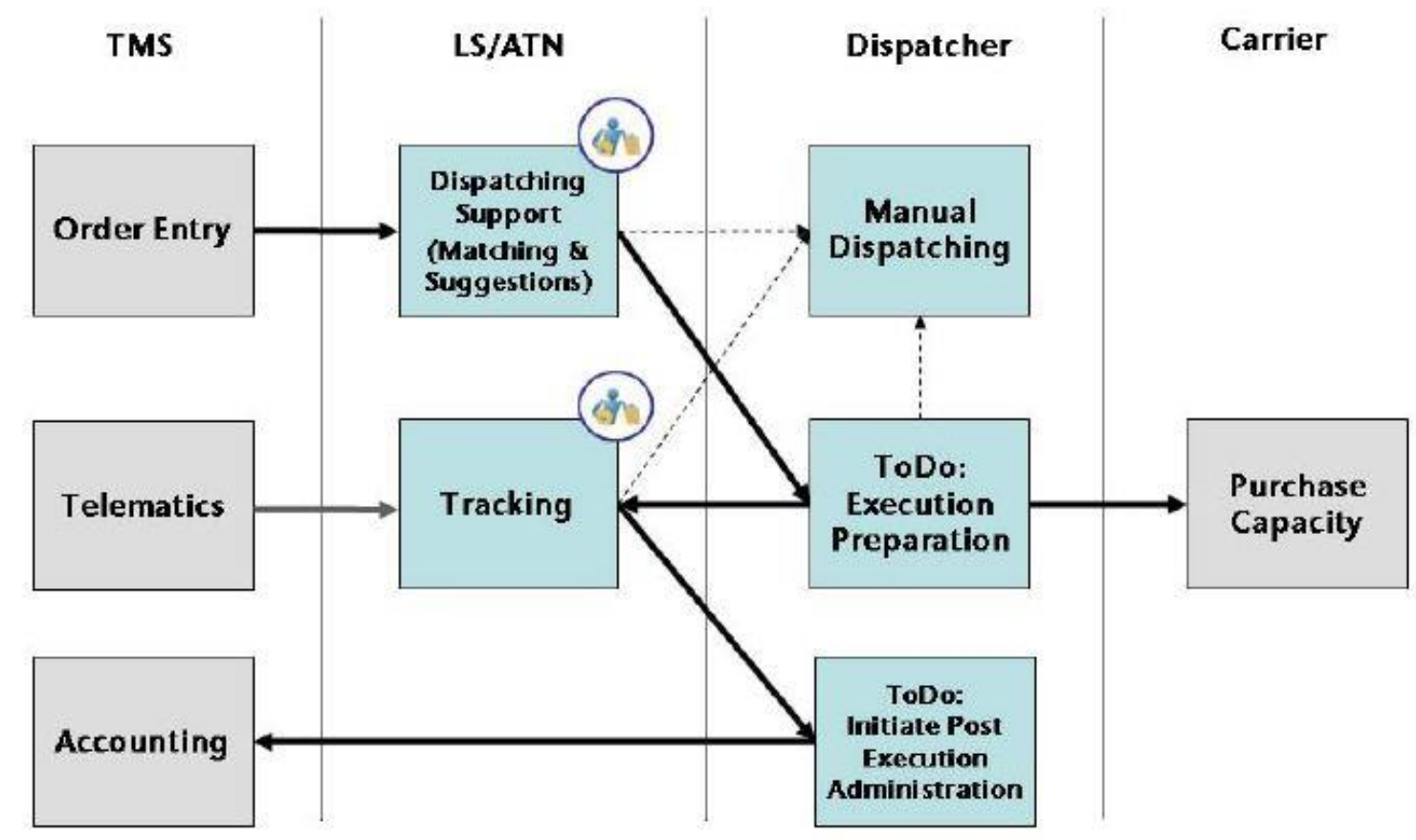

Source: Greenwood Dannegger, \& Dorer, 2009 
The algorithm employed by the Dispatching Support checks all trucks within the desired region and runs the cost estimate against each, choosing the option with the least cost. The algorithm also develops suboptimal assignments based on transfer between route options. Optimization here is based solely on minimizing costs. Constraints include capacity, weight limits, and operational hours for delivery (Greenwood, Dannegger, and Dorer, 2009). Violating these costs assigns a penalty to the optimization problem.

DHL $\circledast$, with more than 3,500 transportation requests, saw an $11.7 \%$ reduction in costs and a $25.5 \%$ reduction in number of vehicles used with the switch from manual handling of dispatch to the LS/ATN agent-based optimization system (Greenwood, Dannegger, and Dorer, 2009).

The benefits are quantified in amount of time saved and implementation/maintenance costs. "On board unit" (OBU) technologies and capabilities expanded the abilities of the operational platform and lowered communications costs (in terms of dispatcher cost in providing up to date information to the database). Figure 6 shows the information flow by the OBU's utilized in the $\mathrm{DHL} \circledast$ case study. Take note of the diverging flag to inform for human dispatch in the event of limited options.

Major challenges with this programming technique and application lay in the inter-dependent nature of the freight industry. Inter-company standards and operational abilities are seldom developed in unison. Freight typically travels between alternating carriers as well as via multiple modes of transportation. 
Integration and cooperative system development is recognized as an organizational and cooperative limitation. The implementation of the system requires the update of multiple technologies company-wide which is not cheap and requires the addition of staffing to address issues related to this technology. Due to the newness of the technologies, further analysis will yield more appropriate strategies for implementation.

Figure 6: Information flow between on board sensors and central control to deliver updated schedule in real time.

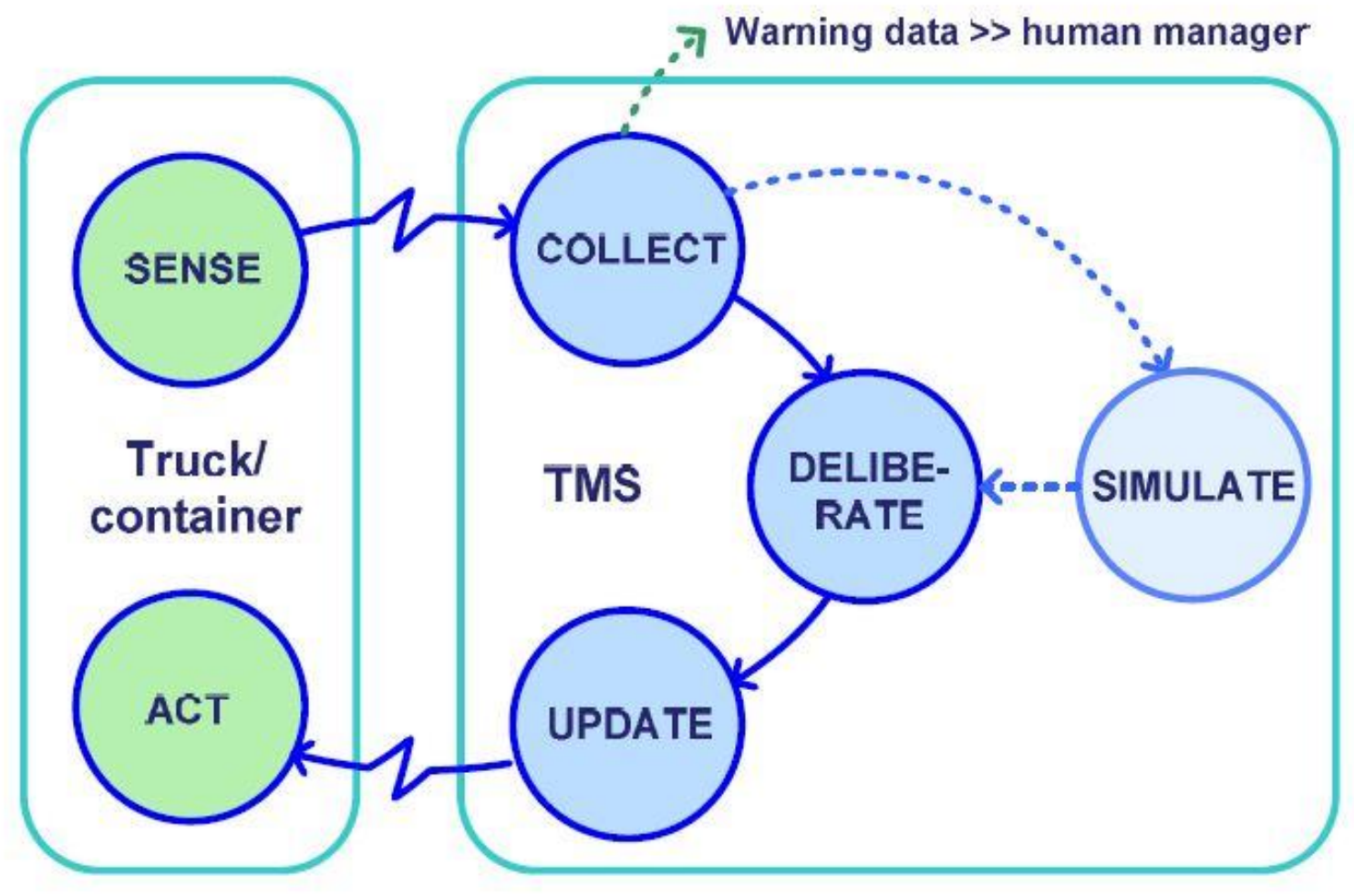

Source: Greenwood, Dannegger, \& Dorer, 2009

Commercial Airline Re-Routing: Continental Airlines

Airline routing operates with more flexible physical capabilities. Their movements are not as limited because they are not physically connected to the 
system in which they operate (the equivalent of a train operating on a track). When aircrafts experience delays and cancellations, their overall routing network is disrupted and airlines scramble to minimize associated costs (Bard, Yu, \& Arguello, 2001). This is the nature of the private airline industry. A route can be defined as a sequence of flights. The goal outcome is to minimize idling time during routing. Cancellations and delay costs are felt throughout the route. The rerouting process involves a change in flight crew and their workforce routing.

Route optimization algorithms developed recalculate based on time-band lengths. Time bands represent the recovery time frame within which the aircrafts land or take off. Changes in rerouting has larger effects for the larger network, as physical limitations of airstrips only allow a certain number of aircraft to maneuver take offs and landings.

The algorithm is a function of station location of stalled aircraft, available options, and time to reroute to get back on schedule. The matrix of options created generates a secondary matrix of associated costs. The model is simple in the sense that it breaks down databases of information into nodes and links values. The model constructs the algorithm with respect to time on a CPLEX platform and run on a SUN Sparcstation 10. This programming system sets up a dual simplex algorithm for solving the optimization problem, setting up the linear parts of the problem and computing the best combinations minimizing time and costs (Bard, Yu, \& Arguello, 2001). 
The program was applied to a Continental Airlines 737-100 fleet with 162 flights by 27 aircrafts over a 30 station network. Uniform delay costs were calculated at $\$ 20$ per minute of delay with a 35 minute turnaround time. In the test one aircraft was grounded. Over 100 runs were performed in the simulation. Quantifying routing options shows stakeholders the financial impact of operational changes.

\section{Bus Dispatching System (BDS): TriMet In PoRTLANd, OR}

Multiple case studies used TriMet's bus dispatch system in Portland as an example for trip variability measures. In Portland the real time reporting of ontime adherence between central control and the individual vehicles have the ability to trigger signal prioritization, holding, and expressing. This has the potential to improve headway adherence (Strathman, Kimpel, Dueker, Gerhart, Callas, 2002)

"Route and schedule design optimize service in relation to recovery and deadhead time" (Strathman, Kimpel, Dueker, Gerhart, Callas, 2002 p.326)

Strathman, Kimpel, Dueker, Gerhart, Callas (2002) found that a significant source of variability in run time was a result of bus operators. TriMet's bus dispatch system was adopted in 1998 and incorporated a number of operational support materials including AVL, APC, Central Control, visual and audible communications system, and a visual data communication system displaying ontime performance and other information. The expanded network allowed for 
increased communication between dispatchers and bus operators. Full time operators showed a reduction in running time variation (Strathman, Kimpel, Dueker, Gerhart, \& Cellas, 2002).

TriMet defines the appropriate recovery time: “...the difference between the chosen benchmark and the running time associated with the $95^{\text {th }}$ percentile trip in the frequency distribution" (Strathman, Kimpel, Dueker, Gerhart, Callas, 2002, p.327). Peak times were analyzed and it was found that there was a scheduling proactive of "setting running times low enough to avoid having operators kill time, while having generous recovery times avoided late departures" (Strathman, Kimpel, Dueker, Gerhart, Callas, 2002, p.331). In the AM inbound dataset, the data showed that with every $6^{\text {th }}$ trip there was sufficient time to run and recover another vehicle at no additional cost. However union contracts contain stipulations that schedules must have five minutes of recovery/layover time for each hour of running time. These stipulations acted as a barrier to operational improvements.

TriMet defines run time as a function of distance, lifts, stops, number of on and off passengers, types of and a series of dummy variables. When a threshold is breached between acceptable arrival time, a notification is sent to central control dispatcher. The reaction to the situation often resulted in the addition of fleet vehicles and higher on time variability (Strathman, Kimpel \& Callas, 2003). For routes with high demand and frequent service, it may be worthwhile to constrain assignments to achieve greater homogeneity among operators with respect to experience. 
A second strategy utilized was holding the lead bus to equalize headways in sequence of affected trips. Field supervisors restored regularity by limiting layover time. It is important to keep in mind that continuous and systematic delay is a result of a schedule which does not reflect adequate running or recovery time (Strathman, Kimpel \& Callas, 2003). Reducing headway delay by $25 \%$ is estimated to yield an $89.4 \%$ reduction in morning peak hour passenger overloads, and a $75.8 \%$ reduction during the evening peak hour (Strathman, Kimpel \& Callas, 2003).

For trips with scheduled layovers, headway delays at the route origin can be traced to two basic causes: 1) the carry-over of a delay from a previous trip; and 2) a late departure following an excessive layover.

Secondary responses to improving transit service involve the operations of "holding" and "jumping." Holding involves vehicle remaining in position at a location in order to balance the preceding and succeeding headways. Jumping strategies are generally applied to systems which have the infrastructure to do so, including physical capacity such as routes, and technological capabilities such as continual connection to the command center for routing instruction.

\section{CASE Study: Boston's GREen LINE}

Boston's Green Line is a subway service that is operated under similar conditions as Muni. The B, C, D, and E paths are subject to similar right of way and operational constraints. Portions of the lines operate in dedicated right of way and some portions provide a mixed right of way. The lines converge in an 
underground subway. There are a limited number of crossover points to turn needed vehicles (Malikova, 2012). Figure 7 details the overall system network of Boston's Green Line. Studies have been initiated by the Massachusetts Bay Transportation Authority (MBTA) to evaluate reliability and operations abilities.

\section{Figure 7: Massachusetts Bay Transportation Authority Green Line Map}

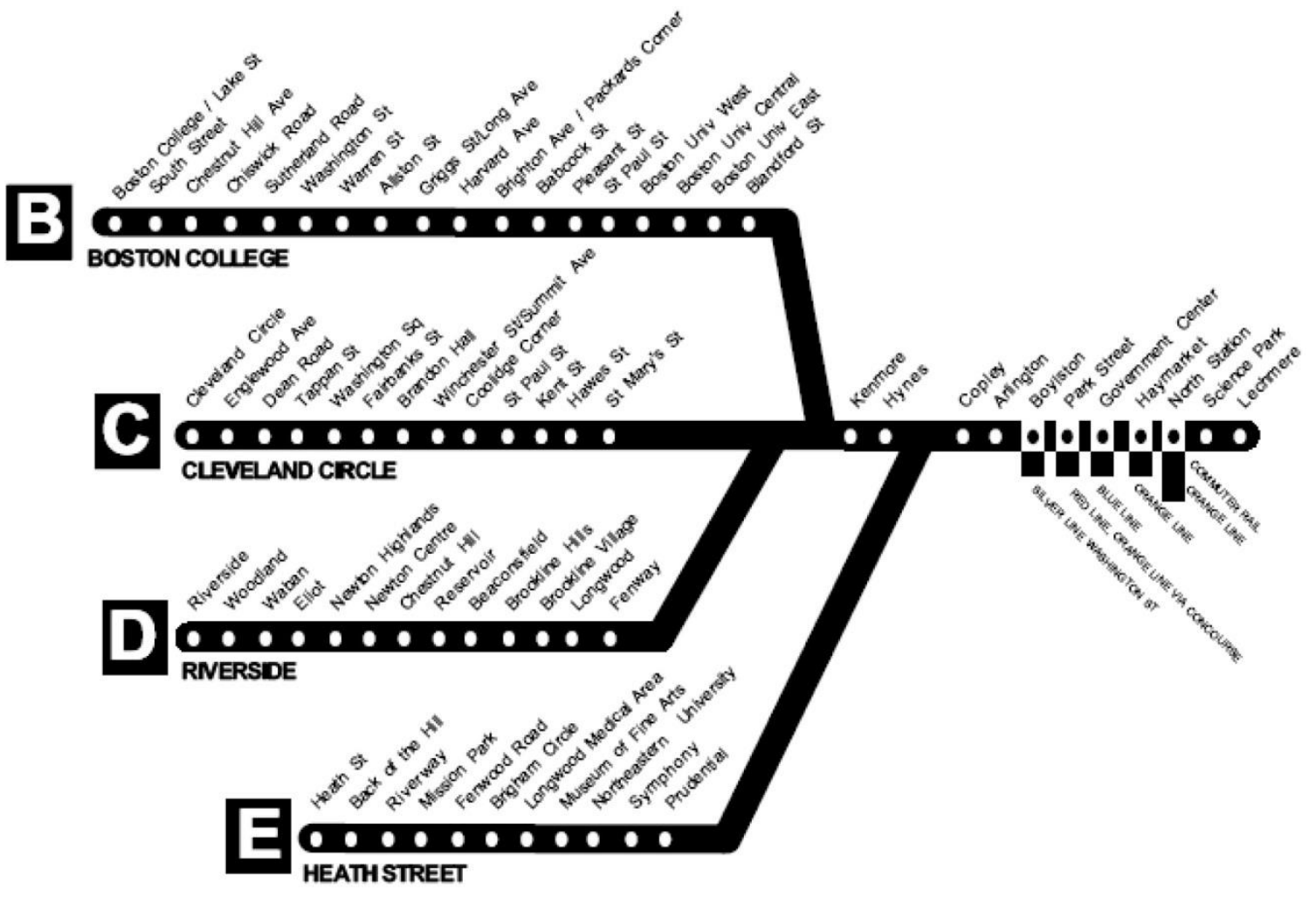

Source: Railway Preservation, 2012

Efforts to improve the system are concentrated on double berthing and the addition of a turnaround facility specifically. The primary performance measures for the study were travel times, reliability, and throughput (capacity). Currently, short turning, station skipping, manual turning, inefficient placement of wayside signals and inaccurate data collection were identified as operational inefficiencies that could be improved upon (Malikova, 2012). 
The signals are tripped by the transponders attached to each vehicle, communicated to the wayside signal and on to central dispatch. The signal equipment recognizes the route number attached to the lead car in a train sequence. When the train arrives at a decision point, the switch adjusts to direct the train to the appropriate route. The equipment does not allow dispatchers to assign routes at these locations (Terry Byrne, personal correspondence, December 12, 2012).

Dispatchers utilize multiple operational strategies to get trains to where they want to send them. The communications system is set up in a way that the operator controls the route designation, which signals to the switches, guiding the train. The Dispatchers do not have the ability to change the route designation. Figure 8 shows the MBTA Operations Control Center.

Currently dispatchers can affect the headway deviations by implementing the following (Malikova, 2012):

- Short-turning

- Expressing

- Deadheading

- Holding

These strategies have been in place for years and the decisions are based on the information coming into the control center and application is made by the Inspectors, placed through the system at platforms and terminals. 


\section{Figure 8: MBTA Operations Control Center}

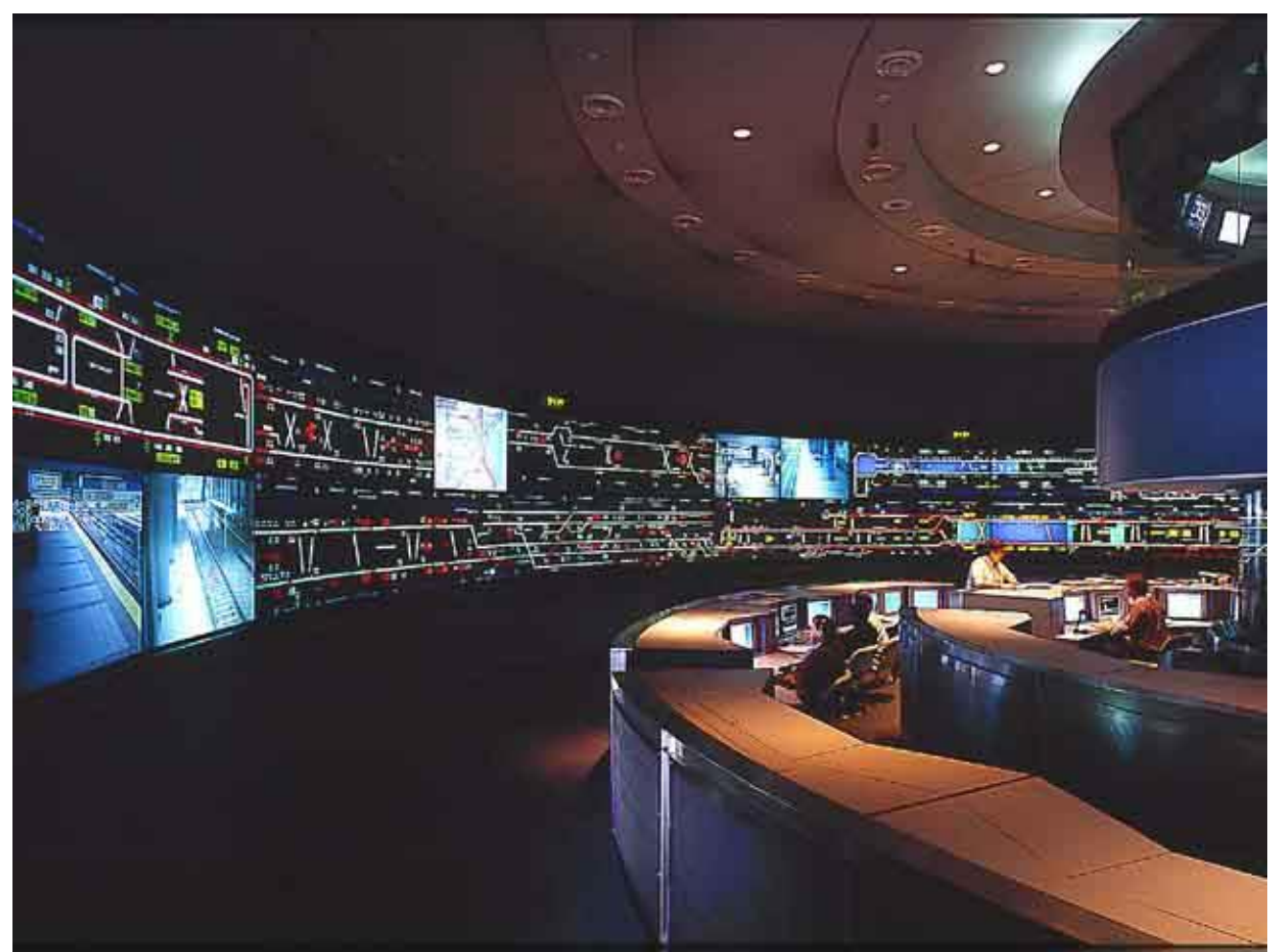

Source: United Signal \& Switch, 2000

MBTA has seen significant delays and gaps in service resulting from passenger (boarding) delay, manual operations, and operational limitations. Maximum throughput was recorded at over 40 trains per hour (Malikova, 2012).

Dispatcher equipment shows relative locations of all trains on the overhead board in addition to the personal CPU, allowing the dispatcher to create reports based on location or status. The system setup limits the number of trains for report generation. According to the Dispatcher's Training Manual (1998, p.53), "It is not possible for the dispatcher to control any of the wayside equipment on the Green Line or to view the status of switches and interlocking signals on the Green Line." The system does not support a dynamic rerouting based on current conditions. 
Previous work by Malikova (2012) resulted in the following recommendations for the Green Line:

- More AVL data collecting time points along the routes

- More active monitoring of schedule adherence

- Headway management strategies listed previously

- Upgrade to the power system

Case Study: ROMA (Railway-Optimization by Means of Alternative GRAPHS) IN THE NETHERLANDS

ROMA is a dynamic scheduling system developed and operated in the Netherlands. The primary function of the algorithm is to predict short-term variable options dynamically when there are system "disturbances" (D'Ariano, 2008). These disturbances are recorded and multiple alternatives are graphed to predict the short term future conditions if reassignment or rerouting takes place. The resulting alternatives are reviewed and evaluated by a human dispatcher who makes the appropriate final decision.

The major independent variables are the minimum safety requirements of train operations (i.e. braking distance between successive cars and acceptable speed profile) and physical limitations (i.e. limited number of tracks for routing options). The performance measures are speed table accuracy and a feasibility check. Figure 9 details ROMA's system architecture. The system checks available options against feasibility parameters for optimization. 
The system solves the following:

- Assign a track route to avoid conflicts / blocked track way

- Specifying arrival \& departure times as well as stop points and crossover points

- Maintaining safe headways and speed profiles

\section{Figure 9: ROMA System Architecture}

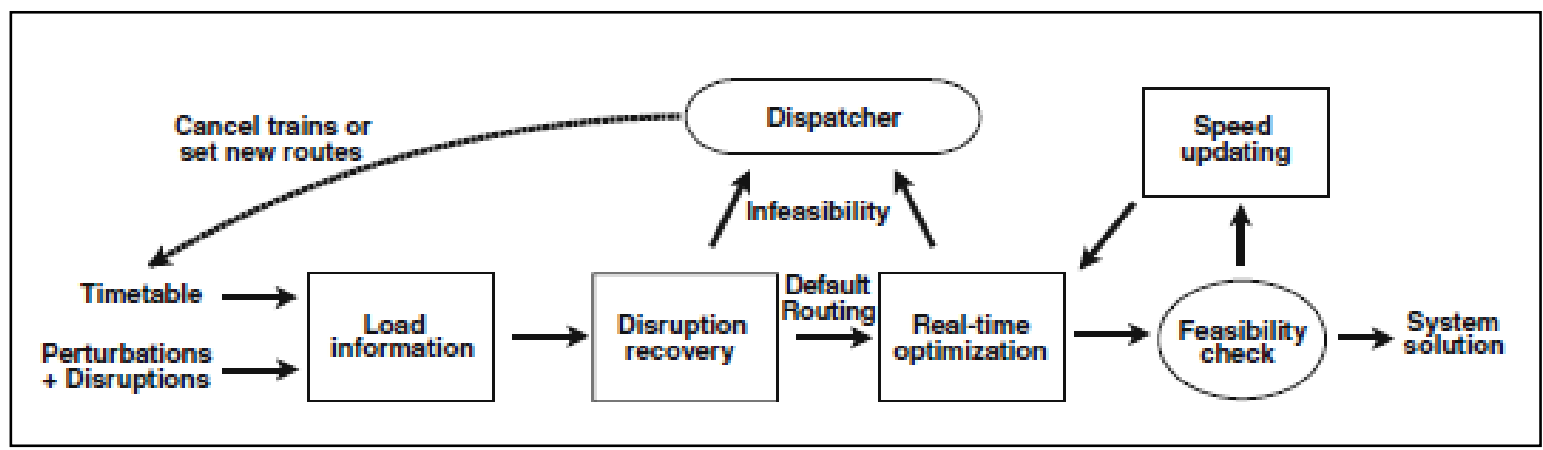

Source: D’Ariano, 2008

The system follows an algorithm similar to the traditional branch and bound algorithm, which defines all possible solutions to an optimization problem. By using upper and lower bounds of independent variable(s) the algorithm automatically eliminates the infeasible possible outcomes. The best solution minimizes the maximum delay. If there is no possibility, then another option would be applied extemporaneously by the dispatcher (such as short-turning vehicles) (D’Ariano, Pacciarelli, \& Pranzo, 2007). Propagation of train delays up to several hours and results in a short term train dispatching problem. 
"Dynamic control therefore coordinates the speed of successive trains on open tracks, secures the time windows at a junction/crossing points and synchronizes the trains arriving at stations." (D’Ariano, 2008, p.70)

The application of the branch and bound algorithm found optimal solutions for 297 of the 300 test cases. This was performed with an average computation time of 1.93 seconds. This application was bounded by the First Come First Served and First Leave First Served rules, similar to the First In First Out rule that is effective for most trains entering the Embarcadero turnaround. This accounts for the severely limited physical nature of the dispatch point. This rule increased the delay times through the system (D'Ariano, Pacciarelli, \& Pranzo, 2007). 


\section{Methodology}

The following section describes the formulation of the dynamic reassignment program as well as the data used to evaluate its effectiveness. This effectiveness is measured with respect to transit service reliability. The methodology presented here is based on previous research and the available current data sets. The reasoning behind the development of the program is to decrease the variability of headways at the time a train is dispatched from Embarcadero. The data was used in a way that time of departure remained the same and only the line designation was changed. This program is the first step to a more developed algorithm for dynamic LRV dispatch. This first step in the process of informing a dispatch system lays the framework for an unconstrained system. Further development of the algorithm, as explained in a later chapter, will introduce constraints and limitations (physical, fiscal, operational, etc.) to the optimization process.

Advanced Train Control System (ATCS) data was acquired in the fall of 2012 from Central Control servers of the San Francisco Municipal Transportation Agency "Muni." This study utilizes data from the month of March in the year 2012. March was identified as a representative month with few major holidays or major shutdowns in the city. The dataset included Excel files with variables that are identified and defined as follows:

- Platform Designation: Van Ness inbound and outbound (IB/OB), Civic Center IB/OB, Powell IB/OB, Montgomery IB/OB, Embarcadero IB/OB, and Turnaround Pockets. See Table 1 for platform designation codes. 
- Consist: Train designation by car number of the first car of the train

- Date: month, day, year

- Arrival Time: time at which the vehicle's doors open on the platform

- Route Time: time at which the departure message is sent to the operator

- Doors Time: time at which doors are closed

- Move Time: time at which the vehicle(s) begins to move

- Depart Time: time at which vehicle(s) depart from the platform

- Car 1, 2, 3, \& 4: train-specific unique ID (each member of the fleet has a unique four digit ID) of each car in the train

- Line 1 \& Line 2: route designation $(\mathrm{J}, \mathrm{L}, \mathrm{K}, \mathrm{M}, \mathrm{N})$ of each of the cars

\section{Table 1: Platform Designation Codes}

\begin{tabular}{|c|c|c|}
\hline Station & Inbound Platform & Outbound Platform \\
\hline Van Ness & VNR & VNL \\
\hline Civic Center & CCR & CCL \\
\hline Powell & POR & POL \\
\hline Montgomery & MOR & MOL \\
\hline Embarcadero & EMR & EML \\
\hline
\end{tabular}

Source: SFMTA

Headway maintenance is the operations control objective. A new program is developed to reassign vehicles to maintain a more evenly spaced headway at the time of reassigning the outbound train at Embarcadero Station. This is the point at which the vehicles are empty of customers and have the ability to be reassigned. The reassignment is a function of the preceding and succeeding headways at the time of departure. 


\section{DATA ORgANIZATION}

Data is provided in the form of Excel spreadsheets. Data was cleaned using the following method:

- Due to daily run time (5:30am to $1: 30 \mathrm{am})$, times in the early morning were re-coded as times past 24:00:00. This accounted for trains travelling through the system during the switch over to the next day.

- All deadheads were removed from the set.

- Because the $\mathrm{N}$ and $\mathrm{KT}$ lines neither begin nor end at the Embarcadero station, they were left out of the study. These two lines use the underground system as a thoroughfare.

- Data for official schedules was downloaded from the SFMTA website and manually entered into a separate Excel workbook.

\section{SPREADSHEET DEVELOPMENT}

The spreadsheet development called for the change in assignment based on six headways at the specific time a vehicle departed from EMR. These six headways are the time between said departure and the preceding $\mathrm{J}$, preceding $\mathrm{L}$,

preceding $\mathrm{M}$, next $\mathrm{J}$, next $\mathrm{L}$, and next $\mathrm{M}$. These headways were calculated based on "arrival" times at EMR.

Example: If Train A arrives EMR at 7:02, Train B arrives at 7:09 and Train $C$ arrives at 7:11, the headway preceding Train $B$ will be 0:07 minutes and the headway succeeding Train $B$ will be 0:02 minutes 
The spreadsheet, built in Microsoft Excel 2007 (see Figures 10 and 11) calculates each of these headways. There are two inputs: 1) Actual Time of Arrival at EML and 2) Actual Line Assignment. Based on the sequence of train designations, the formula pulls the headway as the difference between the preceding and succeeding $J, L, \& M$ trains. The spreadsheet function pulls the difference in departing times from EML. For each line, an average headway is calculated:

$$
\hbar_{\text {zavg }}=\frac{\hbar_{\text {zlast }}+\hbar_{\text {znext }}}{2}
$$

Where:

$$
\begin{gathered}
\hbar_{\text {zavg }}=\text { average headway for line } \mathrm{z} \text { at time of departure } \\
\hbar_{\text {zlast }}=\text { headway between current departure train and nearest preceeding } \mathrm{z} \text { train } \\
\hbar_{\text {znext }}=\text { headway between current departure train and nearest succeeding } \mathrm{z} \text { train }
\end{gathered}
$$

Every time a train would leave EML, the rolling stock would be reassigned to the line with the largest of computed average headways from among $\hbar_{\text {javg, }} \hbar_{\text {lavg, }}$, and $\hbar_{\text {mavg. }}$ Each departure is run through the same calculations. Each subsequent calculation takes the previous reassignments into consideration when calculating the new average headways. Each successive departure considers the reassignments preceding it. Trains at the beginning and end of each day were eliminated from the set if one of the six headways were missing (first and last $\mathrm{J}$, $\mathrm{L}$, and $\mathrm{M}$ of the day). There was one instance where the average headway was 
equal between two lines. This case was manually changed to represent the original line designation over the changed designation.

The worksheet highlights which train departures are actively reassigned at time of departure within these constraints with a "FALSE" statement. Statistical before-and-after comparisons can be made relating the largest average headways of each line and overall. The averages and standard deviation changes present performance measures by which to judge the strength of the reassignment system.

The worksheet can be manipulated to compare specific times of day (i.e. peak hour), specific days of the week, schedule deviation, or other combination for assessment. The scheduled headways are inserted into the spreadsheet as a baseline. Table 2 details the different runs of reassignment made for comparison. The following section details the statistical significance of each run and the before/after results.

\section{Table 2: Run Designations}

\begin{tabular}{|c|c|}
\hline Run \#1 & Current Schedule (21 hours) \\
\hline Run \#2 & 03.01 .2012 All Day (21 hours) \\
\hline Run \#3 & 03.01 .2012 AM Peak (2 hours) \\
\hline Run \#4 & 03.15.2012 All Day (21 hours) \\
\hline
\end{tabular}


Figure 10: Reassignment Spreadsheet 1 of 2: Run \#2

\begin{tabular}{|c|c|c|c|c|c|c|c|c|c|c|c|c|}
\hline \multicolumn{13}{|c|}{ Current Trains } \\
\hline$\frac{\text { Arrival }}{\underline{\text { Time }}}$ & $\begin{array}{c}\text { Route } \\
\text { Desianation }\end{array}$ & $\frac{\text { Time Since }}{\underline{\text { Last J }}}$ & $\begin{array}{c}\text { Time Since } \\
\underline{\text { Last L }}\end{array}$ & $\frac{\text { Time Since }}{\text { Last M }}$ & Time until & \begin{tabular}{|c|} 
Time until \\
next L
\end{tabular} & $\frac{\text { Time until }}{\underline{\text { next } \mathrm{M}}}$ & $\begin{array}{l}\frac{\text { Current Average }}{\text { Headway of J's at }} \\
\text { Time of Departure }\end{array}$ & $\begin{array}{l}\frac{\text { Current Averaqe }}{\text { Headway of } L \text { 's at }} \\
\underline{\text { Time of Departure }}\end{array}$ & $\frac{\frac{\text { Current Averaqe }}{\text { Headway of M's }}}{\frac{\text { at Time of }}{\text { Departure }}}$ & $\frac{\text { Actual Largest }}{\frac{\text { Headway }}{\text { Average }}}$ & $\begin{array}{l}\frac{\text { Averaqe Actual }}{\text { Headway }} \\
\text { Between Trains }\end{array}$ \\
\hline $6: 44: 58$ & M & $10: 02$ & $12: 33$ & $15: 55$ & 03:31 & $00: 56$ & $09: 49$ & $06: 47$ & $06: 45$ & $12: 52$ & $12: 52$ & $08: 48$ \\
\hline $6: 45: 54$ & $\mathrm{~L}$ & 10:58 & $13: 29$ & $00: 56$ & 02:35 & 14:41 & $08: 53$ & $06: 47$ & $14: 05$ & $04: 54$ & $14: 05$ & $08: 35$ \\
\hline $6: 48: 29$ & J & $13: 33$ & $02: 35$ & 03:31 & 13:02 & 12:06 & $06: 18$ & $13: 18$ & $07: 21$ & $04: 54$ & 13:18 & $08: 31$ \\
\hline $6: 54: 47$ & M & 06:18 & 08:53 & $09: 49$ & $\begin{array}{ll}06: 44 \\
\end{array}$ & 05:48 & $22: 06$ & $06: 31$ & \begin{tabular}{|l|}
$07: 21$ \\
\end{tabular} & \begin{tabular}{|l|}
$15: 57$ \\
\end{tabular} & $15: 57$ & 09:56 \\
\hline $7: 00: 35$ & L & 12:06 & 14:41 & 05:48 & 00:56 & $21: 35$ & 16:18 & 06:31 & 18:08 & \begin{tabular}{l|l}
$11: 03$ \\
\end{tabular} & 18:08 & 11:54 \\
\hline 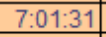 & J & $13: 02$ & \begin{tabular}{l|l}
$00: 56$ \\
\end{tabular} & $06: 44$ & 10:44 & $20: 39$ & $15: 22$ & $11: 53$ & $10: 47$ & \begin{tabular}{l|l}
$11: 03$ \\
\end{tabular} & $11: 53$ & 11:14 \\
\hline $7: 12: 15$ & J & $10: 44$ & $11: 40$ & $17: 28$ & $\begin{array}{l}06: 38 \\
\end{array}$ & 09:55 & 04:38 & $08: 41$ & $10: 47$ & \begin{tabular}{l|l}
$11: 03$ \\
\end{tabular} & 11:03 & 10:10 \\
\hline $7: 16: 53$ & M & 04:38 & $16: 18$ & $22: 06$ & 02:00 & 05:17 & 23:07 & $03: 19$ & $10: 47$ & 22:37 & $22: 37$ & $12: 14$ \\
\hline $7: 18: 53$ & J & $06: 38$ & 18:18 & $02: 00$ & 04:11 & 03:17 & 21:07 & $05: 24$ & $10: 47$ & \begin{tabular}{|l|}
$11: 34$ \\
\end{tabular} & $11: 34$ & 09:15 \\
\hline $\begin{array}{l}7: 22: 10 \\
\end{array}$ & L & 03:17 & $21: 35$ & $05: 17$ & 00:54 & 04:37 & 17:50 & 02:05 & 13:06 & \begin{tabular}{|l|}
$11: 34$ \\
\end{tabular} & 13:06 & $08: 55$ \\
\hline $7: 23: 04$ & J & $04: 11$ & $00: 54$ & $06: 11$ & 05:42 & 03:43 & 16:56 & $04: 57$ & 02:18 & \begin{tabular}{|l|}
$11: 34$ \\
\end{tabular} & $11: 34$ & $06: 16$ \\
\hline $7: 26: 47$ & L & 03:43 & 04:37 & 09:54 & $\begin{array}{l}01: 59 \\
\end{array}$ & 07:00 & 13:13 & 02:51 & $05: 49$ & \begin{tabular}{l|l|}
$11: 34$ \\
\end{tabular} & 11:34 & $06: 44$ \\
\hline $\begin{array}{l}7: 28: 46 \\
\end{array}$ & J & $05: 42$ & $\begin{array}{l}01: 59 \\
\end{array}$ & $11: 53$ & 13:53 & 05:01 & 11:14 & $09: 47$ & $03: 30$ & 11:34 & 11:34 & 08:17 \\
\hline $\begin{array}{l}7: 33: 47 \\
\end{array}$ & L & 05:01 & 07:00 & $16: 54$ & $\begin{array}{l}08: 52 \\
\end{array}$ & 17:07 & $06: 13$ & $06: 56$ & 12:04 & 11:34 & 12:04 & 10:11 \\
\hline $7: 40: 00$ & $M$ & 11:14 & $06: 13$ & $23: 07$ & \begin{tabular}{|l|l|}
$02: 39$ \\
\end{tabular} & $10: 54$ & 09:23 & $06: 56$ & $\begin{array}{ll}08: 33 \\
\end{array}$ & $16: 15$ & $16: 15$ & $10: 35$ \\
\hline $7: 42: 39$ & J & $13: 53$ & $08: 52$ & $02: 39$ & 03:41 & 08:15 & $06: 44$ & $08: 47$ & $08: 33$ & \begin{tabular}{l|l}
$04: 41$ \\
\end{tabular} & $08: 47$ & $07: 21$ \\
\hline $7: 46: 20$ & J & 03:41 & $12: 33$ & $06: 20$ & $\begin{array}{ll}08: 42 \\
\end{array}$ & $04: 34$ & 03:03 & $06: 11$ & $08: 33$ & $04: 41$ & $08: 33$ & $06: 29$ \\
\hline $7: 49: 23$ & M & 03:03 & 15:36 & 09:23 & $\begin{array}{l}05: 39 \\
\end{array}$ & 01:31 & 11:08 & \begin{tabular}{|l|}
$04: 21$ \\
\end{tabular} & $08: 33$ & 10:15 & 10:15 & $07: 43$ \\
\hline $7: 50: 54$ & L & $04: 34$ & $17: 07$ & 01:31 & \begin{tabular}{l|l}
$04: 08$ \\
\end{tabular} & $04: 52$ & 09:37 & \begin{tabular}{|l|}
$04: 21$ \\
\end{tabular} & $10: 59$ & 05:34 & $10: 59$ & $06: 58$ \\
\hline $7: 55: 02$ & J & $08: 42$ & 04:08 & 05:39 & \begin{tabular}{l|l|}
$08: 24$ \\
\end{tabular} & $00: 44$ & 05:29 & 08:33 & $02: 26$ & $05: 34$ & $08: 33$ & 05:31 \\
\hline $7: 55: 46$ & L & $00: 44$ & $04: 52$ & $06: 23$ & 07:40 & 11:31 & $04: 45$ & $04: 12$ & $08: 12$ & 05:34 & $08: 12$ & $05: 59$ \\
\hline $8: 00: 31$ & M & $05: 29$ & $04: 45$ & 11:08 & 02:55 & $06: 46$ & $04: 10$ & $04: 12$ & $05: 46$ & \begin{tabular}{l|l}
$07: 39$ \\
\end{tabular} & 07:39 & $05: 52$ \\
\hline $8: 03: 26$ & J & $08: 24$ & $07: 40$ & $02: 55$ & \begin{tabular}{ll|}
$06: 51$ \\
\end{tabular} & 03:51 & 01:15 & 07:37 & $05: 46$ & $02: 05$ & $07: 37$ & $05: 09$ \\
\hline $8: 04: 41$ & M & 01:15 & 08:55 & 04:10 & 05:36 & $02: 36$ & $\begin{array}{l}07: 15 \\
\end{array}$ & 03:25 & $05: 46$ & $05: 42$ & $05: 46$ & 04:58 \\
\hline $8: 07: 17$ & L & 03:51 & \begin{tabular}{|l|}
$11: 31$ \\
\end{tabular} & $02: 36$ & 03:00 & $06: 49$ & 04:39 & 03:25 & $09: 10$ & 03:37 & 09:10 & 05:24 \\
\hline $8: 10: 17$ & J & $06: 51$ & 03:00 & 05:36 & $\begin{array}{ll}07: 25 \\
\end{array}$ & $03: 49$ & 01:39 & 07:08 & $03: 24$ & \begin{tabular}{|l|}
$03: 37$ \\
\end{tabular} & 07:08 & 04:43 \\
\hline \begin{tabular}{|c|}
$8: 11: 56$ \\
\end{tabular} & M & 01:39 & $\begin{array}{l}04: 39 \\
\end{array}$ & $07: 15$ & 05:46 & $02: 10$ & $09: 54$ & $03: 43$ & $03: 24$ & $08: 34$ & $08: 34$ & $05: 14$ \\
\hline $8: 14: 06$ & L & 03:49 & $06: 49$ & $02: 10$ & 03:36 & $05: 29$ & $07: 44$ & $03: 43$ & $06: 09$ & \begin{tabular}{l|l}
$04: 57$ \\
\end{tabular} & $06: 09$ & $04: 56$ \\
\hline $8: 17: 42$ & J & $07: 25$ & 03:36 & $05: 46$ & $11: 00$ & $01: 53$ & 04:08 & 09:13 & $02: 45$ & $\begin{array}{l}04: 57 \\
\end{array}$ & $09: 13$ & 05:38 \\
\hline $8: 19: 35$ & L & $01: 53$ & $05: 29$ & 07:39 & $\begin{array}{l}09: 07 \\
\end{array}$ & $06: 50$ & $02: 15$ & $05: 30$ & $06: 10$ & \begin{tabular}{l|l}
$04: 57$ \\
\end{tabular} & $06: 10$ & $05: 32$ \\
\hline $8: 21: 50$ & M & $04: 08$ & $02: 15$ & $09: 54$ & $\begin{array}{ll}06: 52 \\
\end{array}$ & $04: 35$ & 09:00 & $05: 30$ & $03: 25$ & $09: 27$ & $09: 27$ & $06: 07$ \\
\hline $8: 26: 25$ & L & $08: 43$ & $06: 50$ & 04:35 & $\begin{array}{l}02: 17 \\
\end{array}$ & 07:06 & $04: 25$ & 05:30 & $06: 58$ & \begin{tabular}{l|l|}
$04: 30$ \\
\end{tabular} & $06: 58$ & 05:39 \\
\hline 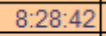 & J & $11: 00$ & $02: 17$ & $06: 52$ & \begin{tabular}{|l|}
$13: 27$ \\
\end{tabular} & $04: 49$ & 02:08 & $12: 13$ & $03: 33$ & \begin{tabular}{l|l|}
$04: 30$ \\
\end{tabular} & $12: 13$ & $06: 45$ \\
\hline $8: 30: 50$ & M & 02:08 & \begin{tabular}{l|l|}
$04: 25$ \\
\end{tabular} & 09:00 & 11:19 & 02:41 & 18:00 & $06: 44$ & $03: 33$ & $13: 30$ & $13: 30$ & $07: 55$ \\
\hline \begin{tabular}{|l|}
$8: 33: 31$ \\
\end{tabular} & L & $04: 49$ & 07:06 & $02: 41$ & $\begin{array}{l}08: 38 \\
\end{array}$ & 13:55 & $15: 19$ & $06: 44$ & $10: 30$ & 09:00 & $10: 30$ & $08: 45$ \\
\hline $8: 42: 09$ & J & 13:27 & $08: 38$ & $11: 19$ & 08:41 & 05:17 & $06: 41$ & $11: 04$ & $06: 57$ & 09:00 & $11: 04$ & 09:00 \\
\hline $8: 47: 26$ & L & $05: 17$ & $13: 55$ & $16: 36$ & $03: 24$ & 09:07 & $01: 24$ & $04: 20$ & $11: 31$ & \begin{tabular}{l|l}
$09: 00$ \\
\end{tabular} & $11: 31$ & $08: 17$ \\
\hline $8: 48: 50$ & M & $06: 41$ & 01:24 & 18:00 & 02:00 & 07:43 & 05:21 & 04:20 & 04:34 & $\begin{array}{l}11: 40 \\
\end{array}$ & 11:40 & $06: 52$ \\
\hline $8: 50: 50$ & J & 08:41 & 03:24 & $02: 00$ & $\begin{array}{l}04: 16 \\
\end{array}$ & 05:43 & 03:21 & $\begin{array}{ll}06: 28 \\
\end{array}$ & $04: 34$ & $02: 41$ & $06: 28$ & 04:34 \\
\hline 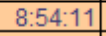 & M & 03:21 & $06: 45$ & $05: 21$ & 00:55 & 02:22 & $07: 22$ & 02:08 & $04: 34$ & $06: 22$ & $06: 22$ & $04: 21$ \\
\hline \begin{tabular}{|c|}
$8: 55: 06$ \\
\end{tabular} & J & 04:16 & $07: 40$ & $00: 55$ & 11:58 & \begin{tabular}{|l|l|}
$01: 27$ \\
\end{tabular} & $06: 27$ & $08: 07$ & $04: 34$ & \begin{tabular}{l|l}
$03: 41$ \\
\end{tabular} & 08:07 & $05: 27$ \\
\hline $8: 56: 33$ & L & $01: 27$ & 09:07 & $02: 22$ & $10: 31$ & 08:13 & 05:00 & $05: 59$ & $08: 40$ & $03: 41$ & $08: 40$ & $06: 07$ \\
\hline $9: 01: 33$ & M & $06: 27$ & $05: 00$ & $07: 22$ & 05:31 & $03: 13$ & 14:59 & $05: 59$ & $04: 06$ & 11:10 & $11: 10$ & $07: 05$ \\
\hline
\end{tabular}


Figure11: Reassignment Spreadsheet 2 of 2: Run \#2

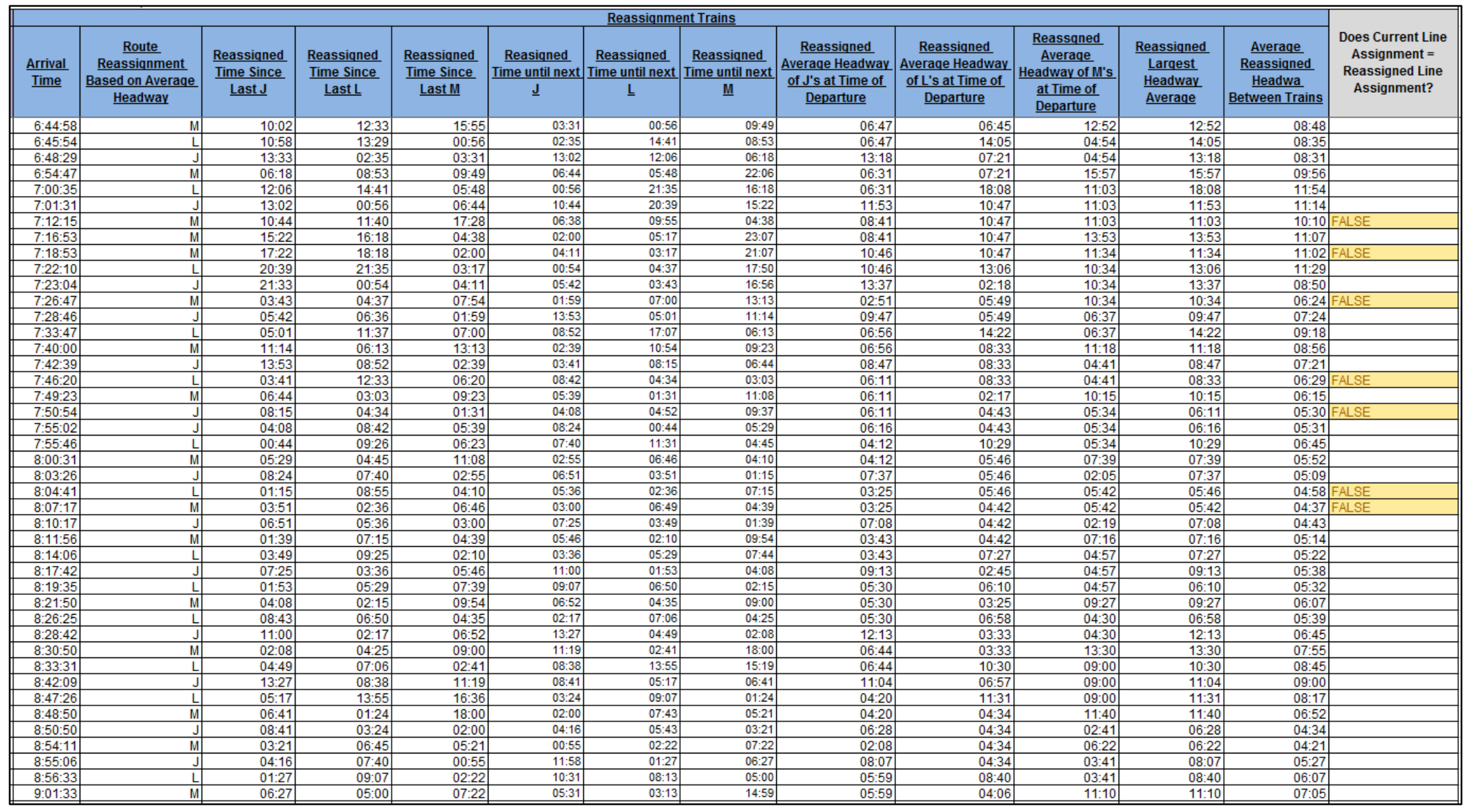




\section{Statistical Analysis}

The reassignment calculator was applied to data from March $1^{\text {st }}$, March $15^{\text {th }}$, and the existing schedule. The measure of performance is headway regularity, especially during critical times such as peak hours (SFMTA defines AM peak period as 7:00 - 9:00 and PM peak period as 16:00 - 18:00). The overall change in reassigning train departures results in shorter average headways. This increases efficiency, on time performance, and reliability.

RUN \#1: CURRENT SCHEDULE

The current schedule reflects how the system is expected to operate on a normal weekday. Table 3 shows the scheduled versus actual headways for the two random days chosen. All results showed larger actual headways over what was scheduled. Headway deviations varied between 17 seconds and 143 seconds.

Table 3: All Day Scheduled versus Actual Headways

\begin{tabular}{|c|c|c|c|c|c|}
\hline Statistic & Schedule & $\mathbf{0 3 . 0 1}$ & $\begin{array}{c}\text { Deviation } \\
\text { from } \\
\text { Schedule }\end{array}$ & $\mathbf{0 3 . 1 5}$ & $\begin{array}{c}\text { Deviation } \\
\text { from } \\
\text { Schedule }\end{array}$ \\
\hline Mean Headway of J & $07: 29$ & $08: 22$ & $00: 53$ & $07: 46$ & $00: 17$ \\
\hline Mean Headway of L & $07: 10$ & $09: 21$ & $02: 11$ & $08: 07$ & $00: 57$ \\
\hline Mean Headway of M & $07: 38$ & $10: 01$ & $02: 23$ & $08: 58$ & $01: 20$ \\
\hline Mean Headway of JLM & $07: 26$ & $09: 15$ & $01: 49$ & $08: 16$ & $00: 50$ \\
\hline Stand. Deviation of J & $03: 35$ & $04: 34$ & $00: 59$ & $04: 10$ & $00: 35$ \\
\hline Stand. Deviation of L & $03: 31$ & $05: 36$ & $02: 05$ & $05: 37$ & $02: 06$ \\
\hline Stand. Deviation of M & $03: 45$ & $05: 07$ & $01: 22$ & $05: 03$ & $01: 18$ \\
\hline Stand. Deviation of JLM & $02: 20$ & $03: 21$ & $01: 01$ & $03: 31$ & $02: 30$ \\
\hline
\end{tabular}


Table 4 shows the average headway deviations during the morning peak period as compared to the schedule. The deviations range between 1 second and 104 seconds between the three lines during the AM peak hours. The lower deviations during the peak hours indicate a response to the need for a more responsive system during specific hours of the day. The schedule is programmed to meet the increased number of customers during these hours.

Table 4: AM Peak Scheduled versus Actual Headways

\begin{tabular}{|c|c|c|c|c|c|}
\hline Statistic & Schedule & $\mathbf{0 3 . 0 1}$ & $\begin{array}{c}\text { Deviation } \\
\text { from } \\
\text { Schedule }\end{array}$ & $\mathbf{0 3 . 1 5}$ & $\begin{array}{c}\text { Deviation } \\
\text { from } \\
\text { Schedule }\end{array}$ \\
\hline Mean Headway of J & $06: 09$ & $06: 08$ & $00: 01$ & $06: 52$ & $00: 43$ \\
\hline Mean Headway of L & $06: 09$ & $07: 15$ & $01: 06$ & $06: 47$ & $00: 38$ \\
\hline Mean Headway of M & $06: 29$ & $08: 11$ & $01: 42$ & $07: 09$ & $00: 40$ \\
\hline Mean Headway of JLM & $06: 16$ & $07: 11$ & $00: 55$ & $06: 56$ & $00: 40$ \\
\hline Stand. Deviation of J & $02: 15$ & $02: 35$ & $00: 20$ & $03: 33$ & $01: 18$ \\
\hline Stand. Deviation of L & $02: 27$ & $03: 35$ & $01: 08$ & $03: 25$ & $00: 58$ \\
\hline Stand. Deviation of M & $02: 33$ & $04: 17$ & $01: 44$ & $02: 52$ & $00: 19$ \\
\hline Stand. Deviation of JLM & $00: 51$ & $02: 11$ & $01: 20$ & $01: 38$ & $00: 47$ \\
\hline
\end{tabular}

Applying the reassignment calculator to the schedule yielded only a $0.9 \%$ (3 of 323) reassignment of departing trains at EML. This supports the schedule actively reflecting a system where the departures are arranged to meet the largest headway at time of departure.

Table 5 shows the change in headway means and standard deviations after applying the calculator to the schedule. The departure times remain the same but the three changed train departures showed a less than $1 \%$ decrease in the mean headway of lines $J$ and $M$ with no changes to the $L$ line. These three 
changed trains at 6:01, 6:31, and 10:19 were a result of a difference of headway $<30$ seconds.

\section{Table 5: All Day Scheduled versus Reassigned Headways}

\begin{tabular}{|c|c|c|c|}
\hline Statistic & Before & After & $\%$ Change \\
\hline Mean Headway of J & $07: 29$ & $07: 28$ & $-0.3 \%$ \\
\hline Mean Headway of L & $07: 10$ & $07: 12$ & $0.5 \%$ \\
\hline Mean Headway of M & $07: 38$ & $07: 37$ & $-0.3 \%$ \\
\hline Mean Headway of JLM & $07: 26$ & $07: 26$ & $0 \%$ \\
\hline Stand. Deviation of J & $03: 35$ & $03: 35$ & $-0.2 \%$ \\
\hline Stand. Deviation of L & $03: 31$ & $03: 33$ & $0.8 \%$ \\
\hline Stand. Deviation of M & $03: 45$ & $03: 43$ & $-1.0 \%$ \\
\hline Stand. Deviation of JLM & $02: 20$ & $02: 20$ & $0 \%$ \\
\hline
\end{tabular}

The reassignment decreases the average headway by $0 \%$ across all three lines. The standard deviation remained the same also. The current schedule reflects an opportunity to create a base case scenario for day-to-day application.

RUNS \#2 \& \#3: MARCH 1 ${ }^{\text {ST }}, 2012$ ALL-DAY \& AM PEAK

The overall results for a day-long application for March $1^{\text {st }}$ are shown in Table 6. Results show a $0 \%$ decrease in standard deviation during the 21 hour run period and a 3\% decrease in overall mean headway. Although the changes cause the overall average headway of the $\mathrm{J}$ line to increase by 18 seconds, the $\mathrm{L}$ and $\mathrm{M}$ lines benefitted from the reassignment. Overall there was an increase in headway between $\mathrm{J}$ trains but the headway lengths among $\mathrm{L}$ and $M$ trains were reduced. Figures 11 through 18 show the best fit curve relative to the entire day's actual and reassigned line assignments. The best fit curves increased their $r$ - 
squared value on both the $L$ and $M$ lines. The increased $r$-squared value shows closer clustering of data points to the best-fitting line than scheduled.

\section{Table 6: 03.01.2012 All Day Scheduled versus Reassigned Headways}

\begin{tabular}{|c|c|c|c|}
\hline Statistic & Before & After & $\%$ Change \\
\hline Mean Headway of J & $08: 22$ & $08: 40$ & $4 \%$ \\
\hline Mean Headway of L & $09: 21$ & $09: 06$ & $-3 \%$ \\
\hline Mean Headway of M & $10: 01$ & $09: 11$ & $-8 \%$ \\
\hline Mean Headway of JLM & $09: 15$ & $08: 59$ & $-3 \%$ \\
\hline Stand. Deviation of J & $04: 34$ & $04: 38$ & $1 \%$ \\
\hline Stand. Deviation of L & $05: 36$ & $05: 10$ & $-8 \%$ \\
\hline Stand. Deviation of M & $05: 07$ & $04: 50$ & $-6 \%$ \\
\hline Stand. Deviation of JLM & $03: 21$ & $03: 21$ & $0 \%$ \\
\hline
\end{tabular}

Run \#3 details in Table 7 the AM peak hour aspects of the full day run of March $1^{\text {st }}$. During the AM peak hour for this day, mean headway was reduced by 1 second overall, $\mathrm{a}<1 \%$ decrease in time. Again, the $\mathrm{J}$ line saw an increase in mean headway while the $L$ and $M$ lines saw a decrease, resulting in less variable headways.

Table 7: 03.01.2012 AM Peak Scheduled versus Reassigned Headways

\begin{tabular}{|c|c|c|c|}
\hline Statistic & Before & After & $\%$ Change \\
\hline Mean Headway of J & $06: 08$ & $06: 54$ & $13 \%$ \\
\hline Mean Headway of L & $07: 15$ & $07: 09$ & $-1 \%$ \\
\hline Mean Headway of M & $08: 11$ & $07: 09$ & $-13 \%$ \\
\hline Mean Headway of JLM & $07: 11$ & $07: 10$ & $0 \%$ \\
\hline Stand. Deviation of J & $02: 35$ & $02: 48$ & $9 \%$ \\
\hline Stand. Deviation of L & $03: 35$ & $03: 37$ & $1 \%$ \\
\hline Stand. Deviation of M & $04: 17$ & $03: 15$ & $-24 \%$ \\
\hline Stand. Deviation of JLM & $02: 10$ & $02: 13$ & $1 \%$ \\
\hline
\end{tabular}


The system overall saw a benefit from the reassignment system. Mean Headway for the day was decreased by $3 \%$ (about 16 seconds) while trains departing in the AM peak hours were decreased by $0 \%$. More efficient operations in the form of less variation of headway is a better use of operations funding. This could also lead to better informed decisions of the addition of trains to the system.

Table 8 details the change in number of trains for each line. The number of $\mathrm{J}$ trains decreased during the peak hour. The variability is less from the reassignment but there would be less total number of trains during the peak hour.

Table 8: Change in Line Trains per Run from Reassignment

\begin{tabular}{|c|c|c|c|c|}
\hline Run & Line & $\begin{array}{c}\text { Actual Number of } \\
\text { Trains }\end{array}$ & $\begin{array}{c}\text { Number of } \\
\text { Reassigned Trains }\end{array}$ & $\begin{array}{c}\% \\
\text { Change }\end{array}$ \\
\hline 1 & J & 106 & 106 & $0 \%$ \\
\hline & L & 113 & 113 & $0 \%$ \\
\hline & M & 104 & 104 & $0 \%$ \\
\hline & JLM & 323 & 323 & $0 \%$ \\
\hline 2 & J & 103 & 89 & $-13.6 \%$ \\
\hline & L & 97 & 96 & $-1 \%$ \\
\hline & M & 84 & 99 & $17.9 \%$ \\
\hline & JLM & 284 & 284 & $0 \%$ \\
\hline 3 & J & 15 & 13 & $-13.3 \%$ \\
\hline & L & 13 & 12 & $-7.7 \%$ \\
\hline & M & 10 & 13 & $-30 \%$ \\
\hline & JLM & 38 & 38 & $0 \%$ \\
\hline 4 & J & 106 & 99 & $-6.6 \%$ \\
\hline & L & 105 & 102 & $-2.9 \%$ \\
\hline & M & 92 & 102 & $10.9 \%$ \\
\hline & JLM & 303 & 303 & $0 \%$ \\
\hline
\end{tabular}

The decrease in headway average has the potential for operations to add additional trains to the schedule to meet demand. 
Figure 12: Run \#2 Actual Average Headway of J's at Time of Departure. 03.01.202.

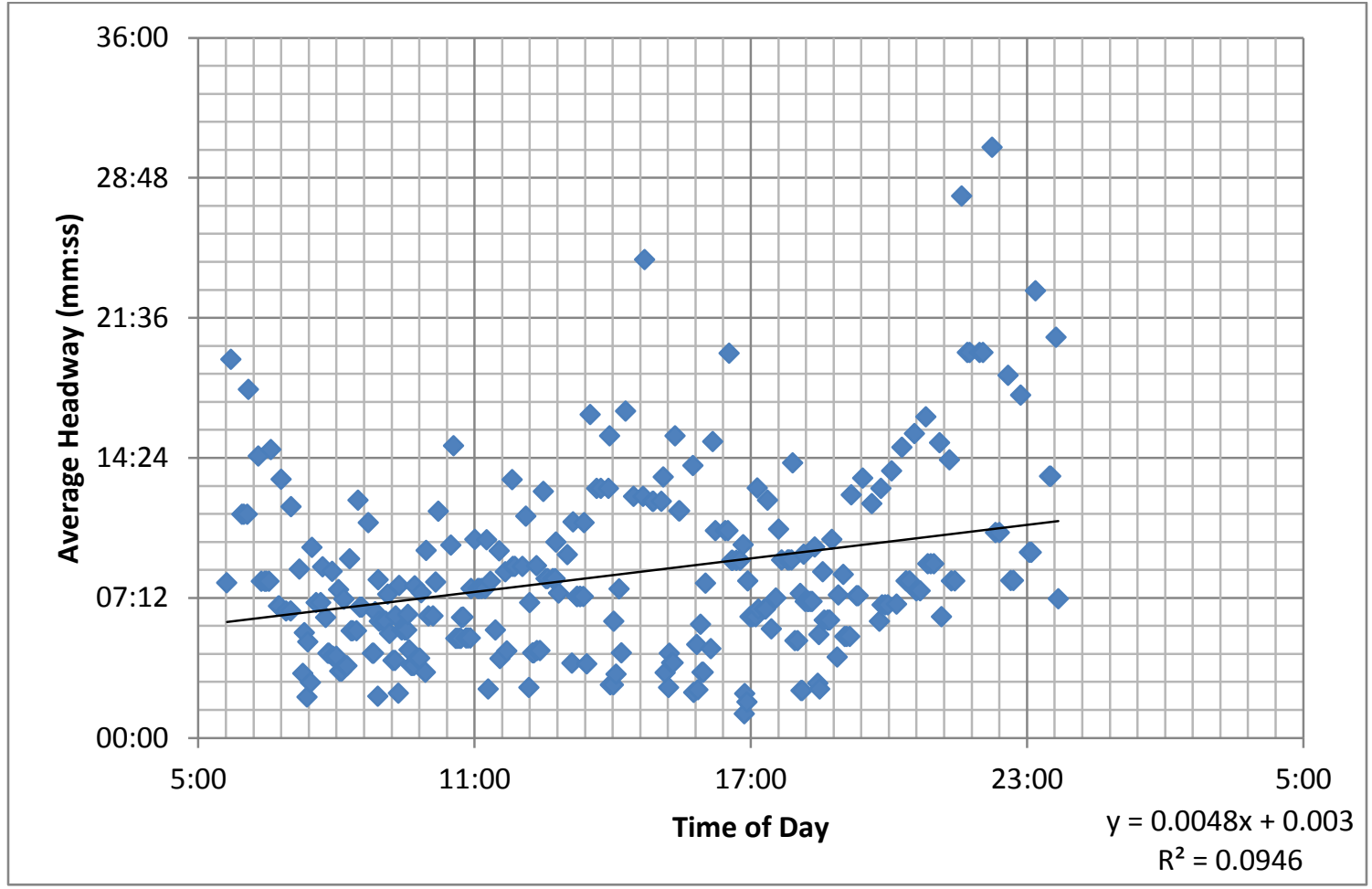

Figure 13: Run \#2 Reassigned Average Headway of J's at Time of Departure. 03.01.2012.

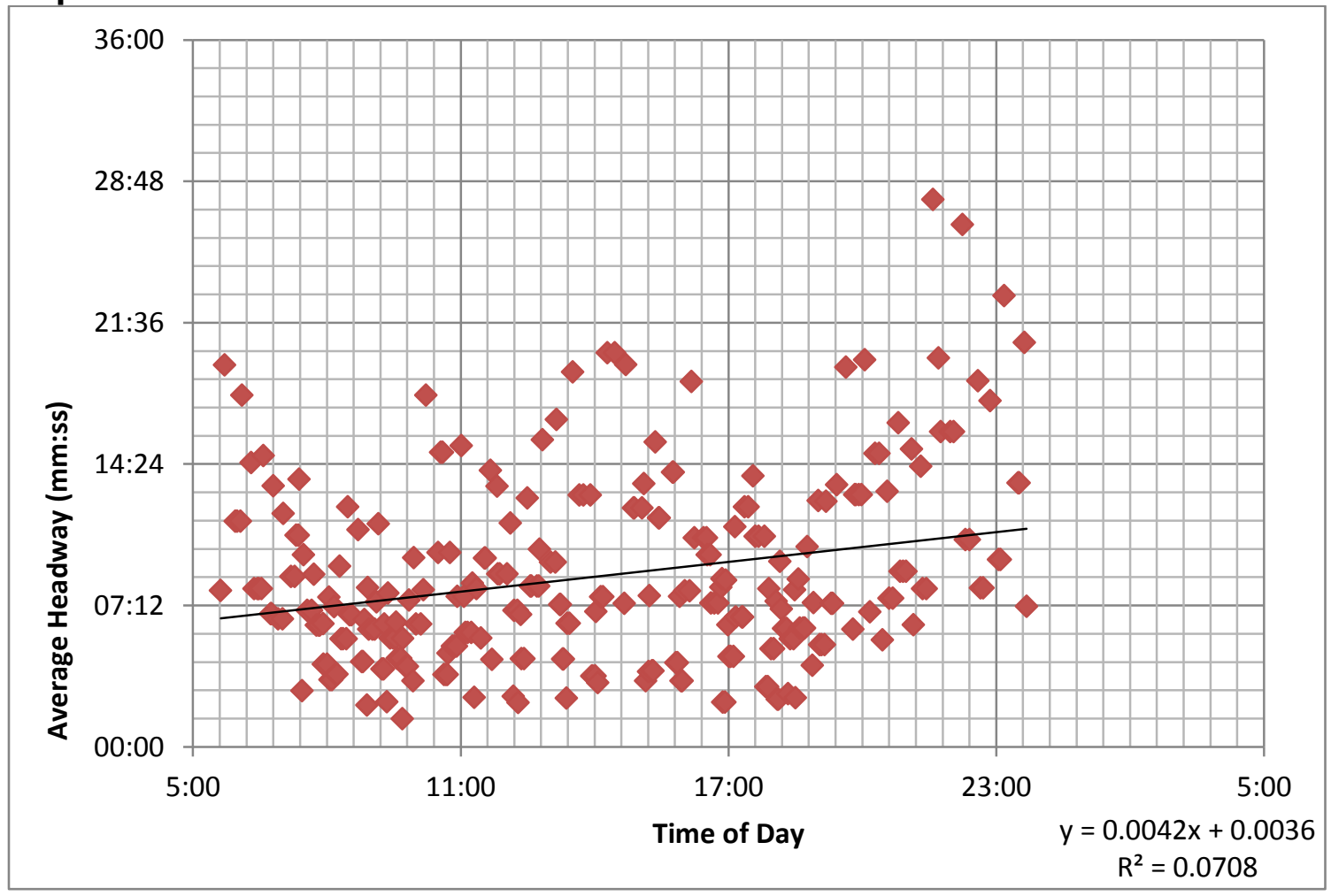


Figure 14: Run \#2 Actual Average Headway of L's at Time of Departure. 03.01.2012.

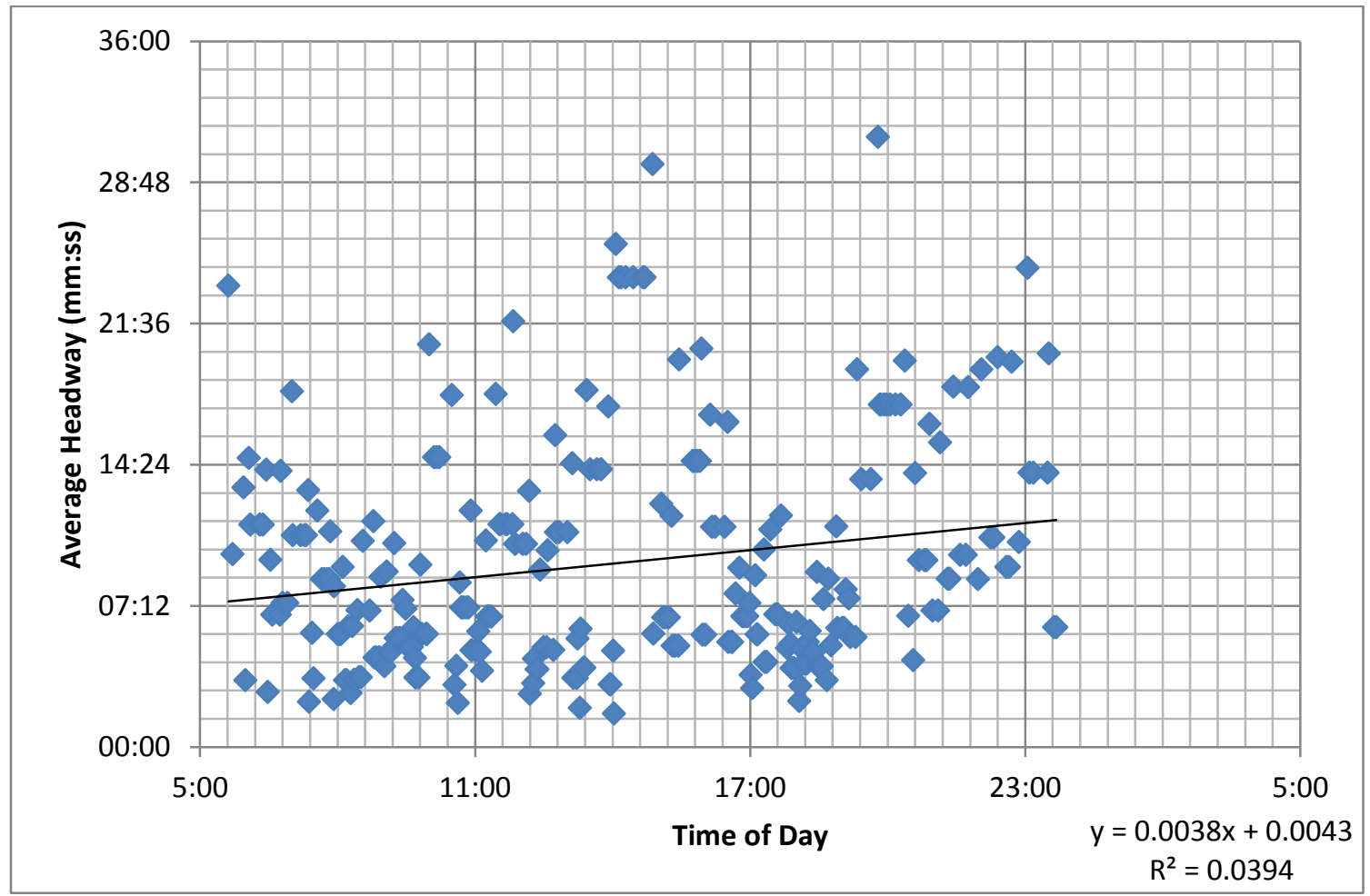

Figure 15: Run \#2 Reassigned Average Headway of L's at Time of Departure. 03.01.2012.

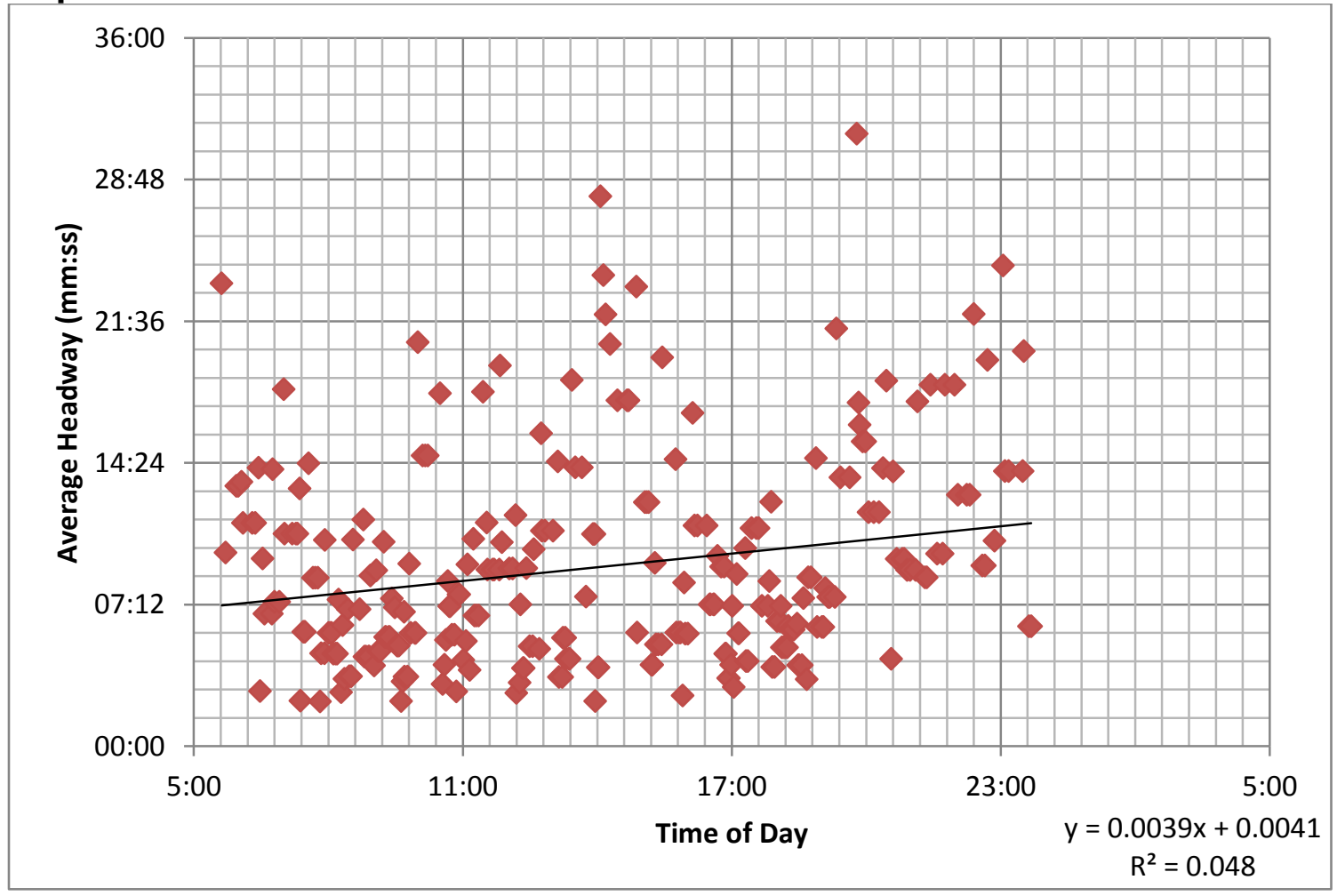


Figure 16: Run \#2 Actual Average Headway of M's at Time of Departure. 03.01.2012.

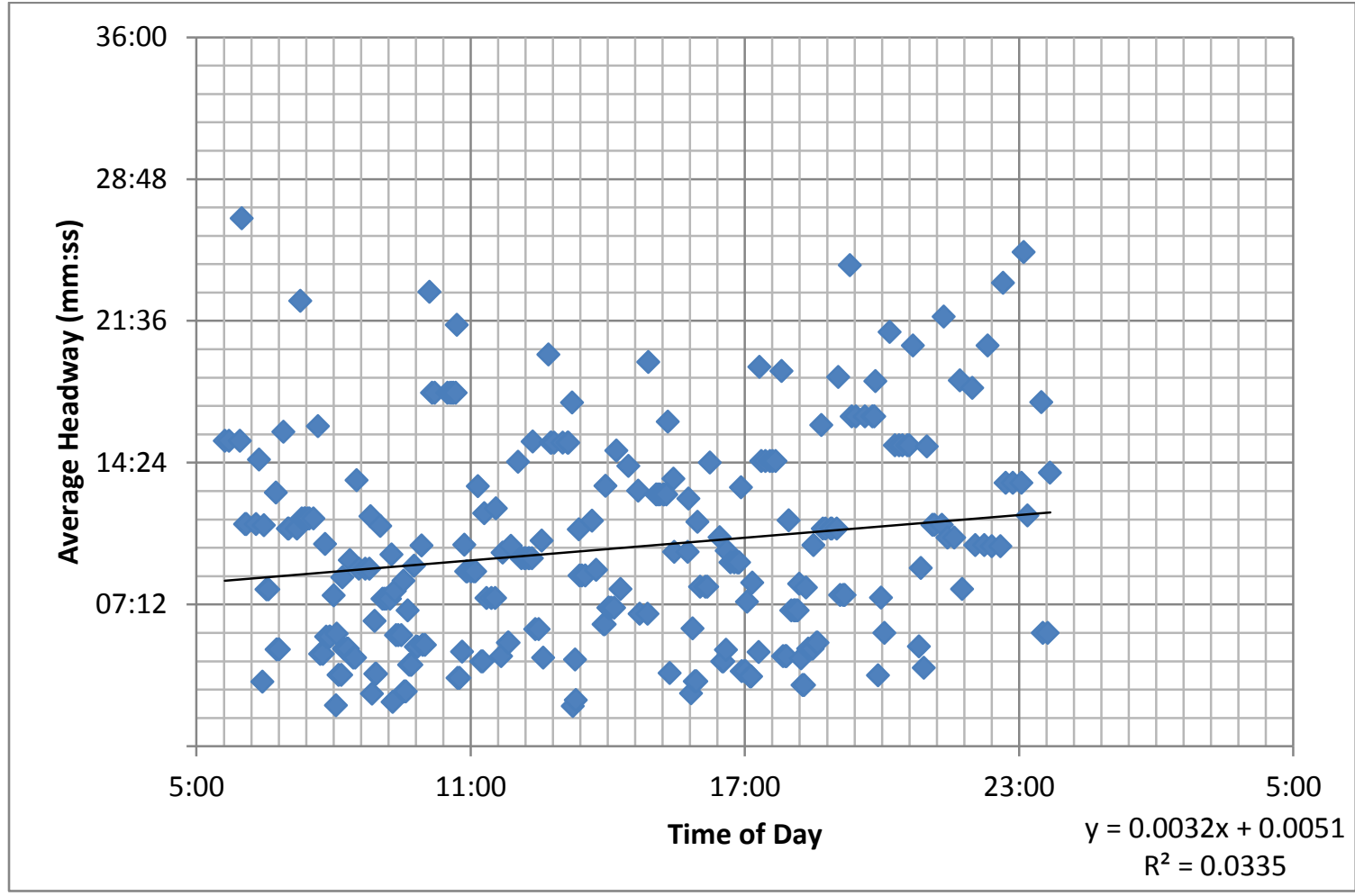

Figure 17: Run \#2 Reassigned Average Headway of M's at Time of Departure. 03.01.2012.

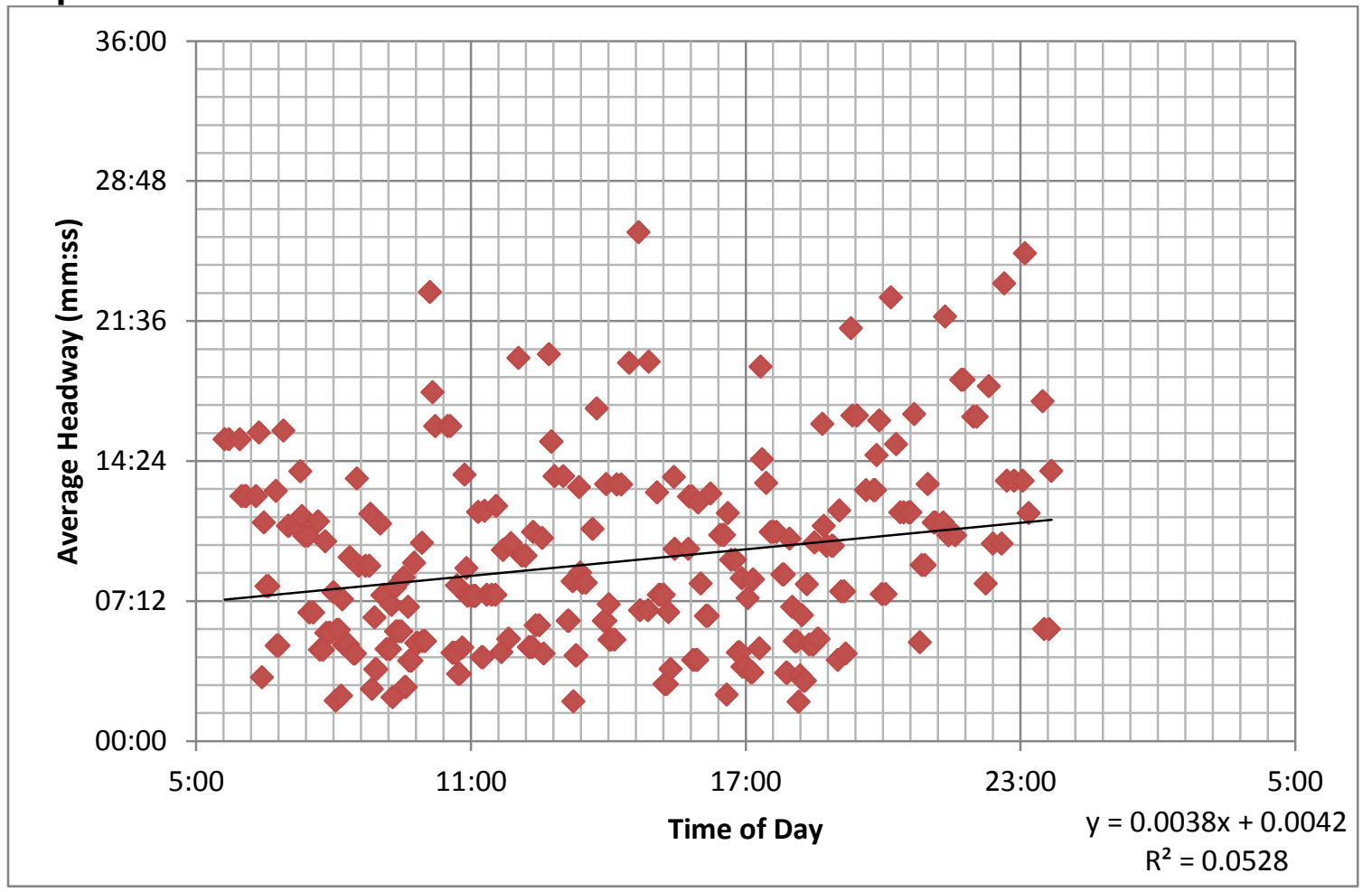


Figure 18: Run \#2 Actual Largest Headway Average of J, L, \& M. 03.01.2012.

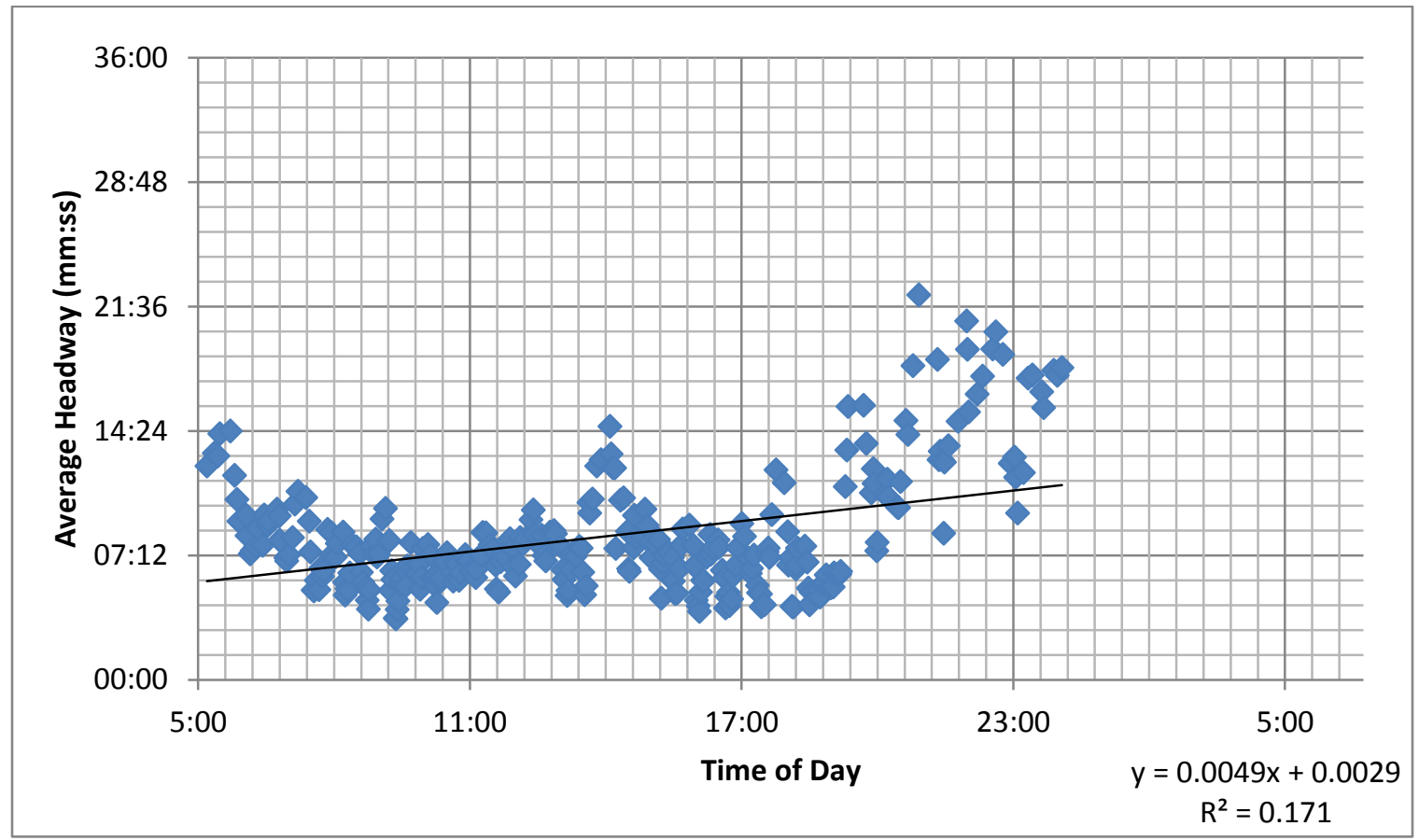

Figure 19: Run \#2 Reassigned Largest Headway Average of J, L, \& M. 03.01.2012.

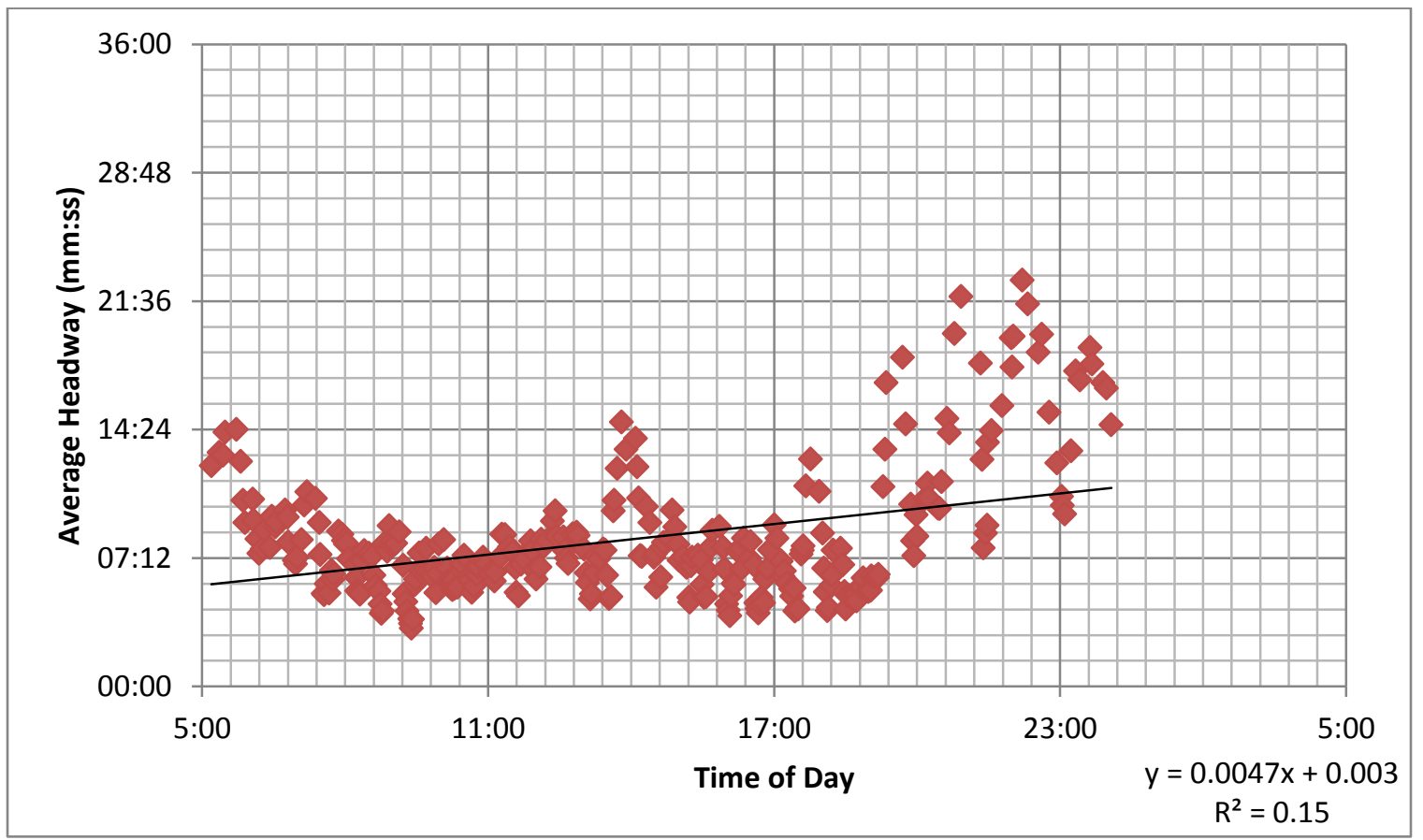


Figure 20 shows the average actual headways versus average reassigned headways throughout the day. The average headways of the actual data were plotted for the $\mathrm{J}, \mathrm{L}$, and $\mathrm{M}$ lines. These data points are shown in blue. The second plot indicated with red is the resulting reassigned trip distribution.

The blue line shows how the actual average headway fluctuated throughout the (March $1^{\text {st }}$ ) day. The reassignment fluctuated similarly but can be seen beneath the original headway for most of the day. This shows an improvement through lower average headways with the reassignment system.

The lowest headways tend to be located within the AM and PM peak periods (shown in grey). These time periods show much smaller differences between headways (fewer variables and a smaller range of times). The other 17 hours of operation show much higher variability in headway times and much sharper changes in subsequent headways. For example, there is a sharp drop at 10:00. At that departure there is an average headway of about 15 minutes. Immediately after that, the next headway is about 4 minutes. The succeeding headway again rises to about 9 minutes. This can be characterized as train bunching, with a single car varying in speed, therefore increasing the headway in one direction and decreasing the headway in the other direction relative to their vehicle.

Figure 21 shows the change in headway relative to how large the headway of the reassignment is. The reassignment benefited all trips that are above the red reassignment line, bringing their average headway down. 
Figure 20: Average Actual Headways versus Average Reassigned Headways: J, L, \&M by Time of Day. 03.01.2012

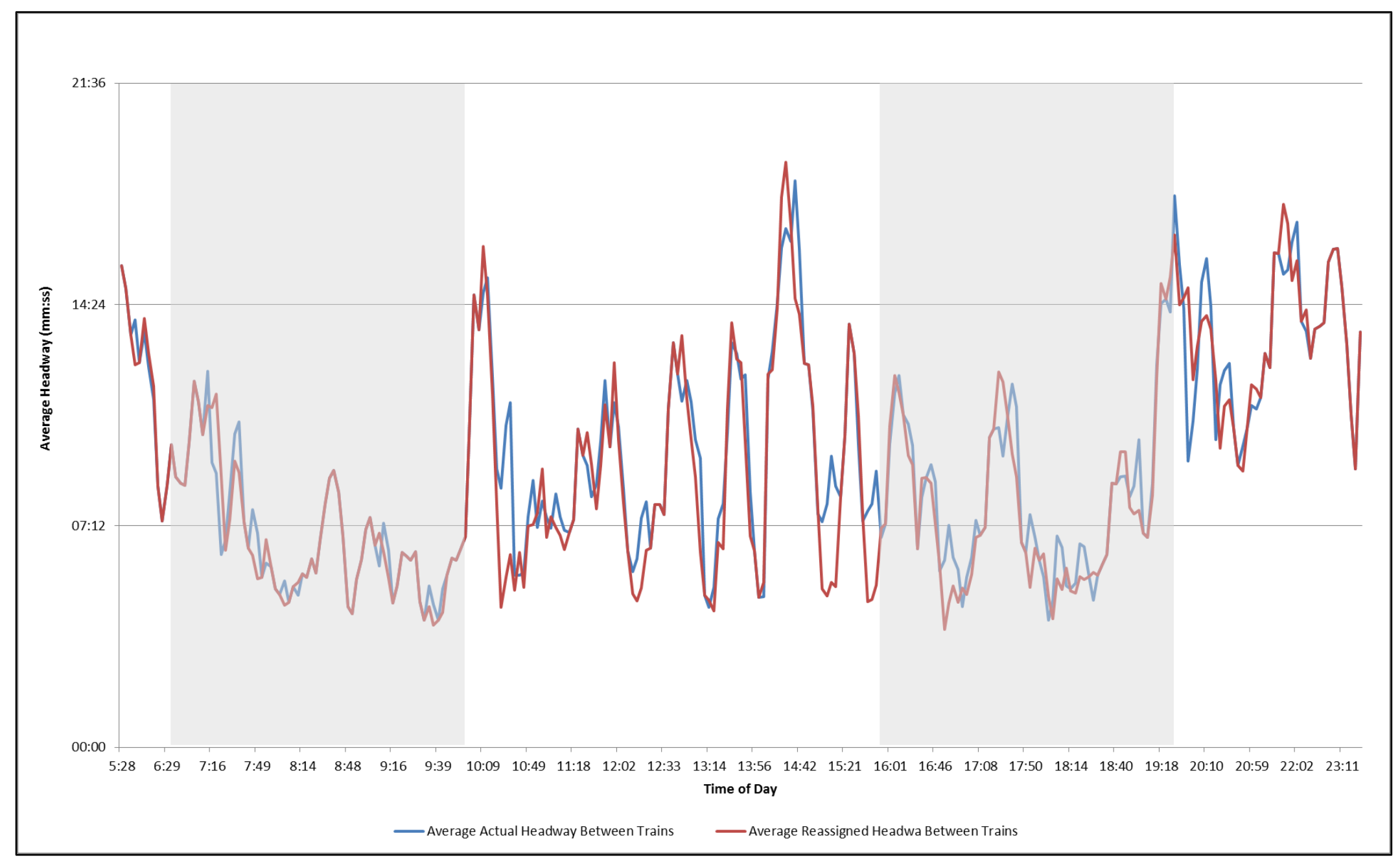


Figure 21: Average Actual Headways versus Average Reassigned Headways: J, L, M by Average Time of Reassigned Headway. 03.01.2012

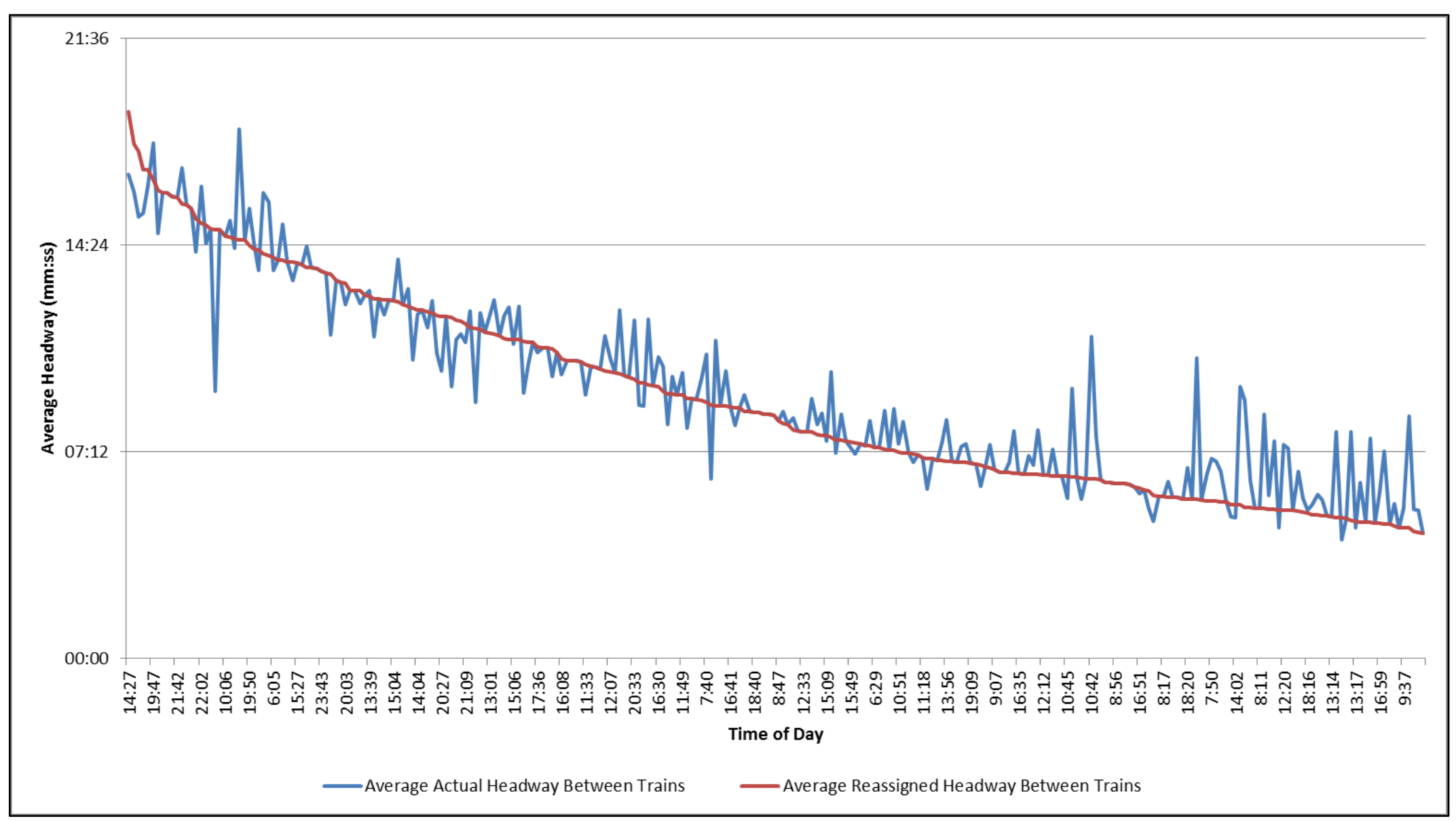


The data was tested for statistical change in average mean headways as a result of the programming change. Paired t-test results are shown in Table 9. The AM peak period showed not as strong of significance as the PM peak, all day, and off-peak time periods. In all cases, the mean headway was decreased. The trains that arrived at the station during the PM peak period had on average a lower average headway at time of departure after the reassignment system.

Table 9: SPSS T-Test of Significance of Headway Means: 03.01.2012

\begin{tabular}{|c|c|c|c|c|c|c|}
\hline \multirow{2}{*}{$\begin{array}{c}\text { Time } \\
\text { Period }\end{array}$} & \multicolumn{2}{|c|}{$\begin{array}{c}\text { Mean Headway } \\
\text { (h:mm:ss) }\end{array}$} & \multicolumn{2}{|c|}{ T-Test @ 95\% Confidence } & Statistical \\
\cline { 2 - 6 } & Before & After & Mean Difference & $\mathbf{t}$ & $\begin{array}{c}\text { p- } \\
\text { value }\end{array}$ & Significance? \\
\hline AM Peak & $0: 07: 11$ & $0: 07: 10$ & $0: 00: 00$ & 0.088 & 0.931 & No \\
\hline PM Peak & $0: 08: 19$ & $0: 07: 56$ & $-0: 00: 22$ & 1.998 & 0.054 & $\checkmark$ \\
\hline All Day & $0: 09: 15$ & $0: 08: 59$ & $-0: 00: 15$ & 3.788 & 0.000 & $\checkmark$ \\
\hline Off-Peak & $0: 09: 48$ & $0: 09: 30$ & $-0: 00: 17$ & 3.443 & 0.001 & $\checkmark$ \\
\hline
\end{tabular}

The reassigned trains successfully (theoretically) experienced better reliability and smaller mean headways. The p-values suggest the rejection of the null hypothesis $\left(\mathrm{H}_{0}\right.$ : means are equal, $\mathrm{H}_{1}$ : means are not equal). The findings suggest that there is a smaller random chance of the stated mean headway during PM peak, all day, and off-peak periods. See Appendix C for complete SPSS outputs regarding the paired t-tests performed on the data sets. 
RUN \#4: MARCH 15 ${ }^{\text {TH }}, 2012$ ALL-DAY

March $15^{\text {th }}$ shows a similar trend to that of March $1^{\text {st }}$. Tables 10 and 11 show the headways that are improved by reassignment. The application showed a $1 \%$ increase in mean headways during the AM peak hour but a $1 \%$ decrease during the entire 21 -hour day run. Figures 22 and 23 detail the close nature of the reassignment. The reassignment value was not as prominent on Run \#4 as it was on Run \#2. Figures 24 and 25 show additional savings of the reassignment system through average headway calculation.

Table 10: 03.15.2012 All Day Scheduled versus Reassigned Headways

\begin{tabular}{|c|c|c|c|}
\hline Statistic & Before & After & $\%$ Change \\
\hline Mean Headway of J & $07: 46$ & $07: 54$ & $2 \%$ \\
\hline Mean Headway of L & $08: 07$ & $08: 08$ & $0 \%$ \\
\hline Mean Headway of M & $08: 58$ & $08: 38$ & $-4 \%$ \\
\hline Mean Headway of JLM & $08: 16$ & $08: 12$ & $-1 \%$ \\
\hline Stand. Deviation of J & $04: 10$ & $04: 19$ & $3 \%$ \\
\hline Stand. Deviation of L & $05: 37$ & $05: 13$ & $-7 \%$ \\
\hline Stand. Deviation of M & $05: 03$ & $04: 59$ & $-1 \%$ \\
\hline Stand. Deviation of JLM & $03: 31$ & $03: 38$ & $3 \%$ \\
\hline
\end{tabular}

Table 11: 03.15.2012 AM Peak Scheduled versus Reassigned Headways

\begin{tabular}{|c|c|c|c|}
\hline Statistic & Before & After & $\%$ Change \\
\hline Mean Headway of J & $06: 52$ & $07: 09$ & $4 \%$ \\
\hline Mean Headway of L & $06: 47$ & $06: 55$ & $2 \%$ \\
\hline Mean Headway of M & $07: 09$ & $06: 55$ & $-3 \%$ \\
\hline Mean Headway of JLM & $06: 56$ & $07: 01$ & $1 \%$ \\
\hline Stand. Deviation of J & $03: 33$ & $03: 13$ & $-10 \%$ \\
\hline Stand. Deviation of L & $03: 25$ & $02: 55$ & $-15 \%$ \\
\hline Stand. Deviation of M & $02: 52$ & $03: 07$ & $9 \%$ \\
\hline Stand. Deviation of JLM & $01: 38$ & $01: 41$ & $3 \%$ \\
\hline
\end{tabular}


Figure 22: Run \#4 Actual Largest Headway Average of J, L, \& M. 03.15.2012.

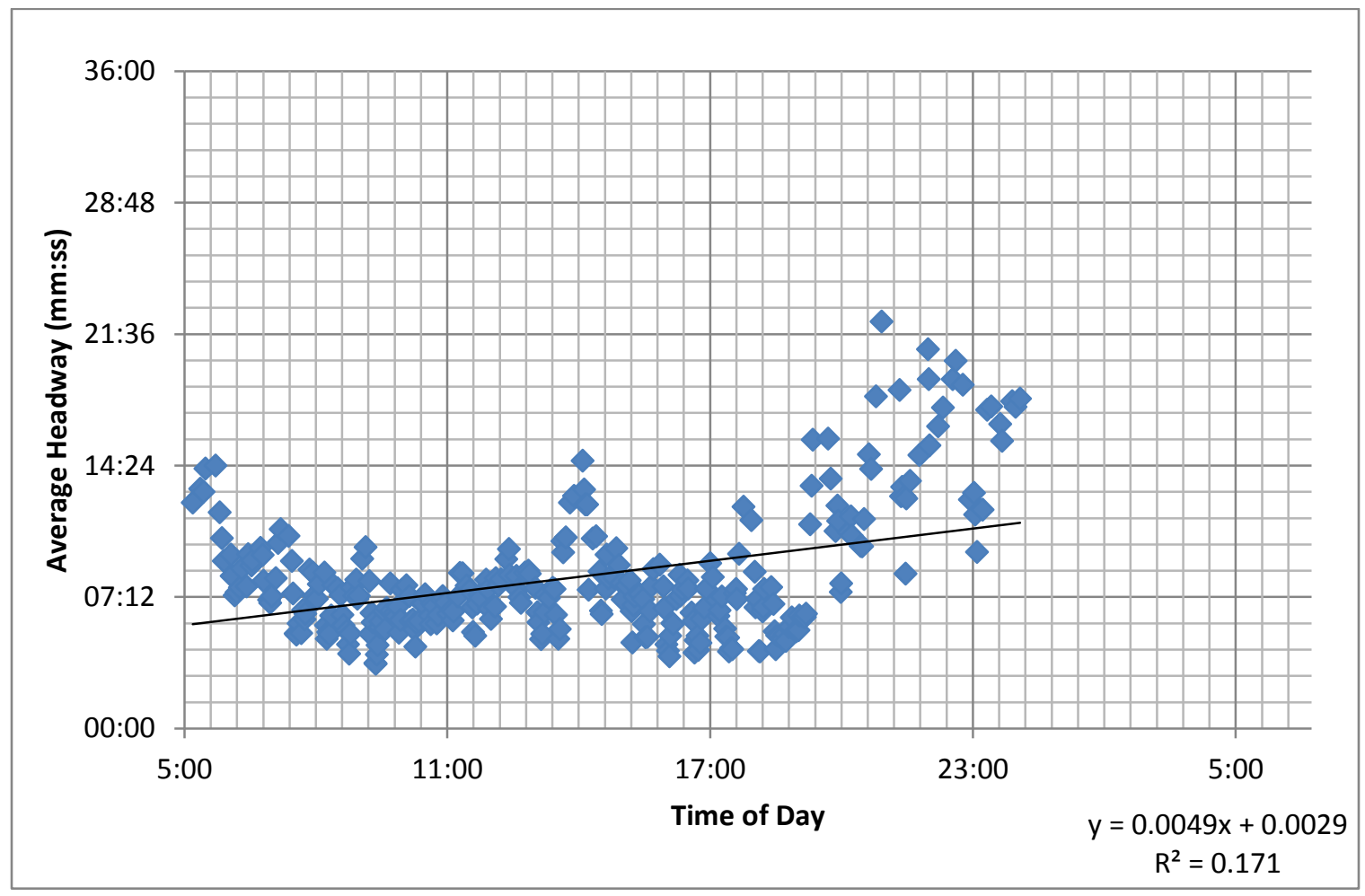

Figure 23: Run \#4 Reassigned Largest Headway Average of J, L, \& M. 03.15.2012.

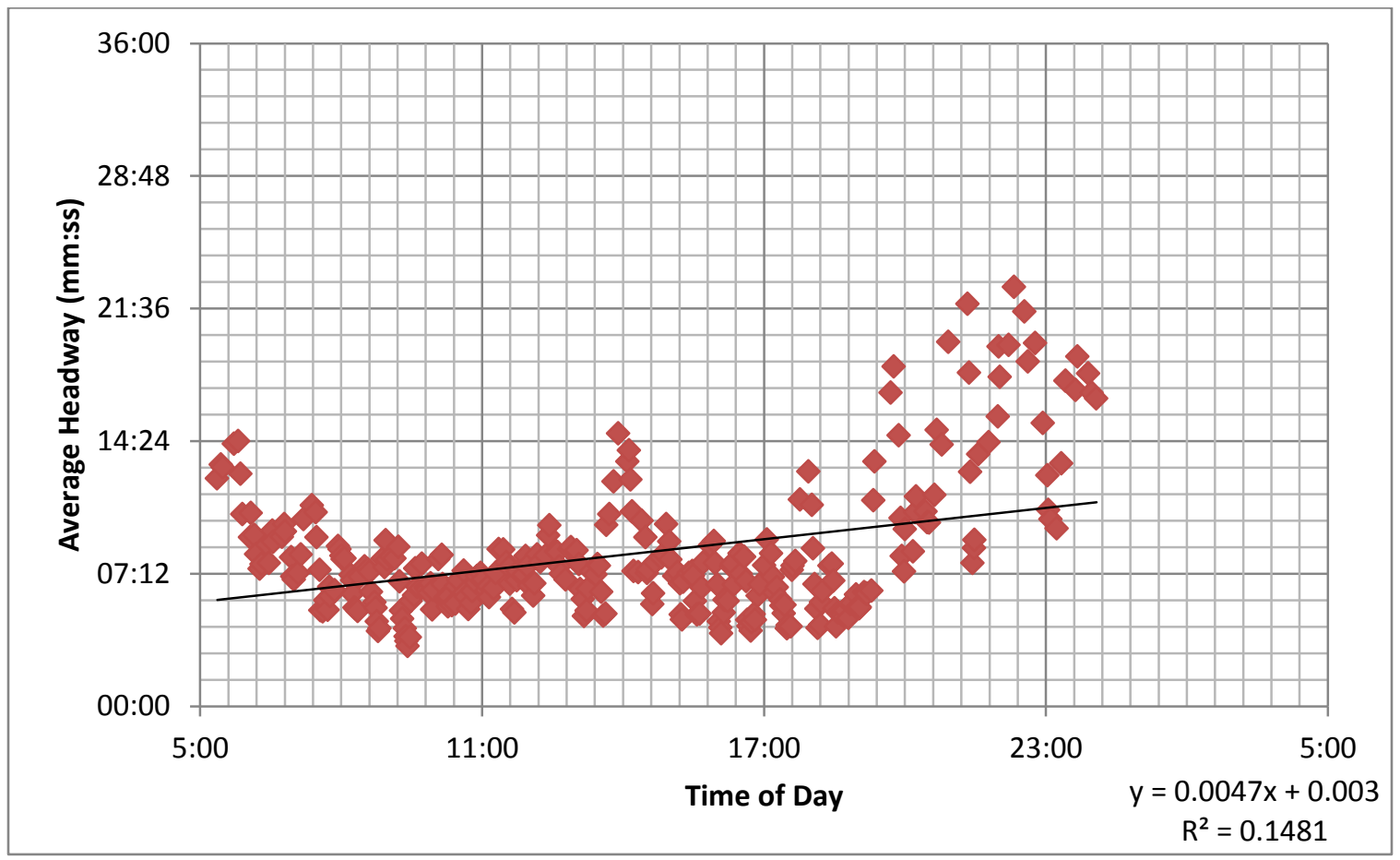


Figure 24: Average Actual Headways versus Average Reassigned Headways: J, L, M by Average Time of Reassigned Headway. 03.15.2012

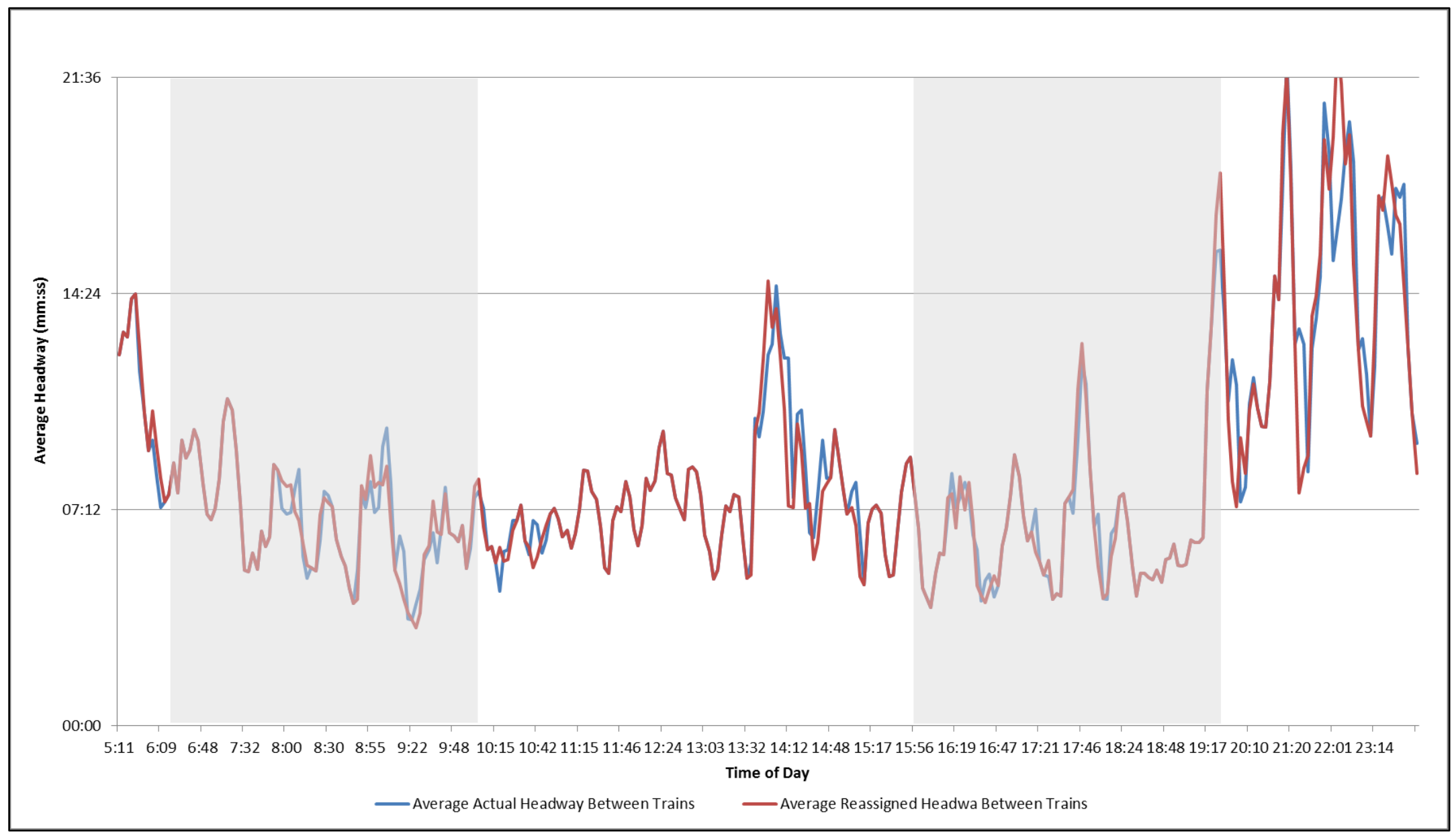


Figure 25: Average Actual Headways versus Average Reassigned Headways: J, L, M by Average Time of Reassigned Headway. 03.01.2012

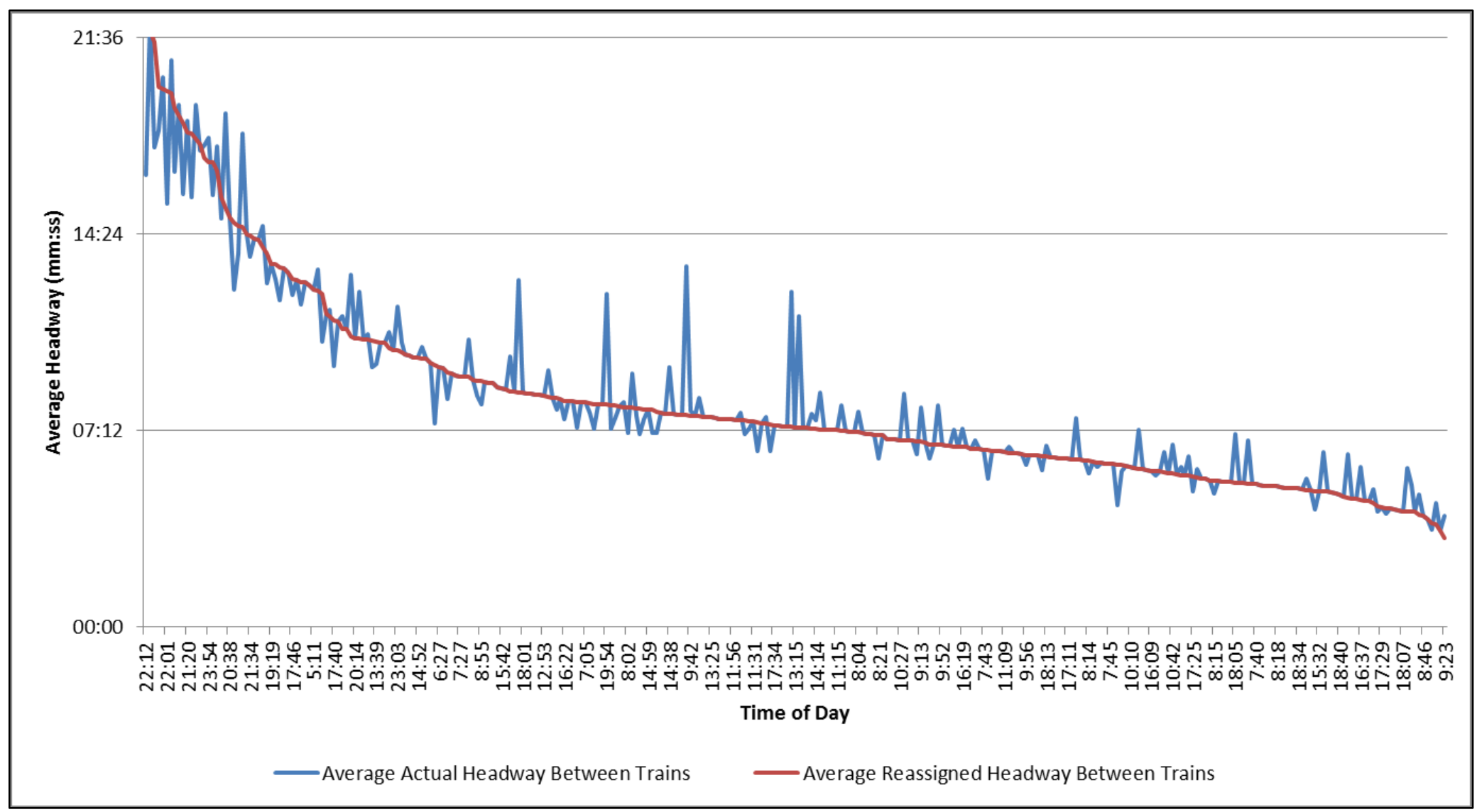


The before and post-reassignment data was entered into SPSS for a test of significance in means. A paired t-test was performed for the AM peak, PM peak, all day, and off-peak time periods for March $1^{\text {st }}$. At $95 \%$ confidence, the data showed no immediate significance. This is different from what we saw from the March $1^{\text {st }}$ data set, which had a statistically significant change in means after the reassignment program was applied. Table 12 details the testing of headway means significance.

Table 12: SPSS T-Test of Significance of Headway Means: 03.15.2012

\begin{tabular}{|c|c|c|c|c|c|c|}
\hline \multirow{2}{*}{$\begin{array}{c}\text { Time } \\
\text { Period }\end{array}$} & \multicolumn{2}{|c|}{$\begin{array}{c}\text { Mean Headway } \\
\text { (h:mm:ss) }\end{array}$} & \multicolumn{2}{c|}{ T-Test @ 95\% Confidence } & \multirow{2}{*}{$\begin{array}{c}\text { Statistical } \\
\text { Significance? }\end{array}$} \\
\cline { 2 - 6 } & Before & After & Mean Difference & $\mathbf{t}$ & $\begin{array}{c}\text { p- } \\
\text { value }\end{array}$ & \\
\hline AM Peak & $0: 06: 55$ & $0: 07: 01$ & $0: 00: 05$ & 1.15 & 0.257 & No \\
\hline PM Peak & $0: 06: 28$ & $0: 06: 27$ & $0: 00: 00$ & 0.033 & 0.974 & No \\
\hline All Day & $0: 08: 18$ & $0: 08: 14$ & $-0: 00: 04$ & 1.279 & 0.202 & No \\
\hline Off-Peak & $0: 08: 52$ & $0: 08: 45$ & $-0: 00: 06$ & 1.537 & 0.126 & No \\
\hline
\end{tabular}

The difference in significance varies by day and hour. The AM peak period saw an increase of an average of 5 seconds in mean headway time. Off-peak however saw an average of 6 second decrease in mean headway time at departure. $95 \%$ of the time analysts can be assured the mean difference is an average of 4 to 6 seconds. 


\section{Potential Costs and Benefits}

Although a full cost and benefit analysis of the program is beyond the scope of this project, certain general characteristics can be determined based on initial findings. This section outlines the potential costs and benefits for the study.

The largest cost associated with the implementation of a program such as this is the money required for retraining of staff on multiple lines. Labor is a large portion of operating costs and is coupled with re-negotiating of collective bargaining agreements. The physical infrastructure costs include equipping each train to change overhead signs for different routes. Costing a project also requires funding for a pilot and future studies to determine the efficiency and accuracy of the program.

The benefits can be quantified into monetary savings by means of travel time reduction and on time variability (or headway deviation). More efficient service is built on the knowledge of using the same amount of dollars to operate a greater number of services (usually through the addition of rolling stock or increased runs for each vehicle). Less headway variability increases the reliability and predictability of services, making the planning for them (financially) easier. 


\section{Vil. Conceptual Development of the Program}

The results of the reassignment program are shown to affect the average headway in a positive way: by decreasing the average headway across the daily and AM peak distributions. Further development has the potential to influence the Agency's operation of Muni service. The program could take the form of a daily operations change standard or a peak-hour reassignment sequencer. The program described in this section is subject to further study of a larger dataset as well as the addition of independent variables into the assignment calculator.

\section{Best Management Practices}

Research has shown that there ought to be a combination of automated and manual decision making in the process. The computer programming automation can aid in eliminating much of the human problem-solving at dispatch. Reducing the final decision-making by human dispatchers to a minimum can allow for more focused, and well thought-out decisions. A combination of algorithmic computer-generated modeling in addition to a case based reasoning applied via human dispatch can keep operations grounded and potential problems easily identified.

\section{LOGISTICS}

Logistically the program would be a joint effort by Muni and Transit Planning. The cooperation of the union representatives and operational support staff is vital to implementation. 


\section{TRAINING}

Implementation requires the division of train operators into two groups: one group trained for the $\mathrm{J}, \mathrm{L}$, and $\mathrm{M}$ lines and the second group trained on the $\mathrm{KT}$ and $\mathrm{N}$ lines. These groupings aim to expand the operational capabilities of reassignment and compartmentalize the training process. Union agreements (See Appendix B for full list of unions) will need to be re-analyzed and possibly re-negotiated to reflect the following changes in operations:

- Turnaround process at Embarcadero: time and location of breaks

- Increased level of work to physically change line assignment

- New policies regarding the changeover to a completely automated system

- New/reassignment of bobs and their descriptions: 1) Dispatch personnel would be required to be re-trained and respond to new system interfaces and communications equipment. 2) New system of designation of line operations options for Operators.

\section{PHYSICAL INFRASTRUCTURE}

Additional physical infrastructure is required for the program. The rolling stock ought to be equipped with the ability to change the overhead to show each of the three line designations and destinations. It should be noted that the $\mathrm{J}$ stop infrastructure is not equipped to handle coupled cars. An evaluation is necessary to see how this conflict could be accommodated. 


\section{CAPACITY}

The reassignment system is most effective during peak hours, when the schedule most closely resembles a headway-based timetable. The current scheduling effectively operates under headway-based conditions during key peak hours and therefore the most effective application of this system would be during these hours. Capacity within the subway acts as a limitation to the program where a limited throughput will act as a constraint of the optimization.

\section{COMMUNICATIONS}

Continual communications between Operators and Dispatchers will allow for a collaborative decision-making environment as various parties would be more aware of conditions in real time.

\section{FURTHER ALGORITHM DEVELOPMENT}

The reassignment calculator has the potential to become more robust and accurate through the addition of reasonable independent variables. Building on the branch and bound optimization algorithm base, the following are recognized as potential variables and constraints to be added in future enhancements:

- Location of coupling / de-coupling platforms

- Deadheads within the schedule

- "Beginning" and "End" locations of individual runs (i.e. yards for storage at the start and the end of the day)

- Based on event need within a zonal system, reassign to a specific line

- Turnaround times within the Embarcadero 
- Wait time studies on specific platforms

- System Travel Time

- Headways to the second farthest of a specific line

- How to keep the number of trains the same for each day

A more comprehensive approach through demand-responsive transit will create a more effective system of operations for the people of San Francisco.

As described earlier, the program applied in this study is essentially "unconstrained" optimization. Addition of constraints to the program will begin to shift the program to a real-world application. Initial findings show multiple trends leading to further development.

An important note is the change in number of trains that are removed from the $\mathrm{J}$ line to the $\mathrm{M}$ line. This is shown by a decrease in sheer number of trains operated as well as the general increase in headway for the $\mathrm{J}$ and decrease in headway for the $\mathrm{M}$ after application of the program. A capacity analysis of each line could warrant the addition of additional vehicles or diversion of vehicles to each particular line. A capacity analysis during peak periods should be compared to this change in service.

More evaluation of the redistribution of headways is recommended. This attempt at redistribution is applied daily and it would be warranted to analyze specific hours of interest (i.e. AM peak and PM peak). Application during these hours only would have less of a chance of delay propagation through the day (particularly during larger headways at the beginning and end of the day's runs. 
The ability to reassign during these peak periods (or any desired designated time slot) while maintaining the number of trains but redistributing them within the time from more evenly (i.e. if $50 \%$ of trains depart in the first ten minutes of the hour and after application $50 \%$ of train depart during half the time period of an hour.) Although it is subject to physical capacity to operate and turn the cars, it is worth exploring further. Maintaining ratios relative to capacity is key.

Modeling methodology could include the spatial distribution of cars through the system, incorporating more carefully the origin and the destination of the individual trips. 


\section{Conclusions and Next Steps}

This tool accompanied by application is intended to demonstrate the importance and applicability of data harnessing and strategy development of a dynamic dispatch system at Embarcadero Station. The interpretation of data acts as the defense for operational changes at the Agency. The Agency is constantly looking for ways to improve reliability and provide more efficient service.

The research has shown that application of a dynamic re-assignment system has the potential to save Muni valuable minutes in headway variability when applied either day-long or during peak times. The ability to reassign requires the cooperation of long term planning, operations, and working stakeholders of the Agency. The barriers in place are institutional, physical, and operational.

This application of a reassignment algorithm has been shown to decrease

the average headways for the $\mathrm{J}, \mathrm{L}$, and $\mathrm{M}$ lines at the Embarcadero turnaround by up to $7 \%$. More research and development of the spreadsheet calculator will take place during the summer of 2013 to be presented to SFMTA as an informational document. The document acts as a reference for operational improvement changes to accompany current efforts by SFMTA for better on-time performance and reliability. 


\section{REFERENCES}

Bard, J., Yu, G. \& Argüello, M. (2001). Optimizing Aircraft routings in reponse to groundings and delays. IIE Transactions, 33, 931-947

Berkow, M., Chee, J., Bertini, R. L., \& Monsere, C. (2007). Transit performance measurement and arterial travel time estimation using archived $A V L$ data. ITE District, 6. Retrieved from http://web.cecs.pdx.edu/ monserec/papers/2007_IEEE_Bus_3.28.06_SU BMITTED.pdf

Berkow M., El-Geneidy, A., Bertini, R. \& Crout, D. (2009). Beyond generating transit performance measures: Visualizations and statistical analysis with historical data. Transportation Research Record: Journal of the Transportation Research Board, No. 2111, 158-168. doi:10.3141/2111.18

Cevallos, F., Wang, X., Chen, Z. \& Gan, A. (2011). Using AVL data to improve transit on-time performance. Journal of Public Transportation, 14, 3.

City and County of San Francisco (2011). Capital Plan: Fiscal Years 2012-2021. Retrieved from http://onesanfrancisco.org/fina-fy-2012-2021-capital-plan/

Chang, J. (2010). Assessing travel time reliability in transport appraisal. Journal of Transport Geography, 18, 419-425. doi:10.1016/j.jtrangeo.2009.06.012

Chicago Transit Authority (1941). Retrieved on March 3, 2013 from http://www.flickr.com/photos/ctaweb/6649990863/in/faves-walkingsf/

Corman, F., D'Ariano, A., Pranzo, M. \& Hansen, I. (2011). Effectiveness of Dynamic Reordering and Rerouting of Trains in a Complicated and Densely Occupied Station Area. Transportation Planning and Technology. 34, 4. doi: 10.1080/03081060.2011.577152.

D'Ariano, A. (2008). Improving Real-Time Train Dispatching: Models, Algorithms and Applications. (Doctoral Dissertation). Retrieved from Springer Database (978-90-5584-100-4)

D'Ariano, A., Pacciarelli, D. \& Pranzo, M. (2007). A Branch and Bound Algorithm for Scheduling Trains in a Railway Network. European Journal of Operational Research, 183, 643-657.

D’Ariano, A. \& Pranzo, M. (2009). An Advanced Real-Time Train Dispatching System for Minimizing the Propogation of Delays in a Dispatching Area Under Severe Disturbances. Netw Spar Econ, 9, 63-84. doi: 10.1007/s11067-008-9088-1. 
Ding, Y. \& Chien, S. (2001) Improving transit service quality and headway regularity with real-time control. Paper No. 01-2150. Washington, DC. Retrieved from http://transportation.njit.edu/nctip/publications/No012150.pdf

Furth, P. \& Nash, A. (1985). Vehicle Pooling in Transit Operations. Journal of Transportation Engineering, 111(2), 268-279. Retrieved from ASCE Library

Gershenson, C. \& Pineda, L. (2009). Why does public transport no arrive on time? The pervasiveness of equal headway instability. PLos ONE 4(1) e7292. Doi:10.1371/journal.pone.0007292

Greenwood, D., Dannegger, C. \& Dorer, K. (2009). Dynamic Dispatching and Transport Optimization - Real-World Experience with erspectives on Pervasive Technology Integration.

Malikova, A. (2012). MBTA Green Line 3-Car Train Operating Plans to Enhance Capacity and Reliability. Master's Thesis. Retrieved from DSpace@MIT.

Mirijello, A. (2010). Reliability approach on light rail vehicle rehabilitation plan. mat. 305726 corso di Laurea in Ingegneria Meccanica, Universit a di Pisa, Italia.

Railway Preservation (2012). Retrieved on April 29, 2013 from http://www.railwaypreservation.com/vintagetrolley/boston.htm

Sadek, A., Smith, B. \& Demetsky, M. (2001). A prototype case-based reasoning system for real-time freeway traffic routing. Transportation Research Part C, 9(5), 353-380.

San Francisco Municipal Transportation Agency (2013). Retrieved on March 26, 2013 from http://www.sfmta.com/maps/muni-metro-map

San Francisco Municipal Transportation Agency: Transit Engineering (2012). Travel time reductions proposals: Transit preferential toolkit (Draft).

San Francisco Municipal Transportation Agency (2013). Retrieved April 29, 2013 from http://www.sfmunicentral.com.

San Francisco Public Utilities Commission Utilities Engineering Bureau (1987). MUNI metro turnaround technical report: Summary report of surface turnback DRAFT. San Francisco, CA: Bechtel National, INC.

San Francisco Public Utilities Commission Utilities Engineering Bureau (1990). MUNI metro turnaround technical report: Conceptual Engineering Report Sumamry. San Francisco, CA: Bechtel National, INC. 
Strathman, J., Dueker, K., Kimpel, T., Gerhart, R., Turner, K., Taylor, P., Callas, S., Griffin, D. \& Hopper, J. (1999). Automated bus dispatching, operations control, and service reliability: Baseline analysis. $78^{\text {th }}$ Annual

Transportation Research Board Meeting(Paper No. 990930).

Strathman, J. G., Kimpel, T. J., Dueker, K. J., Gerhart, R. L. \& Callas, S. (2002). Evaluation of transit operations: data applications of Tri-Met's automated Bus Dispatching System. Transportation, 29(3), 321-345. Retrieved from doi: 10.1023/A:1015633408953

Strathman, J., Kimpel, T. \& Callas, S. (2003). Headway deviation effects on bus passenger loads: Analysis of Tri-Met's archived ACL-APC data. Source?

Transit Cooperative Research Program (2004, July). Computer-Aided Scheduling and Dispatch in Demand-Responsive Transit Services. Chapter 2: Review of the Literature.

Transit Cooperative Research Program (2003, October). Transit capacity and quality of service manual. TCRP 100. $2^{\text {nd }}$ Edition. Retrieved from http://www.trb.org/Main/Blurbs/153590.aspx

Transit Systems, Inc (1998). Green Line Automatic Vehicle Identification (AVI) System Dispatcher Manual. Fourth Edition. Developed for MBTA

United Signal \& Switch (2000). Retrieved on May 27, 2013 from http://www.lightrail.com/photos/boston/boston.htm 


\section{APPENDICES}

APPENDIX A

SAN FRANCISCO MUNICIPAL RAILWAY

Hide details
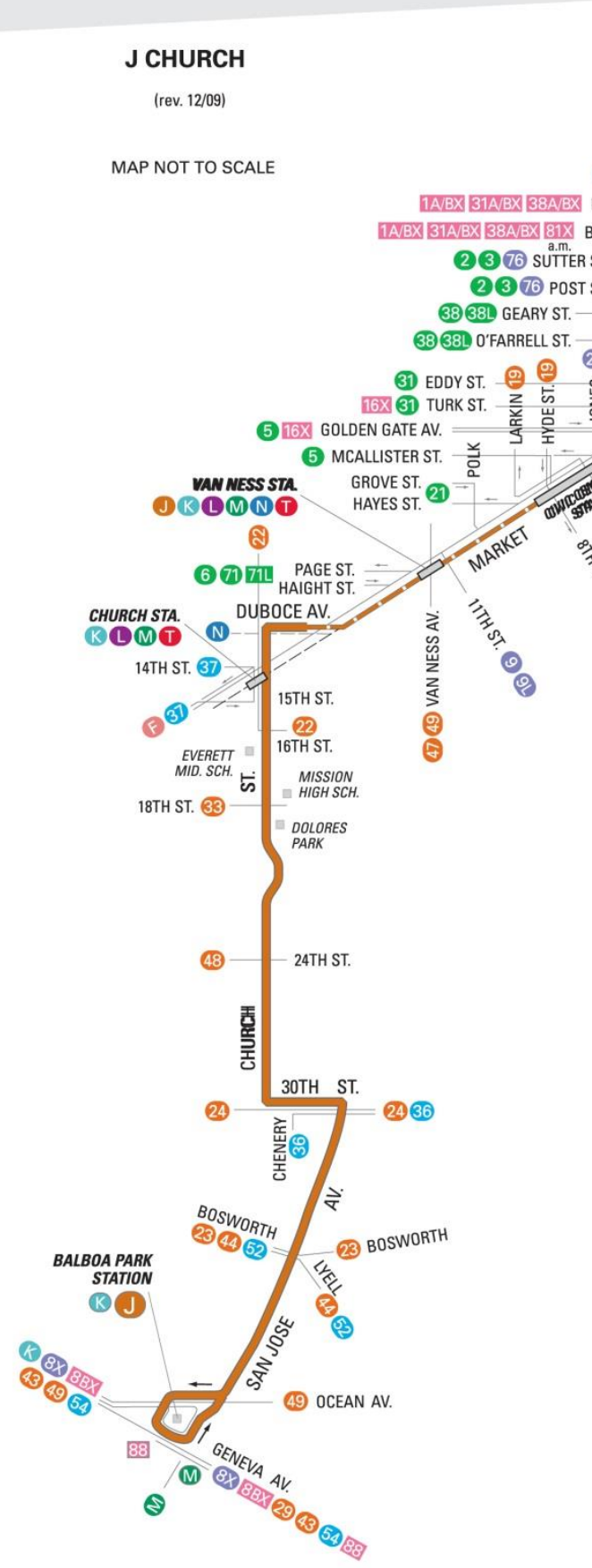

C CALIFORNIA ST.
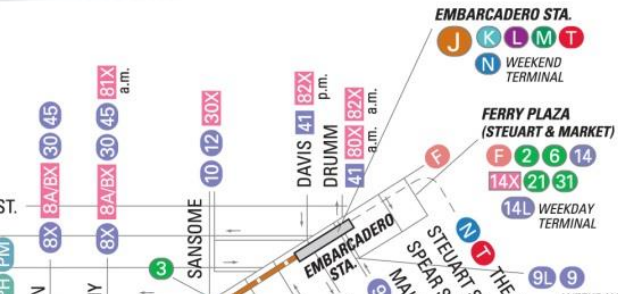

Q
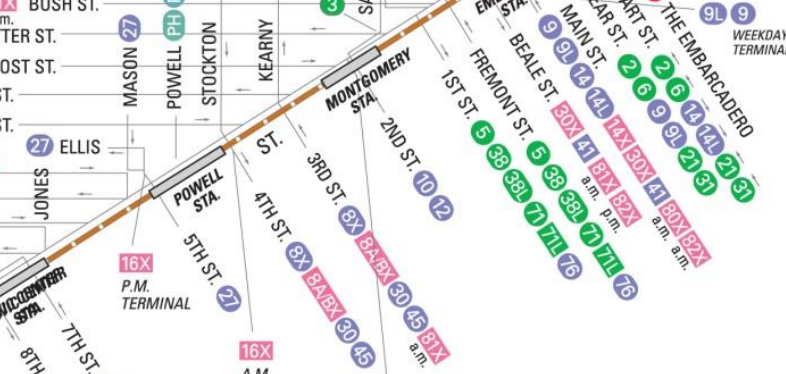
TERMINA
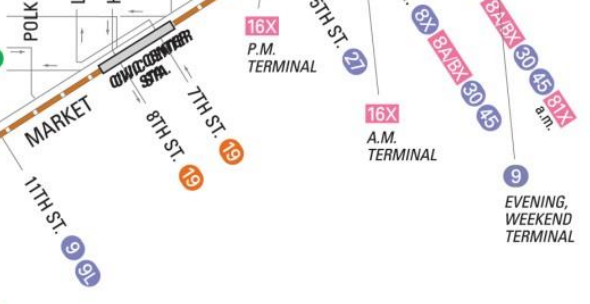

(2)

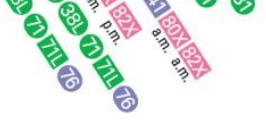




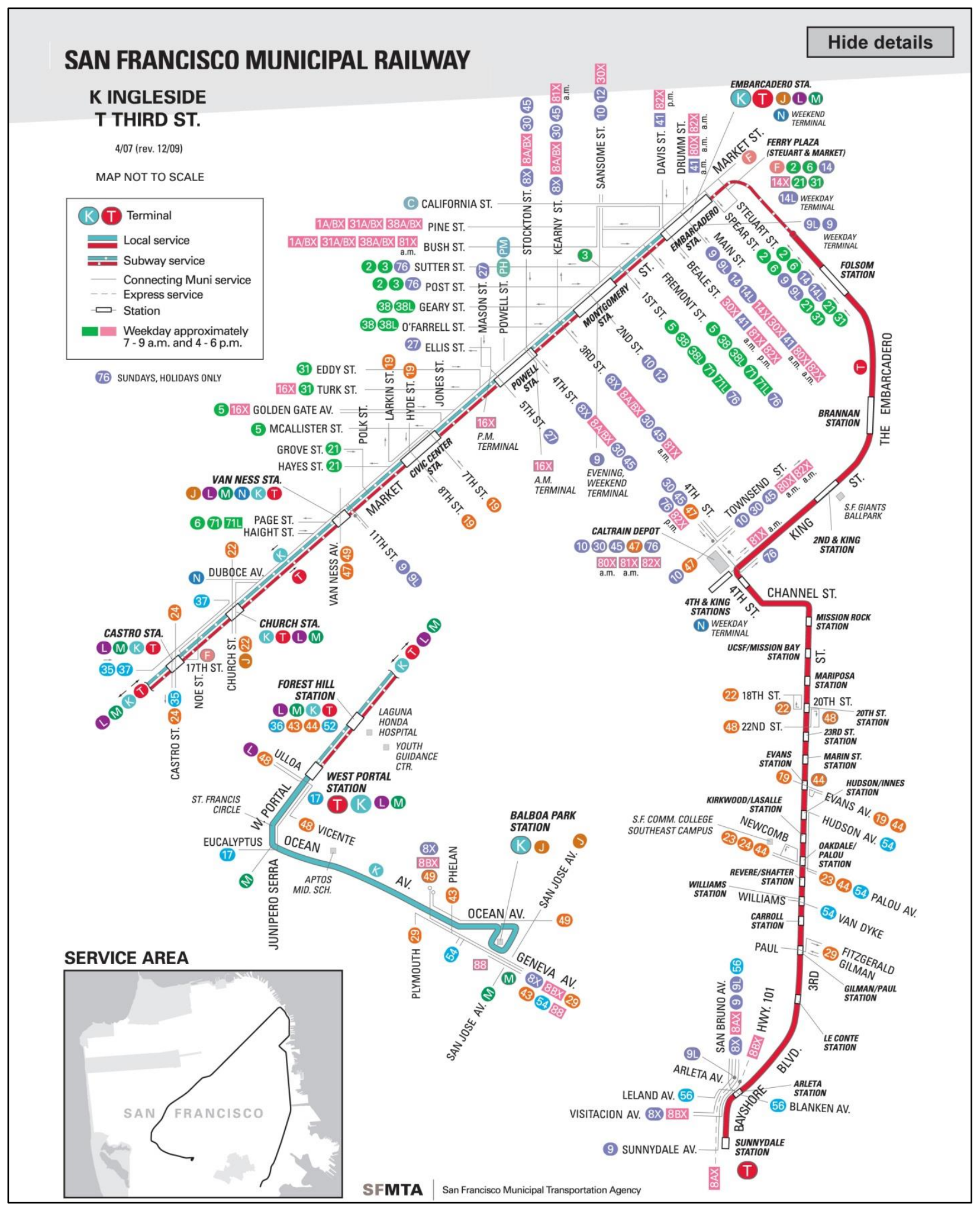




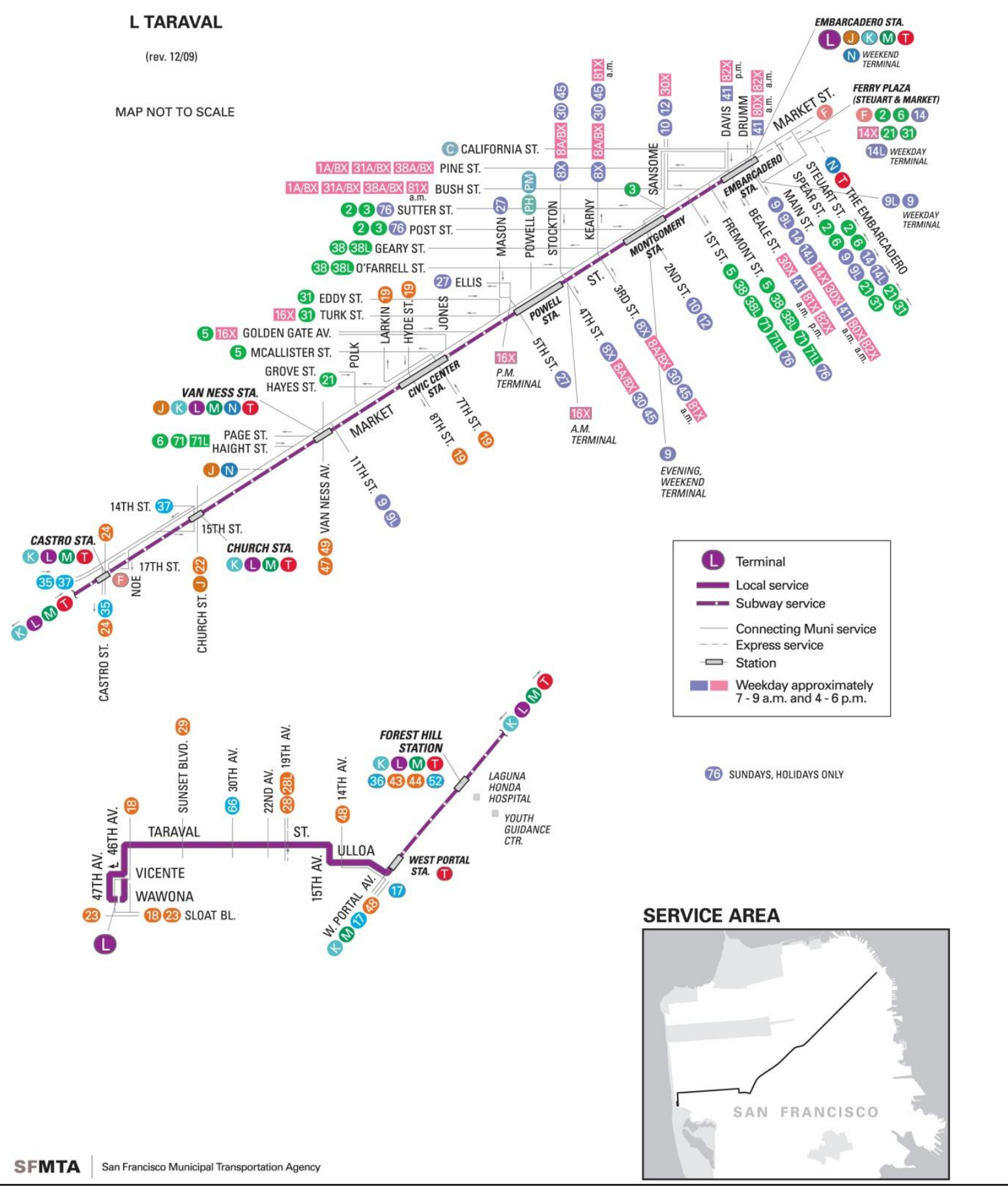




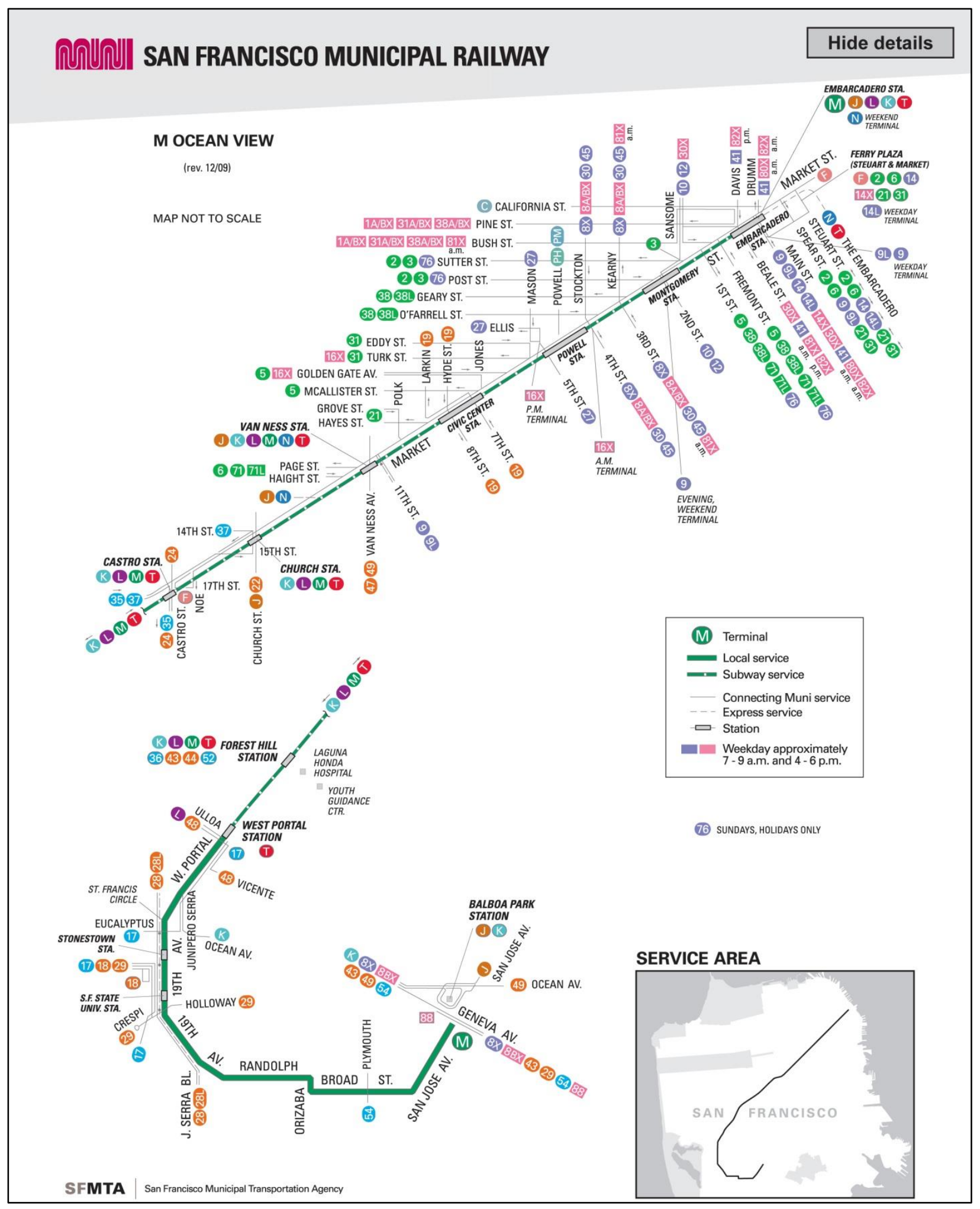




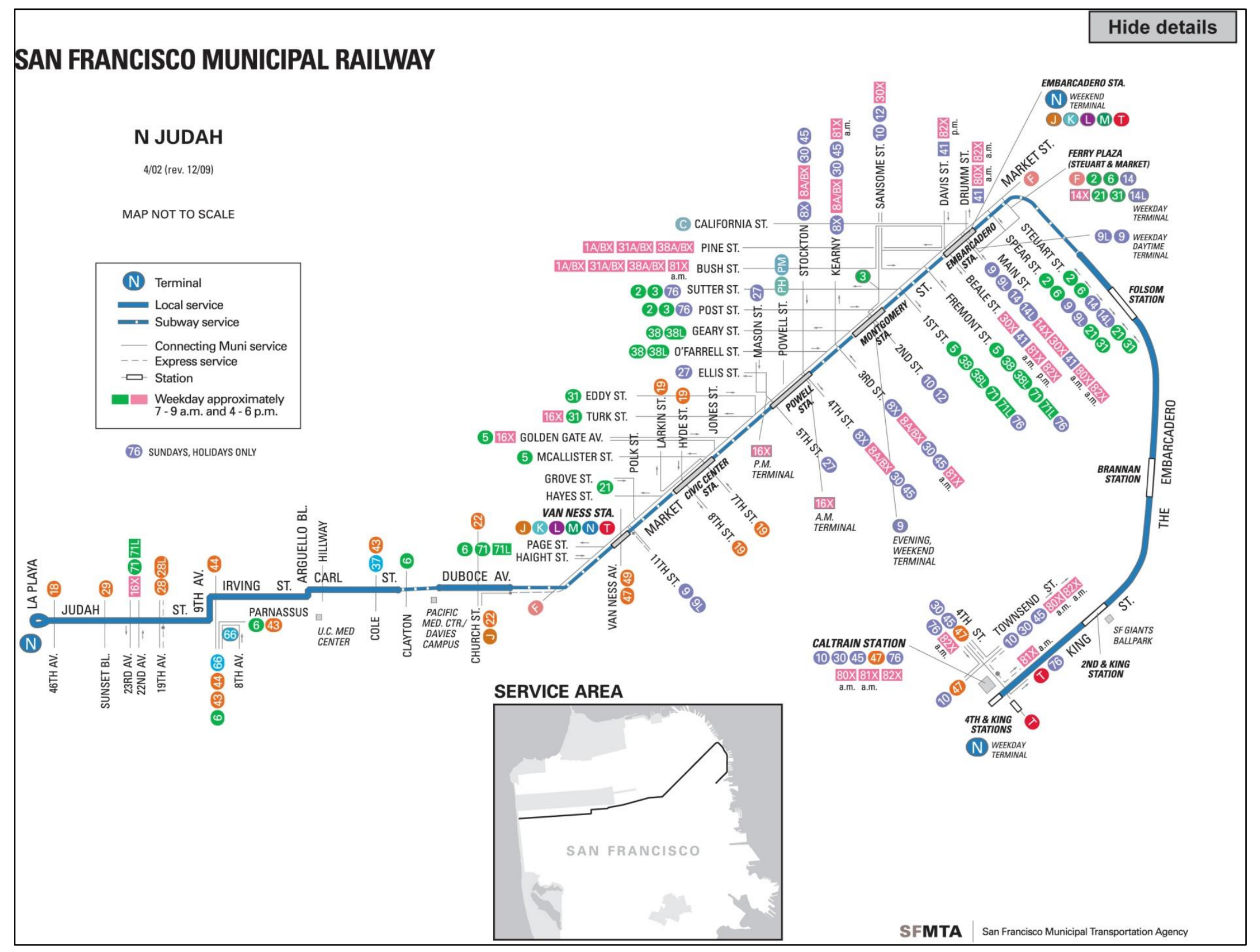




\section{APPENDIX B}

Current Collective Bargaining Agreements (CBA's between SFMTA and various unions:

Accessed May 30, 2013 from

https://beta.sfmta.com//about-sfmta/labor-relations/mouscbas

IBEW (International Brotherhood of Electrical Workers), Local 6

July 1, 2012 - June 30, 2014

IAMAW (International Association of Machinists and Aerospace Workers), Local 1414

July 1, 2012 - June 30, 2014

MEA (Municipal Executive Association)

July 1, 2012 - June 30, 2014

SEIU (Service Employees International Union), Local 1021

July 1, 2012 - June 30, 2014

TWU (Transport Workers Union of America), Local 200

July 1, 2011 - June 30, 2014

TWU (Transport Workers Union of America), Local 250A class 7410

July 1, 2012 - June 30, 2015

TWU (Transport Workers Union of America), Local 250A class 9132

Jul 1, 2011 - June 30, 2014

TWU (Transport Workers Union of America), Local 250A class 9163

July 1, 2011 - June 30, 2014 


\section{APPENDIX C}

SPSS T-Test: March 1, 2012 AM Peak

\section{Paired Samples Statistics}

\begin{tabular}{|ll|c|r|r|r|}
\hline & & Mean & \multicolumn{1}{|c|}{ N } & Std. Deviation & Std. Error Mean \\
\hline \multirow{2}{*}{ Pair 1 } & After & $0: 07: 10$ & 38 & $0: 02: 12$ & $0: 00: 21$ \\
& Before & $0: 07: 11$ & 38 & $0: 02: 09$ & $0: 00: 21$ \\
\hline
\end{tabular}

Paired Samples Correlations

\begin{tabular}{|ll|r|r|r|}
\hline & \multicolumn{1}{|c|}{$\mathrm{N}$} & \multicolumn{1}{c|}{ Correlation } & \multicolumn{1}{c|}{ Sig. } \\
\hline Pair 1 & After \& Before & 38 & .922 & .000 \\
\hline
\end{tabular}

Paired Samples Test

\begin{tabular}{|c|c|c|c|c|c|c|c|c|c|}
\hline & & \multicolumn{5}{|c|}{ Paired Differences } & \multirow[t]{3}{*}{$\mathrm{t}$} & \multirow[t]{3}{*}{$\mathrm{df}$} & \multirow{3}{*}{$\begin{array}{l}\text { Sig. }(2- \\
\text { tailed) }\end{array}$} \\
\hline & & \multirow[t]{2}{*}{ Mean } & \multirow[t]{2}{*}{$\begin{array}{c}\text { Std. } \\
\text { Deviation }\end{array}$} & \multirow[t]{2}{*}{$\begin{array}{l}\text { Std. Error } \\
\text { Mean }\end{array}$} & \multicolumn{2}{|c|}{$\begin{array}{l}95 \% \text { Confidence Interval of } \\
\text { the Difference }\end{array}$} & & & \\
\hline & & & & & Lower & Upper & & & \\
\hline $\begin{array}{l}\text { Pair } \\
1\end{array}$ & $\begin{array}{l}\text { After - } \\
\text { Before }\end{array}$ & 0:00:00 & $0: 00: 51$ & 0:00:08 & $-0: 00: 17$ & 0:00:16 & $\begin{array}{r}- \\
.088 \\
\end{array}$ & 37 & .931 \\
\hline
\end{tabular}

SPSS T-Test: March 1, 2012 PM Peak

\section{Paired Samples Statistics}

\begin{tabular}{|rl|r|r|r|r|}
\hline & & Mean & N & Std. Deviation & Std. Error Mean \\
\hline \multirow{2}{*}{ Pair 1 } & After & $0: 07: 56$ & 34 & $0: 02: 26$ & $0: 00: 25$ \\
& Before & $0: 08: 19$ & 34 & $0: 02: 07$ & $0: 00: 21$ \\
\hline
\end{tabular}

Paired Samples Correlations

\begin{tabular}{|lr|r|r|r|}
\hline & \multicolumn{1}{|c|}{$\mathrm{N}$} & Correlation & \multicolumn{1}{c|}{ Sig. } \\
\hline Pair 1 & After \& Before & 34 & .893 & .000 \\
\hline
\end{tabular}

Paired Samples Test

\begin{tabular}{|c|c|c|c|c|c|c|c|c|c|}
\hline & & \multicolumn{5}{|c|}{ Paired Differences } & \multirow[t]{3}{*}{$t$} & \multirow[t]{3}{*}{ df } & \multirow{3}{*}{$\begin{array}{l}\text { Sig. (2- } \\
\text { tailed) }\end{array}$} \\
\hline & & \multirow[t]{2}{*}{ Mean } & \multirow[t]{2}{*}{$\begin{array}{l}\text { Std. } \\
\text { Deviation }\end{array}$} & \multirow[t]{2}{*}{$\begin{array}{l}\text { Std. Error } \\
\text { Mean }\end{array}$} & \multicolumn{2}{|c|}{$\begin{array}{l}95 \% \text { Confidence Interval of } \\
\text { the Difference } \\
\end{array}$} & & & \\
\hline & & & & & Lower & Upper & & & \\
\hline $\begin{array}{l}\text { Pair } \\
1\end{array}$ & $\begin{array}{l}\text { After - } \\
\text { Before }\end{array}$ & 0:00:22 & 0:01:06 & 0:00:11 & $-0: 00: 45$ & 0:00:00 & $\begin{array}{r}- \\
1.998\end{array}$ & 33 & .054 \\
\hline
\end{tabular}


SPSS T-Test: March 1, 2012 All-Day

Paired Samples Statistics

\begin{tabular}{|c|c|c|c|c|c|}
\hline & & Mean & $\mathrm{N}$ & $\begin{array}{c}\text { Std. } \\
\text { Deviation }\end{array}$ & $\begin{array}{c}\text { Std. Error } \\
\text { Mean }\end{array}$ \\
\hline Pair & After & $0: 08: 59$ & 275 & 0:03:32 & $0: 00: 12$ \\
\hline 1 & Before & $0: 09: 15$ & 275 & $0: 03: 21$ & $0: 00: 12$ \\
\hline
\end{tabular}

Paired Samples Correlations

\begin{tabular}{|l|r|r|r|}
\hline & $\mathrm{N}$ & Correlation & \multicolumn{1}{c|}{ Sig. } \\
\hline $\begin{array}{l}\text { Pair } \\
1\end{array} \quad$ After \& Before & 275 & .945 & .000 \\
\hline
\end{tabular}

Paired Samples Test

\begin{tabular}{|c|c|c|c|c|c|c|c|c|c|}
\hline & & \multicolumn{5}{|c|}{ Paired Differences } & \multirow[t]{3}{*}{ t } & \multirow[t]{3}{*}{ df } & \multirow{3}{*}{$\begin{array}{l}\text { Sig. }(2- \\
\text { tailed) }\end{array}$} \\
\hline & & \multirow[t]{2}{*}{ Mean } & \multirow[t]{2}{*}{$\begin{array}{l}\text { Std. } \\
\text { Deviation }\end{array}$} & \multirow[t]{2}{*}{$\begin{array}{l}\text { Std. Error } \\
\text { Mean }\end{array}$} & \multicolumn{2}{|c|}{$\begin{array}{c}95 \% \text { Confidence Interval of } \\
\text { the Difference }\end{array}$} & & & \\
\hline & & & & & Lower & Upper & & & \\
\hline $\begin{array}{l}\text { Pair } \\
1\end{array}$ & $\begin{array}{l}\text { After - } \\
\text { Before }\end{array}$ & 0:00:15 & 0:01:09 & $0: 00: 04$ & $-0: 00: 24$ & $-0: 00: 07$ & $\begin{array}{r}- \\
3.788\end{array}$ & 274 & .000 \\
\hline
\end{tabular}

SPSS T-Test: March 1, 2012 Off-Peak

Paired Samples Statistics

\begin{tabular}{|c|c|c|c|c|c|}
\hline & & Mean & $\mathrm{N}$ & $\begin{array}{c}\text { Std. } \\
\text { Deviation }\end{array}$ & $\begin{array}{c}\text { Std. Error } \\
\text { Mean }\end{array}$ \\
\hline \multirow{2}{*}{$\begin{array}{l}\text { Pair } \\
1\end{array}$} & After & $0: 09: 30$ & 203 & $0: 03: 45$ & $0: 00: 15$ \\
\hline & Before & $0: 09: 48$ & 203 & $0: 03: 31$ & $0: 00: 14$ \\
\hline
\end{tabular}

Paired Samples Correlations

\begin{tabular}{|l|r|r|r|}
\hline & \multicolumn{1}{|c|}{$\mathrm{N}$} & Correlation & \multicolumn{1}{c|}{ Sig. } \\
\hline Pair 1 After \& Before & 203 & .946 & .000 \\
\hline
\end{tabular}

Paired Samples Test

\begin{tabular}{|c|c|c|c|c|c|c|c|c|c|}
\hline & & \multicolumn{5}{|c|}{ Paired Differences } & \multirow[t]{3}{*}{$\mathrm{t}$} & \multirow[t]{3}{*}{$\mathrm{df}$} & \multirow{3}{*}{$\begin{array}{l}\text { Sig. }(2- \\
\text { tailed) }\end{array}$} \\
\hline & & \multirow[t]{2}{*}{ Mean } & \multirow[t]{2}{*}{$\begin{array}{c}\text { Std. } \\
\text { Deviation }\end{array}$} & \multirow[t]{2}{*}{$\begin{array}{l}\text { Std. Error } \\
\text { Mean }\end{array}$} & \multicolumn{2}{|c|}{$\begin{array}{l}95 \% \text { Confidence Interval of } \\
\text { the Difference }\end{array}$} & & & \\
\hline & & & & & Lower & Upper & & & \\
\hline $\begin{array}{l}\text { Pair } \\
1\end{array}$ & $\begin{array}{l}\text { After - } \\
\text { Before }\end{array}$ & $0: 00: 17$ & $0: 01: 12$ & 0:00:05 & $-0: 00: 27$ & $-0: 00: 07$ & 3.443 & 202 & .001 \\
\hline
\end{tabular}


SPSS T-Test: March 15, 2012 AM Peak

Paired Samples Statistics

\begin{tabular}{|ll|r|r|r|r|}
\hline & & Mean & N & Std. Deviation & Std. Error Mean \\
\hline \multirow{2}{*}{ Pair 1 } & After & $0: 07: 01$ & 40 & $0: 01: 41$ & $0: 00: 16$ \\
& Before & $0: 06: 55$ & 40 & $0: 01: 38$ & $0: 00: 15$ \\
\hline
\end{tabular}

Paired Samples Correlations

\begin{tabular}{|c|c|c|c|c|}
\hline & & $\mathrm{N}$ & Correlation & Sig. \\
\hline Pair 1 & After \& Before & 40 & .953 & .000 \\
\hline
\end{tabular}

Paired Samples Test

\begin{tabular}{|c|c|c|c|c|c|c|c|c|c|}
\hline & & \multicolumn{5}{|c|}{ Paired Differences } & \multirow[t]{3}{*}{$\mathrm{t}$} & \multirow[t]{3}{*}{ df } & \multirow{3}{*}{$\begin{array}{l}\text { Sig. }(2- \\
\text { tailed) }\end{array}$} \\
\hline & & \multirow[t]{2}{*}{ Mean } & \multirow[t]{2}{*}{$\begin{array}{c}\text { Std. } \\
\text { Deviation }\end{array}$} & \multirow[t]{2}{*}{$\begin{array}{l}\text { Std. Error } \\
\text { Mean }\end{array}$} & \multicolumn{2}{|c|}{$\begin{array}{c}95 \% \text { Confidence Interval of } \\
\text { the Difference }\end{array}$} & & & \\
\hline & & & & & Lower & Upper & & & \\
\hline $\begin{array}{l}\text { Pair } \\
1\end{array}$ & $\begin{array}{l}\text { After - } \\
\text { Before }\end{array}$ & 0:00:05 & $0: 00: 30$ & 0:00:04 & $-0: 00: 04$ & $0: 00: 15$ & 1.150 & 39 & .257 \\
\hline
\end{tabular}

SPSS T-Test: March 15, 2012 PM Peak

\section{Paired Samples Statistics}

\begin{tabular}{|ll|l|r|r|r|}
\hline & & Mean & N & Std. Deviation & Std. Error Mean \\
\hline \multirow{2}{*}{ Pair 1 } & After & $0: 06: 27$ & 40 & $0: 02: 03$ & $0: 00: 19$ \\
& Before & $0: 06: 28$ & 40 & $0: 01: 56$ & $0: 00: 18$ \\
\hline
\end{tabular}

Paired Samples Correlations

\begin{tabular}{|ll|r|r|r|}
\hline & \multicolumn{1}{|c|}{$\mathrm{N}$} & Correlation & \multicolumn{1}{c|}{ Sig. } \\
\hline Pair 1 & After \& Before & & .964 & .000 \\
\hline
\end{tabular}

Paired Samples Test

\begin{tabular}{|c|c|c|c|c|c|c|c|c|c|}
\hline & & \multicolumn{5}{|c|}{ Paired Differences } & \multirow[t]{3}{*}{$\mathrm{t}$} & \multirow[t]{3}{*}{ df } & \multirow{3}{*}{$\begin{array}{l}\text { Sig. }(2- \\
\text { tailed) }\end{array}$} \\
\hline & & \multirow[t]{2}{*}{ Mean } & \multirow[t]{2}{*}{$\begin{array}{c}\text { Std. } \\
\text { Deviation }\end{array}$} & \multirow[t]{2}{*}{$\begin{array}{l}\text { Std. Error } \\
\text { Mean }\end{array}$} & \multicolumn{2}{|c|}{$\begin{array}{l}95 \% \text { Confidence Interval of } \\
\text { the Difference }\end{array}$} & & & \\
\hline & & & & & Lower & Upper & & & \\
\hline $\begin{array}{l}\text { Pair } \\
1\end{array}$ & $\begin{array}{l}\text { After - } \\
\text { Before }\end{array}$ & 0:00:00 & 0:00:33 & 0:00:05 & $-0: 00: 10$ & 0:00:10 & $\begin{array}{r}- \\
.033 \\
\end{array}$ & 39 & .974 \\
\hline
\end{tabular}


SPSS T-Test: March 15, 2012 All Day

Paired Samples Statistics

\begin{tabular}{|ll|r|r|r|r|}
\hline & & Mean & N & Std. Deviation & Std. Error Mean \\
\hline \multirow{2}{*}{ Pair 1 } & After & $0: 08: 14$ & 311 & $0: 03: 37$ & $0: 00: 12$ \\
& Before & $0: 08: 18$ & 311 & $0: 03: 30$ & $0: 00: 11$ \\
\hline
\end{tabular}

Paired Samples Correlations

\begin{tabular}{|c|c|c|c|c|}
\hline & & $\mathrm{N}$ & Correlation & Sig. \\
\hline Pair 1 & After \& Before & 311 & .960 & .000 \\
\hline
\end{tabular}

Paired Samples Test

\begin{tabular}{|c|c|c|c|c|c|c|c|c|c|}
\hline & & \multicolumn{5}{|c|}{ Paired Differences } & \multirow[t]{3}{*}{$\mathrm{t}$} & \multirow[t]{3}{*}{ df } & \multirow{3}{*}{$\begin{array}{l}\text { Sig. }(2- \\
\text { tailed) }\end{array}$} \\
\hline & & \multirow[t]{2}{*}{ Mean } & \multirow[t]{2}{*}{$\begin{array}{c}\text { Std. } \\
\text { Deviation }\end{array}$} & \multirow[t]{2}{*}{$\begin{array}{l}\text { Std. Error } \\
\text { Mean }\end{array}$} & \multicolumn{2}{|c|}{$\begin{array}{l}95 \% \text { Confidence Interval of } \\
\text { the Difference }\end{array}$} & & & \\
\hline & & & & & Lower & Upper & & & \\
\hline $\begin{array}{l}\text { Pair } \\
1\end{array}$ & $\begin{array}{l}\text { After - } \\
\text { Before }\end{array}$ & 0:00:04 & $0: 01: 00$ & 0:00:03 & $-0: 00: 11$ & 0:00:02 & $\begin{array}{r}- \\
1.279\end{array}$ & 310 & .202 \\
\hline
\end{tabular}

SPSS T-Test: March 15, 2012 Off Peak

\begin{tabular}{|rl|c|r|r|r|}
\hline & \multicolumn{1}{c|}{ Paired Samples Statistics } \\
\hline \multirow{2}{*}{ Pair 1 } & Mean & N & Std. Deviation & Std. Error Mean \\
\cline { 3 - 6 } & Before & $0: 08: 45$ & 231 & $0: 03: 55$ & $0: 00: 15$ \\
& $0: 08: 52$ & 231 & $0: 03: 46$ & $0: 00: 14$ \\
\hline
\end{tabular}

\section{Paired Samples Correlations}

\begin{tabular}{|l|r|r|r|}
\hline & \multicolumn{1}{|c|}{ N } & Correlation & \multicolumn{1}{c|}{ Sig. } \\
\hline Pair 1 After \& Before & 231 & .957 & .000 \\
\hline
\end{tabular}

Paired Samples Test

\begin{tabular}{|c|c|c|c|c|c|c|c|c|c|}
\hline & & \multicolumn{5}{|c|}{ Paired Differences } & \multirow[t]{3}{*}{$\mathrm{t}$} & \multirow[t]{3}{*}{ df } & \multirow{3}{*}{$\begin{array}{l}\text { Sig. (2- } \\
\text { tailed) }\end{array}$} \\
\hline & & \multirow[t]{2}{*}{ Mean } & \multirow[t]{2}{*}{$\begin{array}{c}\text { Std. } \\
\text { Deviation }\end{array}$} & \multirow[t]{2}{*}{$\begin{array}{l}\text { Std. Error } \\
\text { Mean }\end{array}$} & \multicolumn{2}{|c|}{$\begin{array}{l}95 \% \text { Confidence Interval of } \\
\text { the Difference }\end{array}$} & & & \\
\hline & & & & & Lower & Upper & & & \\
\hline $\begin{array}{l}\text { Pair } \\
1\end{array}$ & $\begin{array}{l}\text { After - } \\
\text { Before }\end{array}$ & 0:00:06 & 0:01:08 & 0:00:04 & $-0: 00: 15$ & 0:00:01 & 1.537 & 230 & .126 \\
\hline
\end{tabular}

